\title{
Thermal Stability of Aluminum Alloys
}

\author{
Frank Czerwinski $\mathbb{D}$
}

CanmetMATERIALS, Natural Resources Canada, Hamilton, ON L8P 0A5, Canada; frank.czerwinski@canada.ca

Received: 14 July 2020; Accepted: 31 July 2020; Published: 4 August 2020

\begin{abstract}
Thermal stability, determining the material ability of retaining its properties at required temperatures over extended service time, is becoming the next frontier for aluminum alloys. Its improvement would substantially expand their range of structural applications, especially in automotive and aerospace industries. This report explains the fundamentals of thermal stability; definitions, the properties involved; and the deterioration indicators during thermal/thermomechanical exposures, including an impact of accidental fire, and testing techniques. For individual classes of alloys, efforts aimed at identifying factors stabilizing their microstructure at service temperatures are described. Particular attention is paid to attempts of increasing the current upper service limit of high-temperature grades. In addition to alloying aluminum with a variety of elements to create the thermally stable microstructure, in particular, transition and rare-earth metals, parallel efforts are explored through applying novel routes of alloy processing, such as rapid solidification, powder metallurgy and additive manufacturing, engineering alloys in a liquid state prior to casting, and post-casting treatments. The goal is to overcome the present barriers and to develop novel aluminum alloys with superior properties that are stable across the temperature and time space, required by modern designs.
\end{abstract}

Keywords: thermal stability; aluminum alloys; transition metals; rare earths; aerospace; automotive

\section{Introduction}

Thermal stability is the key design feature that determines a suitability of materials for specific applications and has a particular meaning for aluminum alloys. As documented throughout the decades, practically all aluminum alloys are thermally unstable with their properties being affected, to some extent, by service temperature and time. This includes grades essentially used at room temperatures, as is the case with aircraft components that may become warm due to exposure to sun, due to aerodynamic heating, or heat transferred from engines, which can deteriorate their properties over years of service [1]. The key engineering interest is, however, in the high temperature range and increasing the upper service limit of high-temperature grades [2].

At present, extending thermal stability to higher temperatures is the technology and knowledge barrier that prevents the substantial expansion of application scope of aluminum alloys, especially in automotive, marine, and aerospace transportation vehicles, designed for long-term service and strategically using aluminum for its lightweighting advantages. It is believed that the future aluminum alloys with improved high-temperature capabilities could compete, in selected applications, with more expensive titanium- and nickel-based grades. Therefore, along with recent refocusing on the strategic importance of aluminum alloys as lightweight structural materials for all forms of transportation vehicles, a substantial research interest is devoted to an improvement in their performance at high temperatures.

Although the thermal stability of aluminum alloys represents the major theme or at least a partial subject of a large number of research papers, differences in its understanding, critical property selection, and testing procedures make it difficult or impossible to combine individual results to draw 
a unified quantitative conclusion. The objective of this report is to review all elements of thermal stability from fundamentals to applications that refer to structural materials and aluminum alloys. Through identifying its detailed controlling factors, a better understanding of the relationship between mechanical, structural, and thermophysical properties that are critical for performance of alloys at increased temperatures will emerge. The outcome will help in optimizing the service conditions for existing aluminum alloys and development of novel alloys with superior thermal stability.

\section{Defining Thermal Stability of Structural Materials and Aluminum}

There is no universal definition or single criterion describing thermal stability of structural materials. While being typically seen as the "material ability of retaining its properties at required temperatures over extended service time", in practice, more major parameters influencing thermal stability are involved including, in addition to (i) temperature and (ii) time, also (iii) load conditions and (iv) environmental conditions. Another definition as a "material resistance to permanent property changes caused by heat" is even less accurate as after cooling to room temperature, some portion of properties frequently recovers, whereas in a design, the properties maintained at the service temperature matter. Thermal stability is also defined as a material "property" characterizing changes after long-time exposure to elevated temperatures [3]. In this case, thermal stability is seen as an "intrinsic property" and, therefore, such an approach has further limitations. The related term "dimensional thermal stability" is also used that describes thermal expansion.

When assessing the thermal stability of a material, a future destination of this description is essential. If thermal stability is assessed for the purpose of comparing different alloys, e.g., during alloy development, the temperature and time are sufficient to characterize the alloy behavior. However, when a design input is required, during a material selection for a specific engineering application, detailed service conditions should be assessed. The design input will require an experimental measurement and/or computer simulation of material performance under conditions of its future application, including the load details and service environment nature.

Due to the low melting point of aluminum, $660.5^{\circ} \mathrm{C}$, the thermal stability of its alloys covers the temperature range, which is substantially lower than that of other materials with much higher melting points that, excluding the corrosive factor, can be used to contain molten aluminum alloys, as schematically marked in Figure 1. In this respect, the term "heat-resistant alloys" also has a relative meaning when applied to aluminum-based grades.

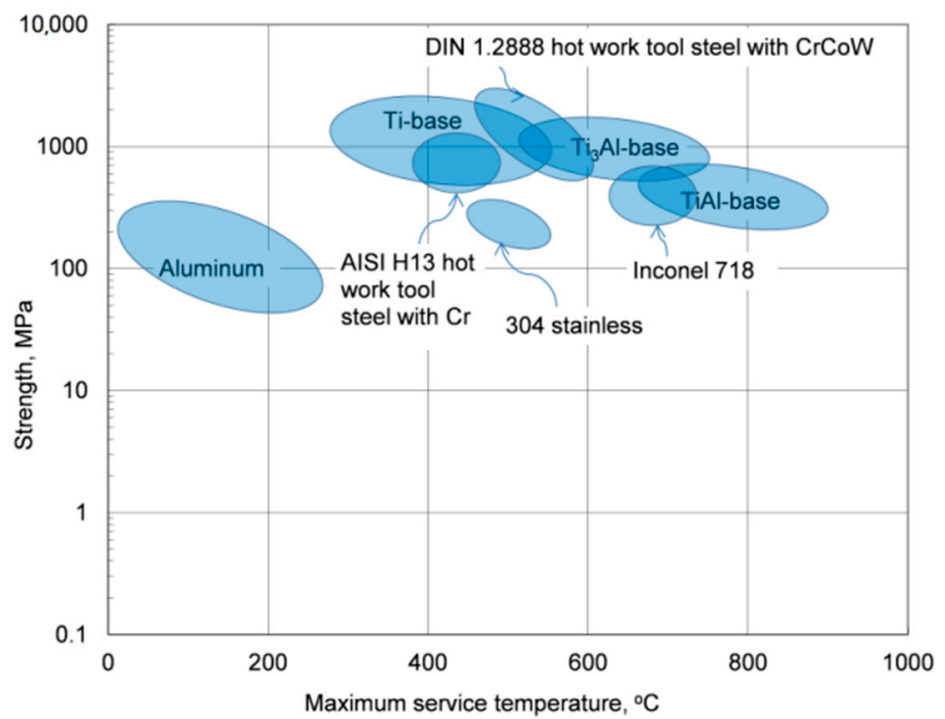

Figure 1. Strength versus maximum service temperature for aluminum alloys and selected structural materials. 
The property variation of aluminum alloys at temperatures from cryogenic to over $400{ }^{\circ} \mathrm{C}$ is different than that observed in other materials, such as steel. As for other materials, the intensity of the temperature-related property change of aluminum alloys is influenced by their chemical composition and initial microstructure, controlled, in turn, by the manufacturing route and post-manufacturing treatment. An example for the wrought AA6061 alloy in T6/T651 condition is shown in Figure 2a,b. At temperatures above $150{ }^{\circ} \mathrm{C}$, the alloy suffers a loss in strength with deterioration increasing over time. Above $200{ }^{\circ} \mathrm{C}$, the weakening is substantial, and is accompanied by some gain in ductility. Most of the strength reduction induced by exposure to elevated temperatures is permanent, so the loss in strength is not recovered when the material is returned to a lower temperature. In case of AA6061, a major portion of the loss in strength is caused by coarsening of the $\mathrm{Mg}_{2} \mathrm{Si}$ precipitates. As shown in Figure 2a, aluminum alloys are susceptible to creep and stress relaxation. Creep is a time-dependent, permanent deformation that occurs under sustained load or stress, even at stresses below the yield strength. For the most part, creep is governed by migration of vacant lattice sites, which increases with temperature.

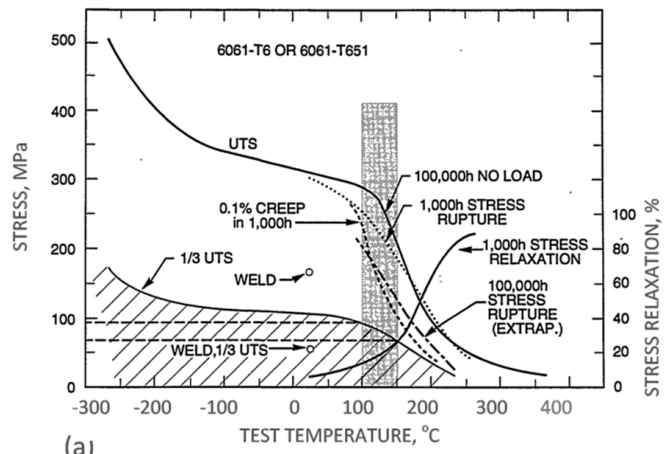

(a)

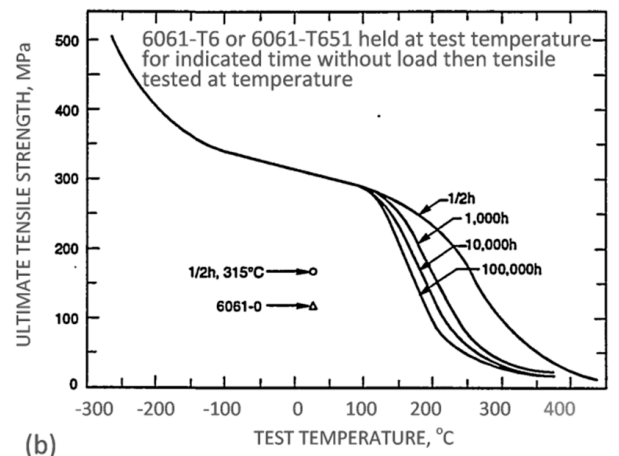

(b)

Figure 2. Example of property deterioration of the AA6061 aluminum alloy upon heating in air: (a) effect of temperature on creep and stress relaxation; (b) effect of temperature and time on ultimate strength [4].

\subsection{Thermal Stability as a Component Design Criterion: Combined Influence of Temperature and Time}

In order to apply a material for a particular design, the certain threshold of properties at service temperature is required. To understand the process of material selection, three hypothetical alloys with different strength vs. temperature/time characteristics are shown schematically in Figure 3a,b.
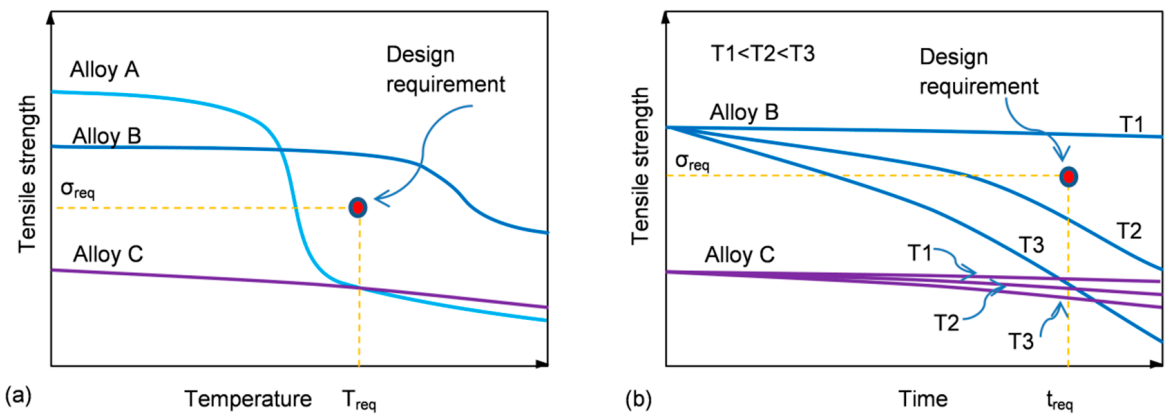

Figure 3. Thermal stability of structural materials and design requirements: (a) schematics of hypothetical changes in tensile strength versus temperature (b) and strength versus time at constant temperature $(\mathbf{b})$, along with the strength required $\sigma_{\text {req }}$ at temperature $T_{\text {req }}$ during service time $t_{\text {req. }}$

Alloy A has an initial strength that substantially exceeds the minimum required but experiences a steep reduction at temperatures much lower than that predicted in its design (Figure 3a). In contrast, alloy $\mathrm{C}$ shows high thermal stability with low reduction in strength, taking place within the entire temperature range. However, its overall low strength makes it not suitable for this application. Thus, from a temperature criterion alone, alloy B meets the design specification. 
At a given temperature, the material properties are affected by the exposure time. The influence of time on the properties of aluminum alloys depends on temperature. At high temperatures, a reduction of strength is the dominant observation for all classes of alloys. In contrast, at room or slightly elevated temperatures the opposite behavior may be observed, where the alloy strength may increase at the cost of plasticity, so an alloy may become prone to brittle cracking. The alloy selection depends, therefore, on the kinetics of the strength variation, and for alloy $\mathrm{B}$, the strength reduction at temperatures $\mathrm{T} 2$ and T3 makes it not suitable for that design.

As portrayed in Figure 3a,b, a definition of thermal stability as "strength (property) retention at service temperature/time" can lead to confusion during a material selection. Therefore, the highly thermally stable alloy $\mathrm{C}$ does not meet design requirements due to its overall low strength. Thus, the thermal stability criterion that is viable during a material selection has two factors: (i) an alloy should achieve at room temperature the strength required and (ii) the strength should be retained within the temperature and time space to meet the level required at service temperature and to remain stable for the predicted service time.

Thermal stability is often expressed through graphs of the alloy strength vs. maximum service temperature. While being very educational, the above examples show that without specifying detailed conditions (time, load, environment, etc.), such characteristics are very approximate.

\subsection{Understanding the Temperature-Load Factors}

The influence of heat on material properties depends not only on temperature but also on temperature changes with time, especially in the case of frequent (periodic) changes, a presence of load applied to a material in structural applications and its nature.

\subsubsection{Thermal Exposure-Stable Temperature}

In general considerations of thermal stability, it is assumed that a material is exposed to constant (or near constant) temperature. As thermal stability refers to all temperature ranges that also include room environment the term "high thermal stability" may often be misleading, when temperature is not specified. For example, an aluminum alloy may be described as having very high thermal stability just at $100{ }^{\circ} \mathrm{C}$. Examples of applications of aluminum alloys that require thermal stability at essentially different temperatures are shown in Figure $4 \mathrm{a}-\mathrm{c}$.

(a)
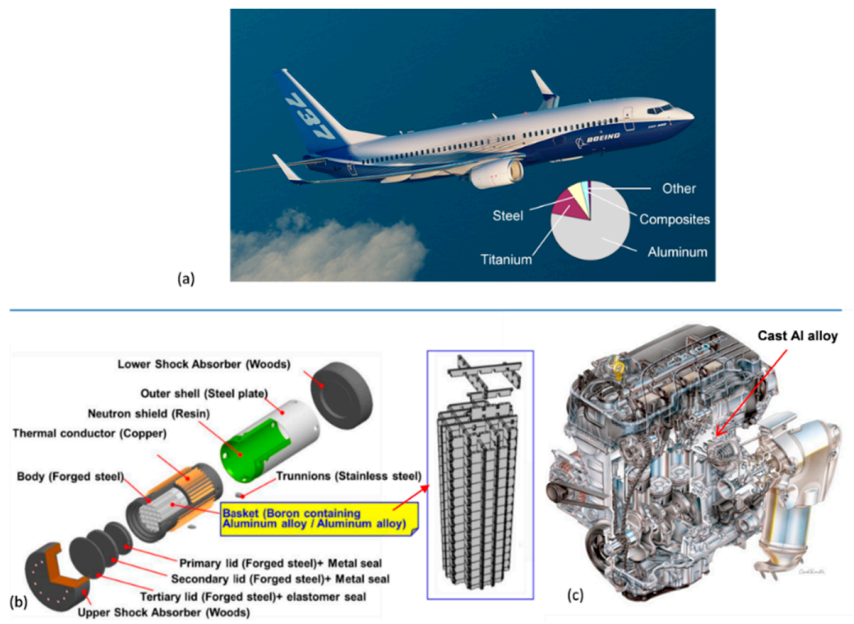

Figure 4. Applications of aluminum alloys requiring thermal stability at different temperatures: (a) commercial airplane with aluminum surface components exposed to room and slightly elevated temperatures [5]; (b) packaging and transportation of radioactive materials: long-term storage/transportation casks for spent fuels in nuclear power plants, requiring exposure to temperature $100-200{ }^{\circ} \mathrm{C}$ for over 60 years [6]; and (c) automotive combustion engine with new designs requiring temperature over $200{ }^{\circ} \mathrm{C}$ [7]. 
Stability at room and slightly elevated temperatures refers to temperatures typically below $100{ }^{\circ} \mathrm{C}$. Such a scenario occurs for aircraft components that may become warm during service due to exposure to sun, aerodynamic heating, or heat transferred from engines. Temperatures from $70^{\circ} \mathrm{C}$ to $85^{\circ} \mathrm{C}$ are typically used to simulate the environment to which the wings and fuselage structures of a commercial aircraft are exposed [8].

The medium temperature range, requiring thermal stability, covers temperatures below $200{ }^{\circ} \mathrm{C}$. They include impellers used in generators/compressors, vacuum pump rotors, and turbocharger impellers of various sizes with service range of 150 to $180{ }^{\circ} \mathrm{C}$. An example of alloy used in this environment is the $\mathrm{Al}-\mathrm{Cu}-\mathrm{Mg}-\mathrm{Fe}-\mathrm{Ni} \mathrm{AA} 2618$ alloy [9]. The medium temperature range will also cover alloys in metastable state, cold-deformed, nanocrystalline, and amorphous ones. However, the most challenging aspect of thermal stability is maximizing the upper service limit of high-temperature grades with the ultimate goal for aluminum alloys being to exceed $400{ }^{\circ} \mathrm{C}$.

Thermal stability is uniquely tested in a case of accidental fire, when aluminum alloys may be exposed to temperatures, exceeding those predicted for regular service that exert damaging effect on their properties. There is a concern of fire safety with using aluminum for load-bearing applications such as lightweight structures, light rail, bridge decks, marine crafts, and off-shore platforms, due to potential dangerous reduction in mechanical properties during exposure to heating [10]. Alloys used in these applications are typically not designed for high temperatures. A related concern is regarding the integrity and stability of an aluminum structure following a fire exposure.

\subsubsection{Constant versus Variable (Cyclic) Temperature-Thermal Fatigue}

Due to thermal exposures, materials expand during heating and contract during cooling. When a material is geometrically constrained, this leads to generation of tensile and compressive stresses. Stresses may also arise within unconstrained materials due to a spatial temperature gradient. As a result of cyclic expansion and contractions the material experiences thermal fatigue. This phenomenon, also called heat checking, is common when a metal surface is repeatedly heated and cooled. Thus, thermal fatigue may occur without mechanical loads. If both thermal and mechanical strain is involved, the degradation mode is termed as thermomechanical fatigue.

\subsubsection{Role of Load in Thermal Stability-Thermal versus Thermomechanical Response}

As the structural materials are subjected to a load at service temperature, the effect of heat on their performance depends on the load level and its nature, with a special impact being exerted by heavy and cyclic loads, in particular with high-speed load alterations. To describe a material performance under particular service conditions the term durability is often used, understood as the ability of a material to sustain mechanical or thermomechanical loads over a predicted service time. Although the durability meaning may vary, depending on an application, for structural materials it is seen as the critical design consideration.

\subsection{Environmental Effect on Thermal Stability}

The ability of retaining the properties by an alloy is strongly affected by reactive environments leading, for example, to oxidation, erosion, molten metal or salt corrosion, or irradiation damage.

\subsubsection{Surface Deterioration}

For room temperature service, surface corrosion, leading to localized reaction and a material loss, forming pitting and stress risers, is of concern. For service at high temperatures, a process of selective oxidation resulting in localized surface degradation should be considered.

The oxidation of aluminum in air can be described as occurring in four distinct stages [11]. At room and lower temperatures, the amorphous alumina layer covers the metallic surface, protecting it against further oxidation, which results in very slow film thickening up to $550{ }^{\circ} \mathrm{C}$. At this stage, the oxide growth is controlled by outward diffusion of $\mathrm{Al}$ ions with a reaction taking place at the oxide-gas 
interface. The amorphous oxide remains stable, due to the energy of the oxide-metal interface, only up to a critical thickness of $\sim 5 \mathrm{~nm}$, then transforms to $\gamma$-alumina, when crystallites are no longer able to form a continuous layer that would cover the aluminum surface. This leads to stage II, above $550{ }^{\circ} \mathrm{C}$, with higher oxidation rate and polycrystalline layer of $\gamma$-alumina covering the entire aluminum surface. At the stage III, which starts at $650{ }^{\circ} \mathrm{C}$, very close to melting, the growth of $\gamma$-alumina continues at a rate controlled by the inward diffusion of oxygen anions along oxide grain boundaries, acting as fast diffusion paths.

In the case of aluminum alloys, the process of high-temperature oxidation may have a preferential nature, leading to localized oxide patches, formed on specific alloy phases, potentially forming stress risers. The role of aluminum surface reactivity is better understood when compared with another light metal, magnesium. Due to the high affinity of magnesium with oxygen, at high temperatures, its surface degradation and formation of $\mathrm{MgO}$ is of higher concern than a reduction in its mechanical properties [12,13]. In this regards, aluminum shows an advantage over magnesium. In contrast to magnesium, there is no concern of ignition or flammability with aluminum and its oxidation rate is substantially slower due to a formation of the protective $\mathrm{Al}_{2} \mathrm{O}_{3}$ alumina film. However, for $\mathrm{Al}-4-5 \mathrm{Mg}$ (wt.\%), only $\mathrm{MgO}$ is formed with a reaction following the linear law up to $500{ }^{\circ} \mathrm{C}$ and parabolic law above $550^{\circ} \mathrm{C}[14,15]$. Then, an environment may essentially change the oxidation kinetics. For example, in a presence of traces of sulfur, spallation of otherwise protective alumina occurs, which is the chronic problem in some aerospace applications.

\subsubsection{Irradiation Damage}

An important environmental factor, necessary to consider during analysis of thermal stability of aluminum, is the influence of radiation. Aluminum alloys are used in applications subjected to irradiation, e.g., as the primary structural material for the reactor reflector vessel of Advanced Neutron Source and for most of the components housed within the vessel [4] or in casks for transportation of nuclear fuels [16]. The deciding factors for the use of an alloy are good combination of low neutron absorption cross section and high thermal conductivity, good resistance to aqueous corrosion, and good performance in high flux reactors. Therefore, changes in mechanical properties expected to occur in alloys under irradiation during their intended lifetimes are of key importance.

The effects of irradiation exposures result in an increase in the metal's volume, caused by development of voids, bubbles, and low-density phases, termed as swelling. Although generally metals undergo hardening during irradiation, softening is also possible, particularly for cold work-hardened or precipitation-hardened alloys, subjected to irradiation. That softening may take place during irradiation at temperatures below the normal temperature for thermal recovery, as a result of radiation enhanced diffusion processes or cascade dissolution of precipitates.

An example for the AA6061 aluminum alloy target holder from the High Flux Isotope Reactor, originally in a precipitation-hardened condition, after exposure to a maximum fast neutron fluence of $9.2 \times 10^{22}$ neutrons $/ \mathrm{cm}^{2}(\mathrm{E}>0.1 \mathrm{MeV})$ and a thermal fluence of $1.38 \times 10^{23}$ neutrons $/ \mathrm{cm}^{2}(\mathrm{E}<$ $0.414 \mathrm{eV}$ ) at $\sim 60{ }^{\circ} \mathrm{C}$, is shown in Figure 5a,b [17]. At temperatures in the range from 25 to $200{ }^{\circ} \mathrm{C}$, significant strength increases were observed that are attributed to the silicon precipitates and to irradiation-induced dislocations. There was a corresponding loss of ductility, particularly severe at $200{ }^{\circ} \mathrm{C}$ for slow strain rate testing conditions. The alloy, tested at temperatures between 200 and $500{ }^{\circ} \mathrm{C}$, at which the microstructure was unstable, showed substantial loss in strength, accompanied by a gain in ductility. For the entire temperature range from 25 to $500{ }^{\circ} \mathrm{C}$, however, the strength of irradiated alloy was higher than that for the alloy without irradiation. The same nature of changes was reported for the AA4043 alloy welds.

In another example, a microwave radiation influenced the thermal stability of aluminum nanosize powder. After microwave radiation with a power flux density of $80 \mathrm{~W} / \mathrm{cm}^{2}$ and carrier frequency of 9.4 GHz, the chemical activity of aluminum powder increased and the temperature for the beginning of its oxidation decreased by $40{ }^{\circ} \mathrm{C}$, while the thermal effect of oxidation decreased by $13.5 \%$ [18]. 

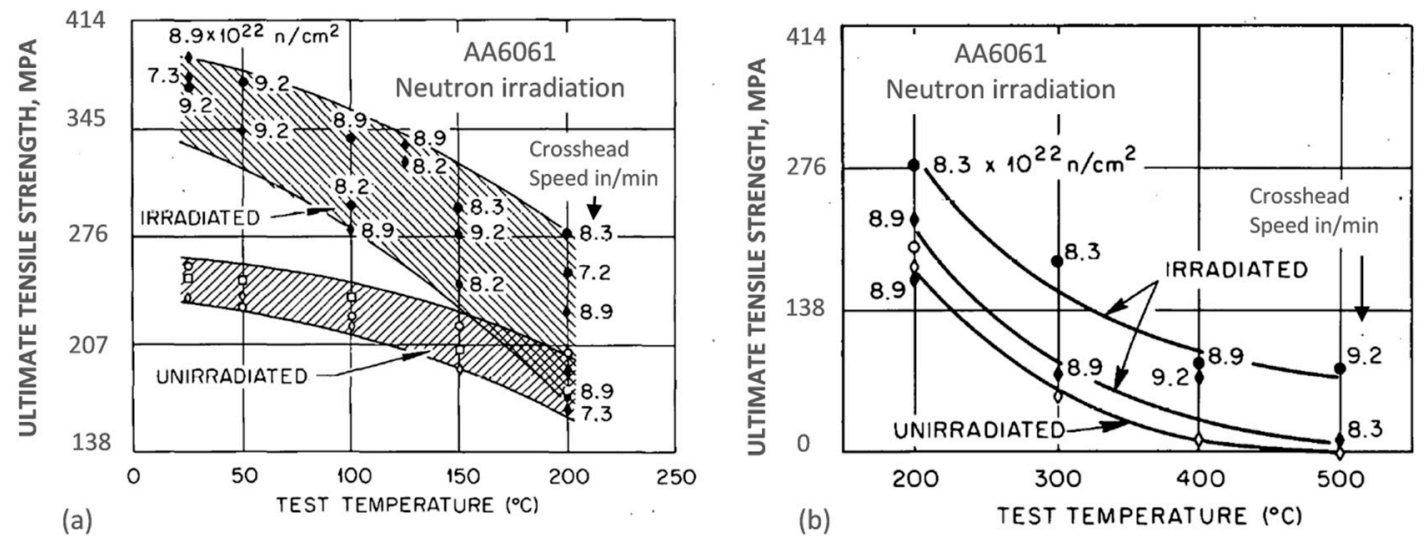

Figure 5. Effect of neutron irradiation on thermal stability of the AA6061 aluminum alloy at temperatures below $200{ }^{\circ} \mathrm{C}$ (a) and above $200{ }^{\circ} \mathrm{C}$ up to $500{ }^{\circ} \mathrm{C}$ (b) [17].

\section{Thermal Deterioration of Alloy Strengthening and Testing Techniques of Thermal Stability}

When operating temperatures of alloys are increasing, additional problems to those encountered at room temperatures arise. Therefore, to improve the thermal stability of modern alloys, understanding the complex relationships between the alloy chemical composition, processing, microstructure, and properties at service temperature is paramount. It is believed that progress achieved in this area within the last few decades was mostly associated with increased understanding of this relationship.

Alloying elements, when added to aluminum, may generate effects of precipitation hardening (age hardening), solid solution hardening, dispersion strengthening, grain refining, modifying metallic and intermetallic phases, suppression of grain growth at elevated temperatures, wear resistance, and other surface-controlled behavior.

The elastic properties of materials can be used to assess certain mechanical properties such as ductility/toughness, hardness, or strength. The Young's modulus of aluminum may be increased through alloying with the effect being controlled by the element content and its form in the alloy. The effect of solute atoms of typical alloying elements on Young's modulus of aluminum is shown in Figure 6. For alloying elements, being in a solid solution, a magnitude of the Young's modulus is determined by the nature of atomic interactions. For alloying elements, forming the second phases, the magnitude of the Young's modulus is determined by the volume fraction and the intrinsic modulus of those phases.

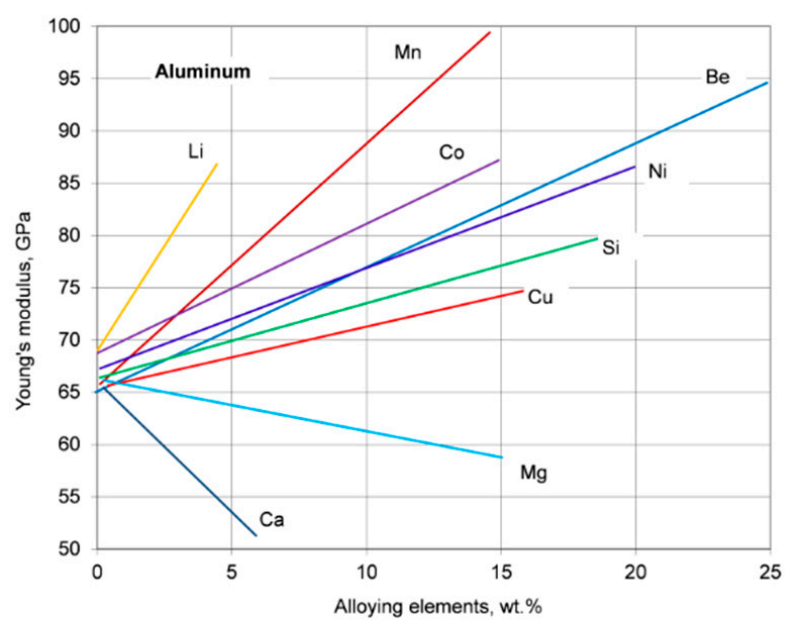

Figure 6. Effect of solute additions on the elastic modulus of aluminum alloys; created based on the work in [19]. 


\subsection{Alloy Strengthening Mechanisms}

Thermal stability relies on changes within an alloy microstructure that are caused by diffusion of alloying elements. During heating, therefore, microstructure components, such as the grain size, phase composition, phase morphology, or solute in the matrix, will evolve. In order to assess the microstructural changes affecting thermal stability, the elementary strengthening mechanisms that act in aluminum should be considered. When an alloy is subjected to heat, the strengthening mechanisms that acted at room temperature will change their effectiveness and contribution to overall alloy strength, measured at high temperature.

\subsubsection{Solid Solution Strengthening by Atoms Dissolved in the Matrix}

The solute atoms affect the alloy strength by imposing lattice strains on the surrounding host atoms, thus decreasing the dislocation movement and the lattice strain field interactions between dislocations and them. Alloying atoms has a tendency to diffuse and segregate around dislocations to find atomic sites more suited to their radii, which decreases the entire strain energy and immobilize (pin) dislocations. The strength from solid solution hardening arises from strain fields around each solute atom, dependent on its misfit radii. The solution strengthening factors include the relative size factor, relative modulus factor, electrical interaction, chemical interaction, and configurational interaction. Among them, the relative size factor $\varepsilon_{\mathrm{a}}$ is expressed as [20,21]:

$$
\varepsilon_{a}=\frac{1}{a} \frac{d a}{d c}
$$

where $a$ is the interatomic spacing of the alloy and $c$ is interatomic concentration of the solute.

\subsubsection{Strain Hardening or Cold Working, Caused by Plastic Deformation}

Strain or work hardening refers to an increase in stress with strain required to continue plastic deformation. As a material is deformed at low homologous temperatures (below recrystallization), dislocation density increases inside its structure. Aluminum, which is characterized by the high stacking fault energy, deforms by dislocation-mediated slip. The process of strain/work hardening is often portrayed as a competition between the dislocation accumulation and dislocation annihilation, described as dynamic recovery. The basic equation that relates flow stress (strain hardening) $\sigma$ to the structure is given as [20]:

$$
\sigma=\sigma_{i}+\alpha G b \rho^{1 / 2}
$$

where $\sigma_{i}$ is the friction stress opposing motion of dislocation, $\alpha$ is a geometrical constant of the order 0.3 , $G$ is the shear modulus, $b=0.286 \mathrm{~nm}$ is the Burgers vector for aluminum, and $\rho$ is the dislocation density.

\subsubsection{Strengthening by Fine Particles}

This strengthening mechanism involves precipitation strengthening or age hardening, resulting from heat treatment and dispersion strengthening after inclusion of dispersoid particles, acting as obstacles to dislocation movement. In an alloy, particles may be cut by dislocations or resist cutting, thereby forcing dislocations to bypass them. In the latter case, the gliding dislocations circumvent dispersoids by the Orowan bypass mechanism and the stress $\sigma$ at room temperature for idealized spherical particles with radius $r$ can be calculated by the Orowan-Ashby equation [20]:

$$
\sigma=0.13 \frac{G b}{\lambda} \ln \frac{r}{b}
$$

where $G$ is the shear modulus, $b$ is the Burgers vector, and $\lambda$ is the dispersoid spacing on a slip plane. 


\subsubsection{Grain Size Strengthening}

When the material is deformed and the resistance to plastic flow is controlled by the dislocation glide and diffusion-controlled processes are not an issue, a decrease in the grain size causes the strengthening effect. In this case, the yield stress $\sigma_{g b}$ is related to the grain size, $\mathrm{d}$, through the Hall-Petch equation, expressed as

$$
\sigma_{g b}=\sigma_{o}+k d^{-1 / 2}
$$

where $\sigma_{o}$ is a material constant for the starting stress for dislocation movement or the resistance of the lattice to dislocation motion and $\mathrm{k}$ is the strengthening coefficient, specific to aluminum.

Another approach to grain boundary strengthening $\sigma_{g b}$ in aluminum alloys is presented by the Nes-Marthinsen formula [22]:

$$
\sigma_{g b}=\alpha G b d^{-1}
$$

where $\alpha$ is a constant and the other symbols are as in Equation (3). An explanation of the theoretical background behind Equation (5) is available in [22].

In practice, there are no alloys with a single strengthening mechanism, and during service several contributors simultaneously control the alloy behavior [23]. As shown in Figure 7a, for Al-Li alloys, the solution of $\mathrm{Li}$ in the $\mathrm{Al}$ matrix is the key contributor and the major strengthening is coming from high volume of $\mathrm{Al}_{3} \mathrm{Li}$ precipitates. Strengthening by the $\mathrm{Al}_{3} \mathrm{Li}$ phase is caused, in turn, by several mechanisms, such as coherency and surface hardening, modulus hardening, and strengthening by coherent ordered precipitates [24]. In strengthening of the Al84Ni7Gd6Co3 (at.\%) alloy shown in Figure $7 \mathrm{~b}$, the nanoscale $\mathrm{Al}$ grain and large volume fraction of intermetallic phases contribute through the composite effect. A lack of fine precipitates in the microstructure results in negligible Orowan strengthening [25].

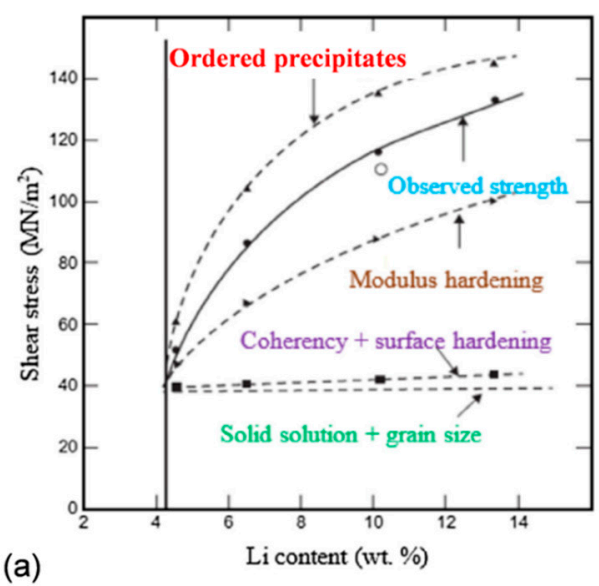

(a)

Figure 7. Contribution of different strengthening mechanisms in various aluminum alloys: (a) $\mathrm{Al}-\mathrm{Li}$ alloys with $\mathrm{Al}_{3} \mathrm{Li}$ precipitates $[26,27]$ and (b) Al84Ni7Gd6Co3 (at.\%) alloy, produced by a combination of gasification, ball milling, and hot pressing [25].

For cold-worked AA1050 alloy, where precipitation hardening is not involved, the contribution from grain boundary strengthening was $\sim 30 \mathrm{MPa}$, with the remaining yield stress of $170 \mathrm{MPa}$ being covered by dislocation strengthening [28]. In the complex microstructure of an extruded AA7075 alloy, the major strengthening contributors consisted of grain boundary, dislocation, solid solution, precipitation, and oxide dispersoid strengthening [29]. As temperature increases, the individual strengthening factors will selectively change their effectiveness. For example, in amorphous alloys, crystallization and formation of fine precipitates will represent key changes. For nanocrystalline alloys, grain growth will be of primary concern, when temperature increases. 


\subsection{Microstructure Deterioration under Thermal Exposure}

\subsubsection{Diffusivity of Alloying Elements in Aluminum}

The diffusivity of alloying elements is the main indicator of the alloy stability at a service temperature. Diffusion, which for substitutional elements is enabled via mobile atomic lattice vacancies, often requires nonequilibrium vacancies to cause structural changes. Aluminum is the trivalent fcc metal with an impurity diffusion, being essentially different than that encountered in the monovalent and fcc noble metals. As evidenced for impurity diffusion, elements with low solid solubility in Al have diffusion coefficient low as compared with Al self-diffusion. A comparison of the diffusivities of selected alloying elements in $\mathrm{Al}$ is shown in Figures 8 and 9.

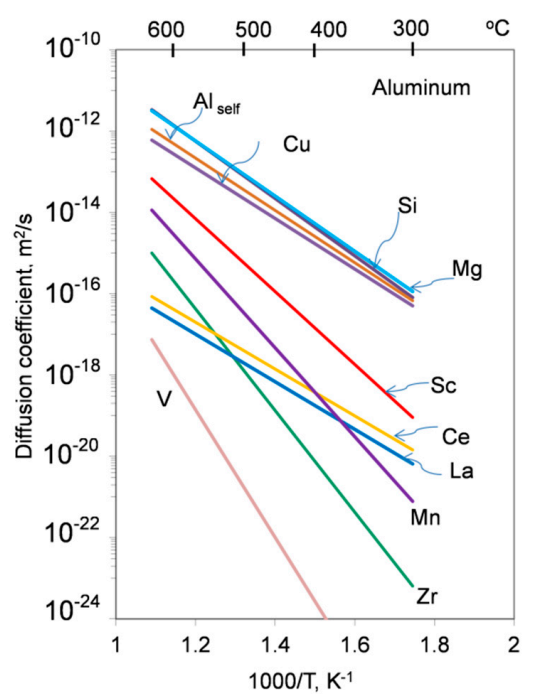

Figure 8. Semi-logarithmic plot of diffusivity in aluminum versus reciprocal temperature for alloying elements, representing transition metals, rare earth and non-transition metals, along with aluminum self-diffusion. Plot based on data selected from Tables A1-A3 in Appendix A.

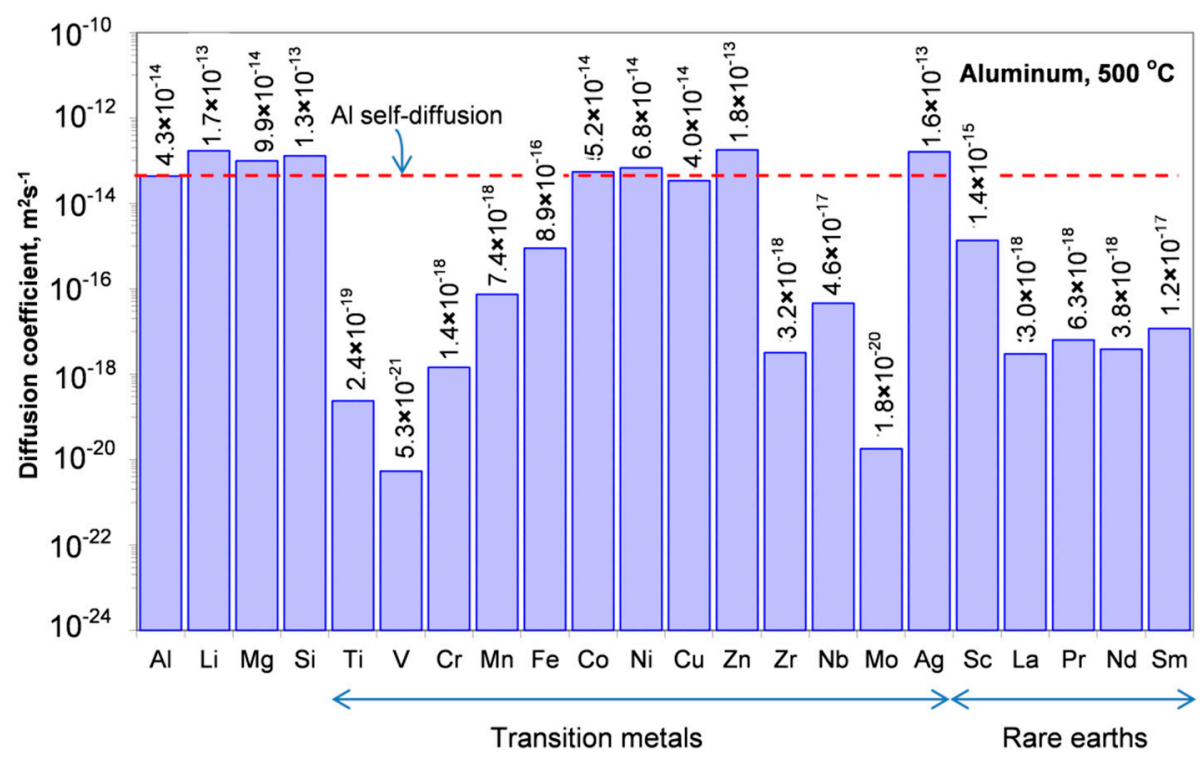

Figure 9. Calculated diffusion coefficients at $500{ }^{\circ} \mathrm{C}$ of selected alloying elements in aluminum, representing transition metals, rare earth and general elements, along with aluminum self-diffusion. Plot based on data from Tables A1-A3 in Appendix A. 
Throughout this report, the classification recommended by International Union of Pure and Applied Chemistry [30] is used, where rare earths elements are seen as a series of 17 elements: scandium, yttrium, and the lanthanide series (lanthanum, cerium, praseodymium, neodymium, promethium, samarium, europium, gadolinium, terbium, dysprosium, holmium, erbium, thulium, ytterbium, and lutetium).

According to alternative classification [31], rare earth elements are seen as lanthanides only and scandium with yttrium along with other 36 elements of Groups III through XII are classified as transition metals. Cerium belongs to Light Rare Earth Elements (LREE) also known as the cerium group (Sc, La, Ce, Pr, Nd, Pm, Sm, Eu, and Gd). The second group-Heavy Rare Earth Elements (HREE) - is known as the yttrium group ( $\mathrm{Y}, \mathrm{Tb}, \mathrm{Dy}, \mathrm{Ho}, \mathrm{Er}, \mathrm{Tm}, \mathrm{Yb}$, and $\mathrm{Lu}$ ).

\section{Diffusion of General Elements and Self-diffusion of Al}

Aluminum preserves its fcc structure up to the melting temperature. The self-diffusion of aluminum has been measured by combining various techniques, including radiotracer with 26Al [32], Nuclear Magnetic Resonance Spectroscopy [33], and TEM observation of voids shrinkage [34].

General alloying elements have diffusivities slightly higher than the aluminum self-diffusion with only small variations among different elements (Appendix A, Table A1). Their activation enthalpies are similar to those of aluminum self-diffusion and almost independent of their valence. The key element in this group, $\mathrm{Si}$, diffuses faster than $\mathrm{Al}$ in $\mathrm{Al}-\mathrm{Si}$ alloys, as proven during determination of diffusion coefficients in Al-Si alloys by Matano's method, where Kirkendall markers were found to move toward the Si-rich side [35].

Diffusion of Transition Metals in Aluminum

The majority of transition metals have diffusivities lower than the aluminum self-diffusion (Appendix A, Table A2). In general, they have high activation enthalpies and they also have high pre-exponential factors. High activation barriers and anomalously low diffusion coefficients, for partially filled d-shell $3 \mathrm{~d}$ elements, reflect strong bonding of $3 \mathrm{~d}$ elements with $\mathrm{Al}$. Exceptions to this are $\mathrm{Co}$ and Ni with high $\mathrm{d}-\mathrm{d}$ interactions, and thus weak bonding with $\mathrm{Al}$ [36].

Similar diffusivity as $\mathrm{Al}$ self-diffusion is shown by $\mathrm{Co}, \mathrm{Ni}$, and $\mathrm{Cu}$; higher diffusivity is shown $\mathrm{Zn}$ and $\mathrm{Ag}$ but lower diffusivities have Fe, Mn, Cr, Ti, V, Hf, Mo, and Pd [37,38].

\section{Diffusion of Rare-earth Metals in Aluminum}

Rare earth metals have very low solid state solubility in aluminum, large atomic radii and ionic charge of three- the same as aluminum. Unfortunately, the diffusion data for rare earth elements in aluminum are limited, with the work in [39] from the 1960s still being the major source (Appendix A, Table A3). In general, their diffusion coefficients are up to 4 orders of magnitude lower than $\mathrm{Al}$ self-diffusion. An exception is Sc, sitting in the midway between the rare earths and aluminum (Figures 8 and 9).

\subsubsection{Coarsening Resistance of Precipitates}

The essential factor that preserves the alloy properties at high temperatures is dispersed strengthening particles, resistant to diffusion-controlled coarsening, called Ostwald ripening. This coarsening mechanism, with an example shown in Figure 10, is governed by the Gibbs-Thompson effect, which alters the concentration at the particle-matrix interface, depending on the curvature of the interface. As a result of the concentration gradient, solutes diffuse from small particles to larger ones, leading to the coarsening phenomenon. With increasing temperature, large particles tend to grow at the expense of small ones, the average particle size increases and the total number of particles 
decreases. Through Ostwald ripening, the system may reduce its interfacial area, and thus its energy. The concentration at the particle-matrix interface is expressed by [40]:

$$
C_{A}(R)-C_{A}(\infty)=\frac{\alpha}{R}
$$

where $C_{A}(R)$-composition of the matrix phase $\mathrm{A}$ outside of a particle with radius $\mathrm{R}$; $C_{A}(\infty)$-composition of the matrix phase $\mathrm{A}$ at equilibrium, when the interface is flat; and $\alpha$-constant, proportional to the specific interfacial energy.
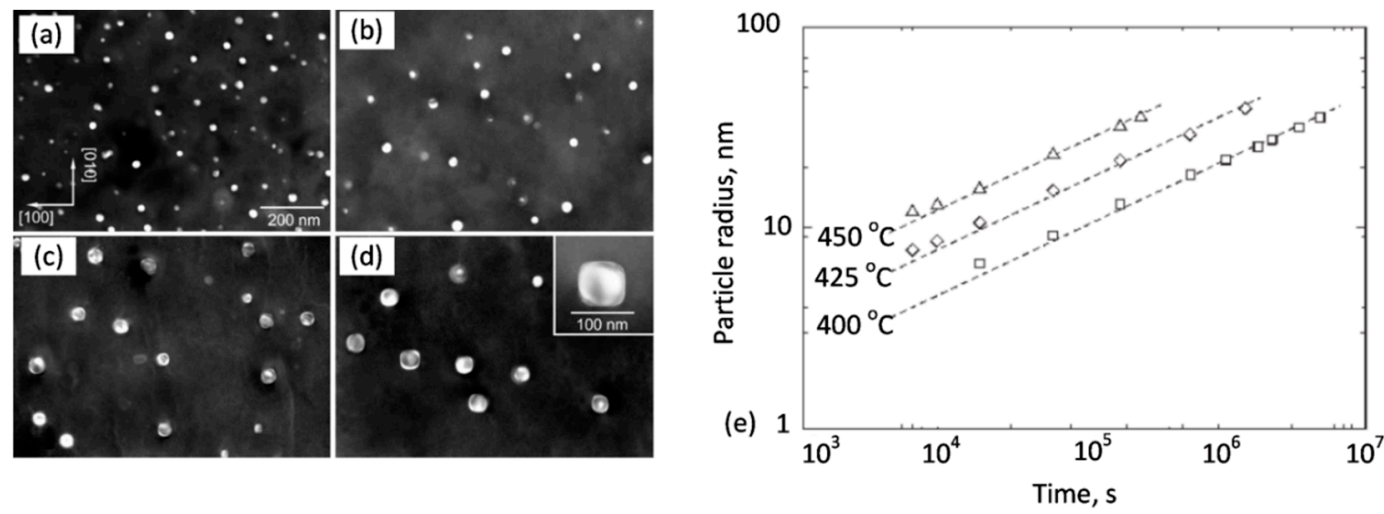

Figure 10. Precipitate coarsening during aging of Al-0.28 wt.\% Sc alloy: dark-field TEM images of $\mathrm{Al}_{3} \mathrm{Sc}$ precipitates aged at (a) $400{ }^{\circ} \mathrm{C}$ for $5 \mathrm{~h}$, (b) $400{ }^{\circ} \mathrm{C}$ for $50 \mathrm{~h}$, (c) $425^{\circ} \mathrm{C}$ for $50 \mathrm{~h}$, and (d) $450{ }^{\circ} \mathrm{C}$ for $50 \mathrm{~h}$; (e) change in the average precipitate radius $r$ with aging time $t$ for temperatures indicated [41].

The classical interpretation (LSW) of the Ostwald ripening was developed by Lifshitz and Slyozov [42] and Wagner [43] during examination of coarsening in a system, where globular particles are indefinitely separated. According to the LSW theory, under steady-state conditions the cube of the average particle radius increases linearly with time:

$$
(\mathrm{R}(\mathrm{t}))^{3}-(\mathrm{R}(\mathrm{t}))^{3}=\mathrm{K}_{\mathrm{LSW}} \mathrm{t}
$$

where $R(0)$ and $R(t)$ represent the average radius at time $t=0$ and $t=t$, respectively, and $K_{L S W}$ coarsening rate constant expressed as [44]:

$$
K_{L S W}=\frac{8 \gamma D C \infty v m}{9 R T}
$$

where $\gamma$ is the interface energy, $D$-apparent diffusion coefficient of solute atoms, $C \infty$ the solute concentration at equilibrium, $v_{m}$-solute molar volume, $R$ is the gas constant, and $T$-temperature. In the $L S W$ theory the diffusional interactions between particles are neglected so the mechanism is applicable in a negligible fraction of the coarsening phase.

\subsection{Testing Techniques of Thermal Stability}

The thermal stability of an alloy consists of many components that individually also depend on temperature. For example, thermal stability of microstructure, which, in turn, will impose thermal stability of phase composition, which will further separate into thermal stability of phase size (resistance to coarsening), chemical stability of individual phases, etc.

\subsubsection{Microstructure Analysis}

Microstructural observations are essential in assessing thermal stability. During conventional imaging, samples are heated ex situ to different stages and subsequently inspected one by one at room temperature. In contrast, in situ TEM allows direct observations of microstructural changes on the 
nanometer-scale, occurring for all precipitates in a selected sample region. For example, in situ TEM analysis was found effective in assessing thermal stability of the AA5456-H116 Al-Mg alloy after ultrasonic impact treatment [45]. Based on TEM observations, the alloy structure was found stable up to $300{ }^{\circ} \mathrm{C}$ followed by grain growth, especially intensive above $400{ }^{\circ} \mathrm{C}$.

\subsubsection{Thermal Analysis}

Thermal analysis is defined as a group of physical/chemical methods that deal with studying materials and processes under conditions of programmed changes of the surrounding temperature. The physical parameters, measured during thermal analysis, include mass, temperature, heat flux or dimension [46]. While the early thermal analysis techniques assessed exclusively the temperature of the examined sample on heating/cooling, during technology development the reference (inert) sample was added, leading to Differential Thermal Analysis. The most common techniques of thermal analysis include Differential Scanning Calorimetry (DSC), Thermogravimetric Analysis (TGA), Dynamic Mechanical Analysis (DMA), Isothermal Calorimetry (TAM), Thermomechanical Analysis (TMA), Flash Diffusivity, Thermal Conductivity, and Dilatometry (DIL).

Thermal analysis methods are sometimes combined to gather complimentary data, e.g., DSC with TGA for studying the oxidation of aluminum [11] or Al-Mg-Er alloy thermal stability [47]. Most often, however, they are used with other experimental techniques, such as metallography, X-ray, or mechanical testing. For example, DSC coupled with tensile tests and TEM was successfully applied to investigate the effect of thermal exposure at $150{ }^{\circ} \mathrm{C}$ on microstructure and mechanical properties of the AA 2524 alloy [48].

Although very useful, thermal analysis techniques have limitations, as shown in Figure 11 for the cryomilled Al-Mg-Er powders [47]. A combination of DSC and TGA measurements of the nanocrystalline system during heating successfully detected phenomena of melting at $\sim 635^{\circ} \mathrm{C}$ (liquidus) and recovery at $\sim 160{ }^{\circ} \mathrm{C}$. However, the solidus temperature, expected at $\sim 575^{\circ} \mathrm{C}$ and recrystallization, expected at $\sim 330^{\circ} \mathrm{C}$, as verified by TEM/X ray, were not detected by the DSC/TGA techniques.
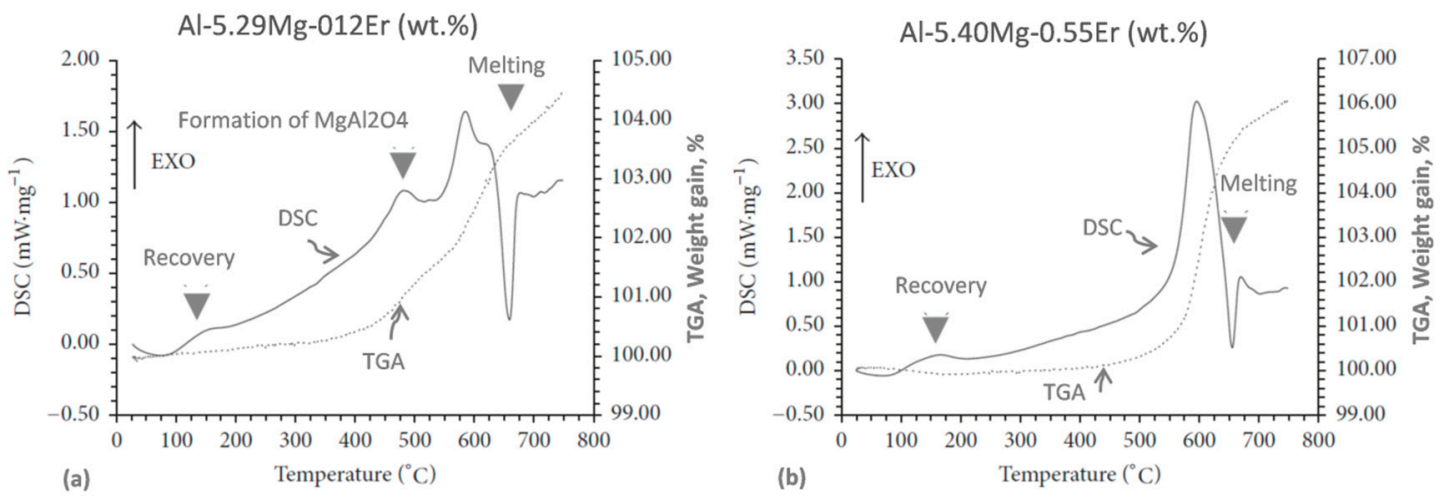

Figure 11. Application of DSC/TGA combination to study thermal stability of Al-Mg-Er alloys: (a) $\mathrm{Al}-5.29 \mathrm{Mg}-012 \mathrm{Er}$ (wt.\%); (b) $\mathrm{Al}-5.40 \mathrm{Mg}-0.55 \mathrm{Er}$ (wt.\%). The characteristic temperature of solidus being $575{ }^{\circ} \mathrm{C}$ and recrystallization at $\sim 330^{\circ} \mathrm{C}$ are not detected by DSC [47].

\subsubsection{High Temperature X-Ray Diffraction}

X-ray diffraction (XRD), combined with in situ high-temperature experiments, allows for qualitative/quantitative identification of crystalline phases, with details regarding the crystallite size, texture, lattice parameters, and residual stresses. It allows determining crucial details, such as temperature-dependent phase transformations, thermal changes of structural parameters, and thermal stability of individual phases. High-temperature XRD may measure the changes of physical properties taking place within materials during a simulation of industrial processes.

An example of application of high-temperature XRD to study thermal stability of phases in the Al-7Si-1Cu-0.5Mg (wt.\%) alloy, modified with micro-additions of transition metals is shown 
in Figure 12 [49]. During heating, the XRD measurements were conducted between 30 and $600{ }^{\circ} \mathrm{C}$, with the particular temperature being selected based on thermal analysis, emphasizing the major transformation points. The experiment concluded that the $\mathrm{Cu}$ - and $\mathrm{Mg}$-rich phases along with eutectic Si dissolved between 300 to $500{ }^{\circ} \mathrm{C}$. In contrast, the complex ( $\left.\mathrm{AlSi}\right)_{\mathrm{x}}(\mathrm{TiVZr})$ phases with $\mathrm{D0}_{22} / \mathrm{DO}_{23}$ tetragonal crystal structure and different lattice parameters, containing transition metals and being key to the alloy thermal stability, were stable up to $696-705^{\circ} \mathrm{C}$.
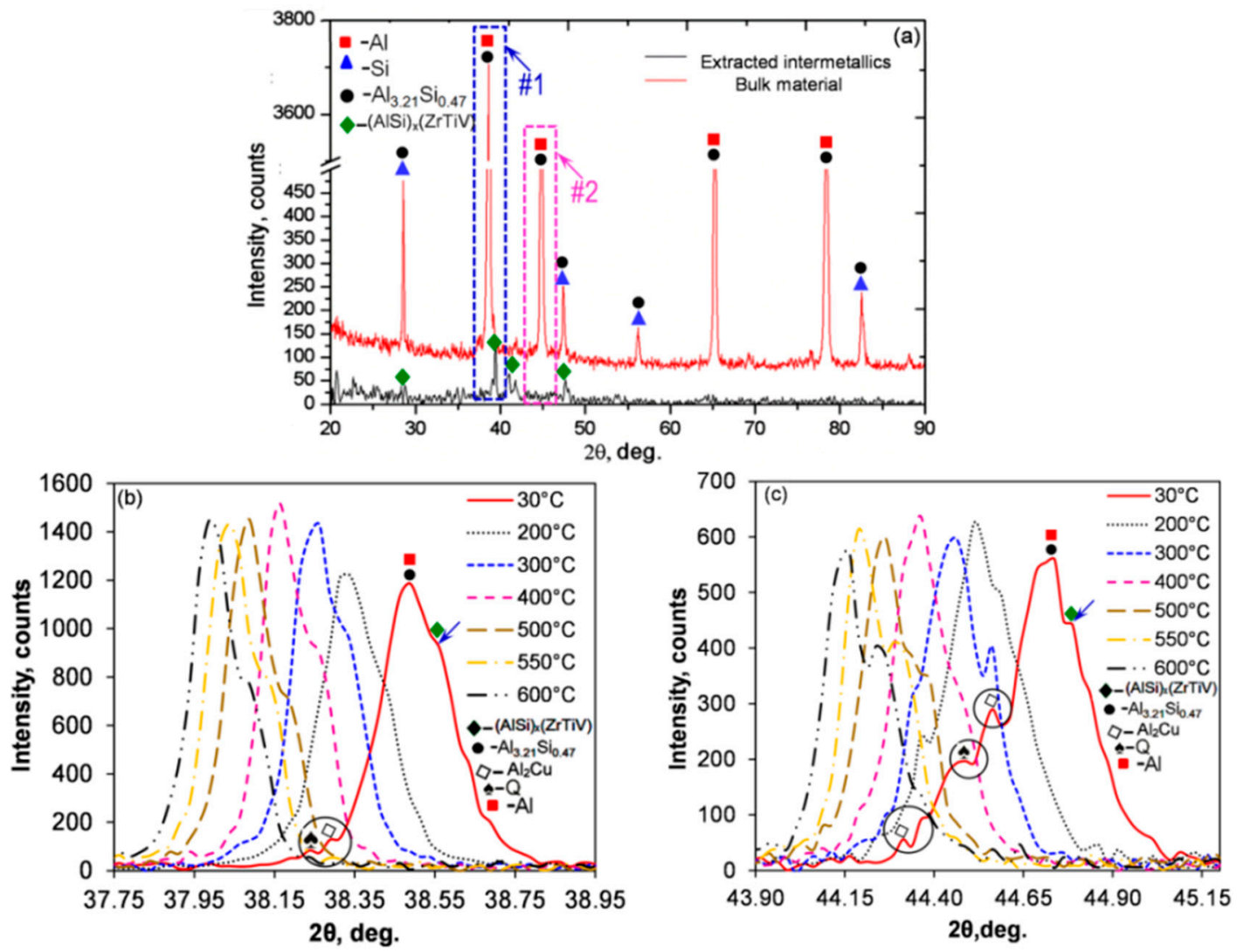

Figure 12. An application of high-temperature $X$-ray diffraction for thermal stability testing of phases in as-cast Al-7Si-1Cu-0.5 Mg alloy with 0.21Ti, 0.3V, and 0.47Zr (wt.\%): (a) room temperature diffraction patterns obtained from bulk materials and extracted intermetallics; $(\mathbf{b}, \mathbf{c})$ diffraction patterns at $2 \theta$ locations for peaks \#1 and \#2 at temperatures from 30 to $600{ }^{\circ} \mathrm{C}$. The experiment was conducted with $\mathrm{Cu}_{\mathrm{K} \alpha}$ radiation at $45 \mathrm{kV}$ and $40 \mathrm{~mA}$, with a step size of $0.05 \mathrm{deg}$, and duration of $0.2 \mathrm{~s}$ for each step [49].

\subsubsection{Neutron Diffraction}

Neutron diffraction is a form of elastic scattering, where the intensity pattern around the sample irradiated with neutrons allows a determination of its atomic and/or magnetic structure. The technique is similar to described above X-ray diffraction, but the different type of radiation gives complementary information. An advantage of using neutrons lies in the highly penetrating nature of radiation that ensures that the scattering observed is representative of the large material volume. Therefore, it is well suited to measure the thermal stability of alloys subjected to external load.

An example in Figure 13 shows an application of in situ neutron diffraction for assessing the influence of temperature on performance of aluminum alloys through measurement of the creep strain for individual $\mathrm{hkl}$ planes under tensile load [50]. The conditions of temperature and pressure used during measurements are typical to those experienced by automotive engine heads in service. The in situ neutron diffraction measurements provided data on $d$ spacing evolution for various $h k l$ crystallographic planes as a function of temperature, tensile load, and time, thereby revealing $h k l$-specific evolution 
of elastic strains. As a result, high temperature plastic and elastic creep properties of alloys were characterized that may be used as a benchmark during development of heat-resistant alloys.
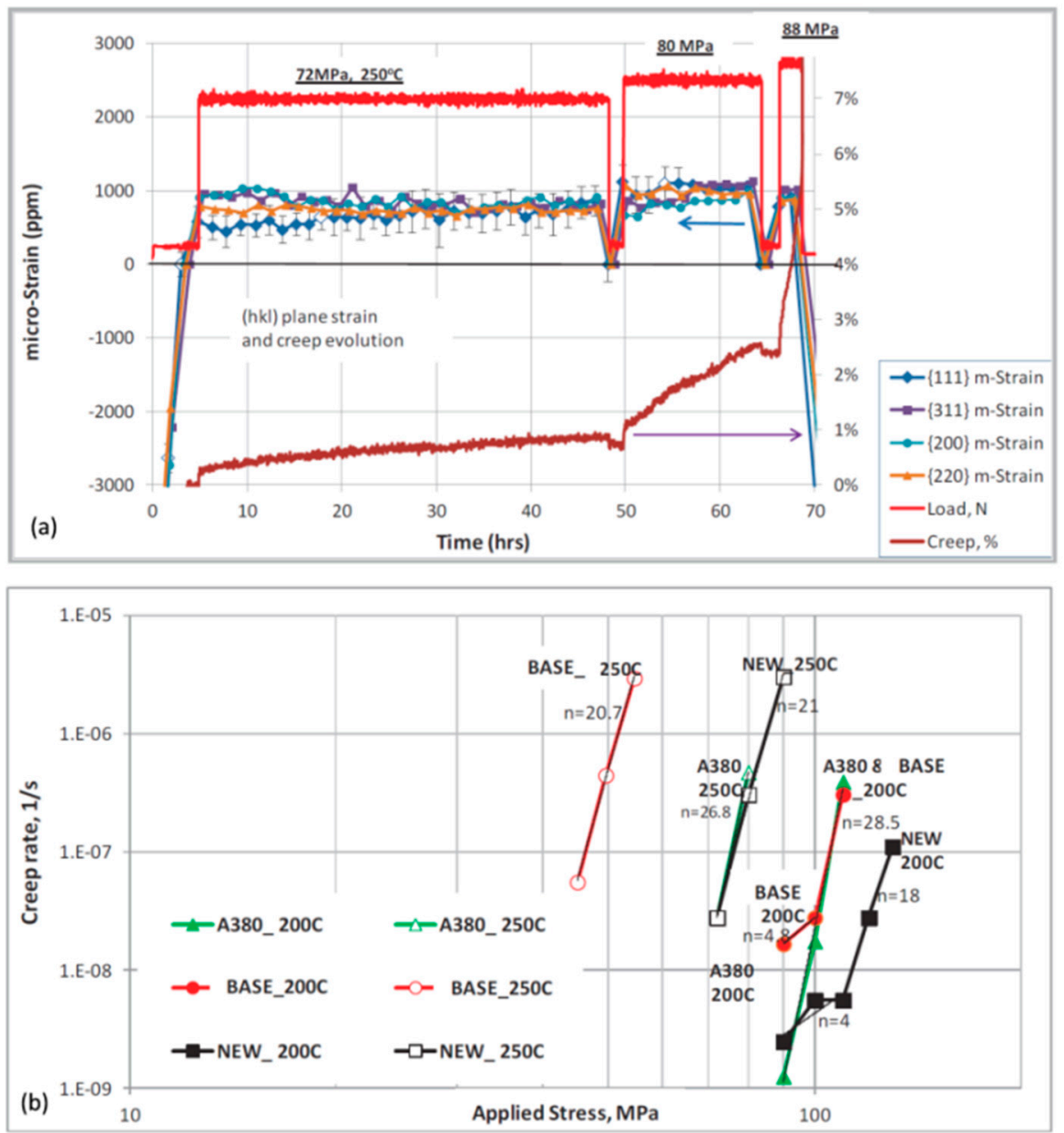

Figure 13. Application of neutron diffraction to the in situ study of thermal stability through measurements of creep evolution: (a) creep strain (\%) and elastic microstrain (ppm) evolution at selected hkl planes at $250{ }^{\circ} \mathrm{C}$ under ascending cyclic loading for $\mathrm{Al}$ alloy marked as New below; (b) calculated stress exponents of the tested alloys at $200{ }^{\circ} \mathrm{C}$ and $250{ }^{\circ} \mathrm{C}$. Alloys: A380: A19.5Si-3.4Cu, Base: $\mathrm{Al}-7.1 \mathrm{Si}-1 \mathrm{Cu}-0.5 \mathrm{Mg}$, New: Al-7Si-0.9Cu-0.5Mg-0.56Zr-0.20Ti-0.32V (wt.\%) [50].

The alloy containing additions of transition metals $\mathrm{Ti}, \mathrm{Zr}$, and $\mathrm{V}$ shows superior performance under conditions simulating an in-service automotive powertrain component. Its performance was superior in both the ultimate strength and total (plastic and elastic) creep, which can be explained in part by activation all the observed $h k l$ planes to support the load. Such findings contribute to in-depth understanding of the structural factors, controlling thermal stability of different alloys under specific load conditions, required in service environment.

\subsubsection{Methodology Based on Correlating Hardness and Phase Transformations}

To develop the methodology for assessment of the performance of aluminum alloys at high temperatures, the maximum temperature that alloys can withstand without drastic loss of hardness was determined and correlated with the corresponding phase transformation data [51]. The methodology essence is shown in Figure 14, and the results suggest that the dilatometric measurements in a combination with electrical resistivity experiments represent an efficient and powerful tool to predict the temperature of hardness reduction in commercial aluminum alloys. The methodology was tested on A356 (Al-7.5Si-0.45Mg, wt.\%), F357 (Al-7.5Si-0.1Cu-0.5Mg wt.\%), and C355 
(Al-5Si-1Cu-0.5Mg, wt.\%) alloys, being key candidates for a variety of structural applications. During heating up to $500{ }^{\circ} \mathrm{C}$, the alloys experienced from 34 to $66 \%$ reduction of the initial hardness with the hardness reduction showing a steep transition between 220 and $238^{\circ} \mathrm{C}$. This methodology is seen useful to determine the suitability of metallic alloys for high-temperature applications in aerospace and automotive industry.

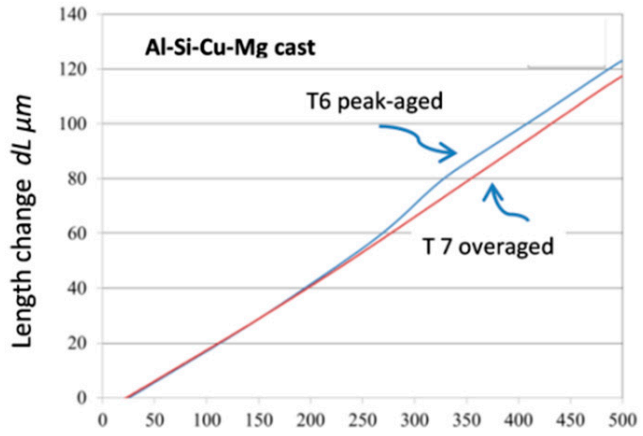

(a)

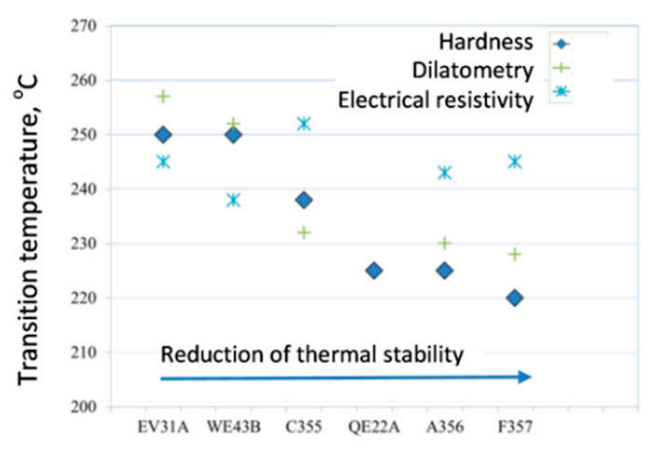

(d)

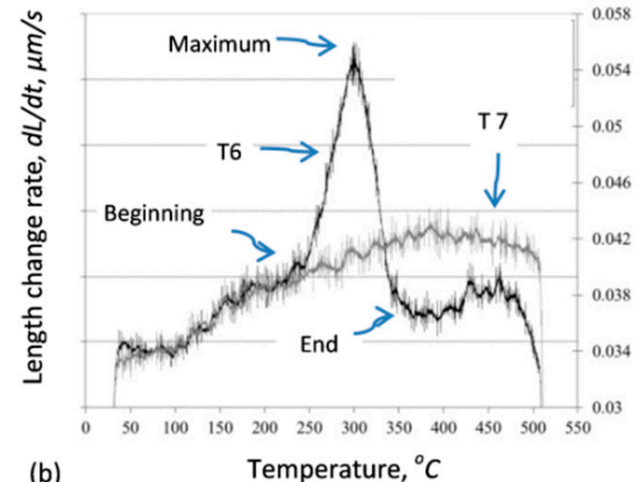

(b)

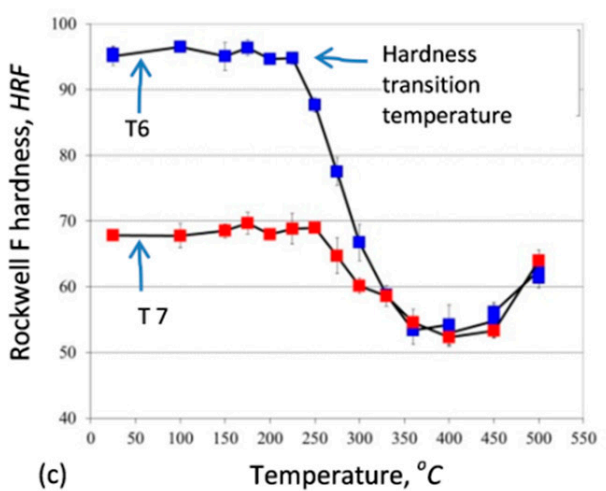

Figure 14. A methodology for determination of alloy thermal stability based on a combination of dilatometry and hardness measurements. Example for cast $\mathrm{Al}-\mathrm{Si}-\mathrm{Cu}-\mathrm{Mg}$ alloy in $\mathrm{T} 6$ peak-aged and T7 over-aged conditions: (a) length change $(\mathrm{dL})$ vs. temperature; $(\mathbf{b})$ length change rate $(\mathrm{dL} / \mathrm{dt}) \mathrm{vs}$. temperature; (c) hardness change versus temperature; (d) methodology application: thermal stability of commercial aluminum and magnesium alloys determined by hardness, dilatometry, and electrical resistivity measurements [51].

Similar techniques, combining isochronal annealing with microhardness, electrical resistivity, and differential scanning calorimetry, are described in the literature. For example, they were used to assess the effect of small additions of Sc and $\mathrm{Zr}$ on microstructure along with thermodynamic and mechanical properties of $\mathrm{Al}-\mathrm{Sc}-\mathrm{Zr}$ alloys [52]. There are also reports on using combinations of dilatometry and electrical resistivity with differential scanning calorimetry for this purpose.

\subsubsection{Assessing Thermal Stability through Mechanical Properties}

Thermal stability is often visually presented through plots of the alloy hardness versus temperature or versus time at a given temperature. In practice, all mechanical properties, being of importance in engineering applications, experience changes at service temperature. The alloy hardness is commonly used as an indicator of its performance at temperatures up to $500^{\circ} \mathrm{C}$. To determine the aging parameters required to activate the specific type of precipitates and to evaluate the phase transformation kinetics during alloy aging, the isochronal annealing experiments are used, where hardness is the key indicator.

In addition to hardness also strength and ductility are seen as important design characteristics that define the resistance of an alloy to degradation of ductility and toughness, when subjected to long-term thermal exposure. The tensile or compression testing may be performed at high or room 
temperature. The routine measurement of thermal stability is the room temperature tensile testing, following high-temperature, often very long-term, exposure.

Creep strength and rupture strength are commonly used when designing components for high temperature service. Rupture strength is defined as the stress at specified environmental conditions, such as temperature and a reactive chemical environment, required to produce rupture in a fixed amount of time. It is of interest that while general properties favor the fine grain structures, creep resistance is improved by coarse grains [20].

In some applications of $\mathrm{Al}$ alloys, e.g., in automotive engines, the temperature effect is superimposed on cyclic loading, leading to high-temperature fatigue. Fatigue failure is defined as a permanent damage of a material due to dynamic loads and may occur at stresses well below the static yield stress. The temperature effect causes the substantial reduction of fatigue life of aluminum alloys. In some applications, the mechanical and thermal strain varies independently, leading to combined, more damaging loading, being termed thermomechanical fatigue.

An example for the cast AlSi8Cu3 (wt.\%) alloy in Figure 15 shows that at $150{ }^{\circ} \mathrm{C}$ the fatigue strength decreased by up to $25 \%$ for locations within the part, having different local porosity [53]. For the AA7075 alloy, fatigue life reduction factor increased with temperature, reaching a maximum of $44 \%$ at $225^{\circ} \mathrm{C}$ [54]. For this alloy, a reduction of fatigue life in the temperature range from 25 to $225^{\circ} \mathrm{C}$ is described by the Basquin's equation [55]:

$$
\sigma_{f}=\alpha N_{f}^{b} T^{c}
$$

where $\sigma_{f}$ is the fatigue strength $(\mathrm{MPa}), N_{f}$ is the number of cycles to failure, $\alpha$ is the fatigue strength coefficient, and $b$ is the Basquin's exponent. According to the authors of [54], the equation is of the form

$$
\sigma_{f}=1558.21 N_{f}^{-0.1308} T^{c}
$$

where

$$
c=0.54564-0.004503 T+1.24567 \times 10^{-5} T^{2}-1.170266 \times 10^{-8} T^{3}
$$

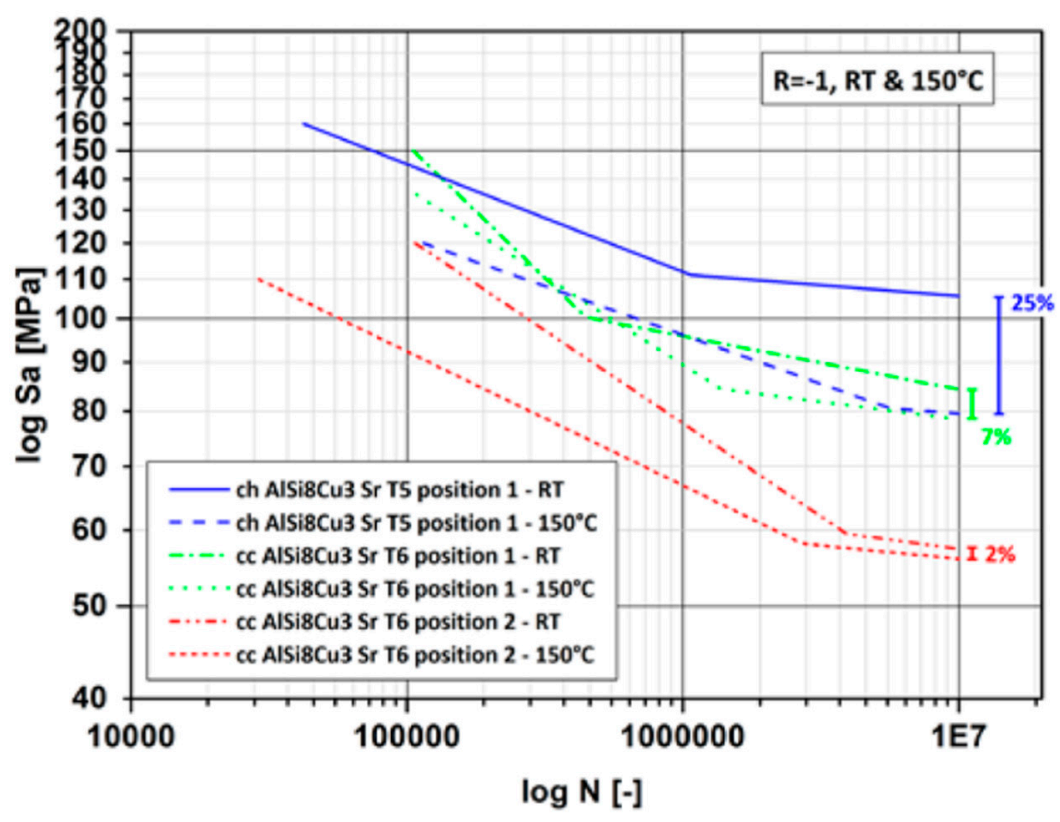

Figure 15. A summary of the stress/cycle $\mathrm{S} / \mathrm{N}$ curves at room temperature and at $150{ }^{\circ} \mathrm{C}$ for a survival probability of $50 \%$ of AlSi8Cu3 (wt.\%) alloy also listed with the fatigue strength reductions in percentage. It shows that at $150{ }^{\circ} \mathrm{C}$ the fatigue strength decreased by up to $25 \%$, depending on location within the part due to porosity; Sa-stress amplitude [53]. 
All the mechanical properties mentioned above are measured with conventional techniques, but with high-temperature capabilities.

\subsubsection{Challenges with Predicting the Effect of Long Service Time at Increased Temperatures}

When specifying the maximum service temperature of structural materials a distinction is often made between the intermittent and continuous service. It is clear that the temperature of the latter is generally lower. There is an obvious challenge to predict the long-term thermal stability of alloys. The key question is how, within a reasonable laboratory testing time (weeks rather than months), to predict the material future performance over many years, often many decades.

In the area of Ni-based superalloys, facing a similar challenge, a program was initiated in the 1970 s to document their long-time thermal stability with testing at $870{ }^{\circ} \mathrm{C}$ for up to $16,000 \mathrm{~h}$ (almost 2 years) [3]. However, the service time of superalloys, e.g., in turbine blades, is strictly controlled and is much shorter than aluminum alloys applied, for example, in automotive combustion engines.

An example of an application requiring long-term thermal stability is packaging and transportation of radioactive materials. An aluminum alloy, used for the basket within the storage/transportation casks for spent fuels in nuclear power plants, due to its low density and good thermal stability, should preserve its properties during exposures to temperatures of $100-200{ }^{\circ} \mathrm{C}$ for over 60 years $[6,16,56]$. The cask is used for transportation of spent fuel to a storage facility, where it serves its storage function for up to 60 years, and then it is used again for transportation of the fuel to a spent fuel reprocessing facility or a final disposal site. Throughout its service time the alloy is subjected to temperatures that gradually decrease from $200{ }^{\circ} \mathrm{C}$ to approximately $100^{\circ} \mathrm{C}$ at the end of 60 years storage (Figure 16a). The alloy should maintain the strength required during storage and transportation, including accidental drop from a height of $9 \mathrm{~m}$, as required by IAEA.
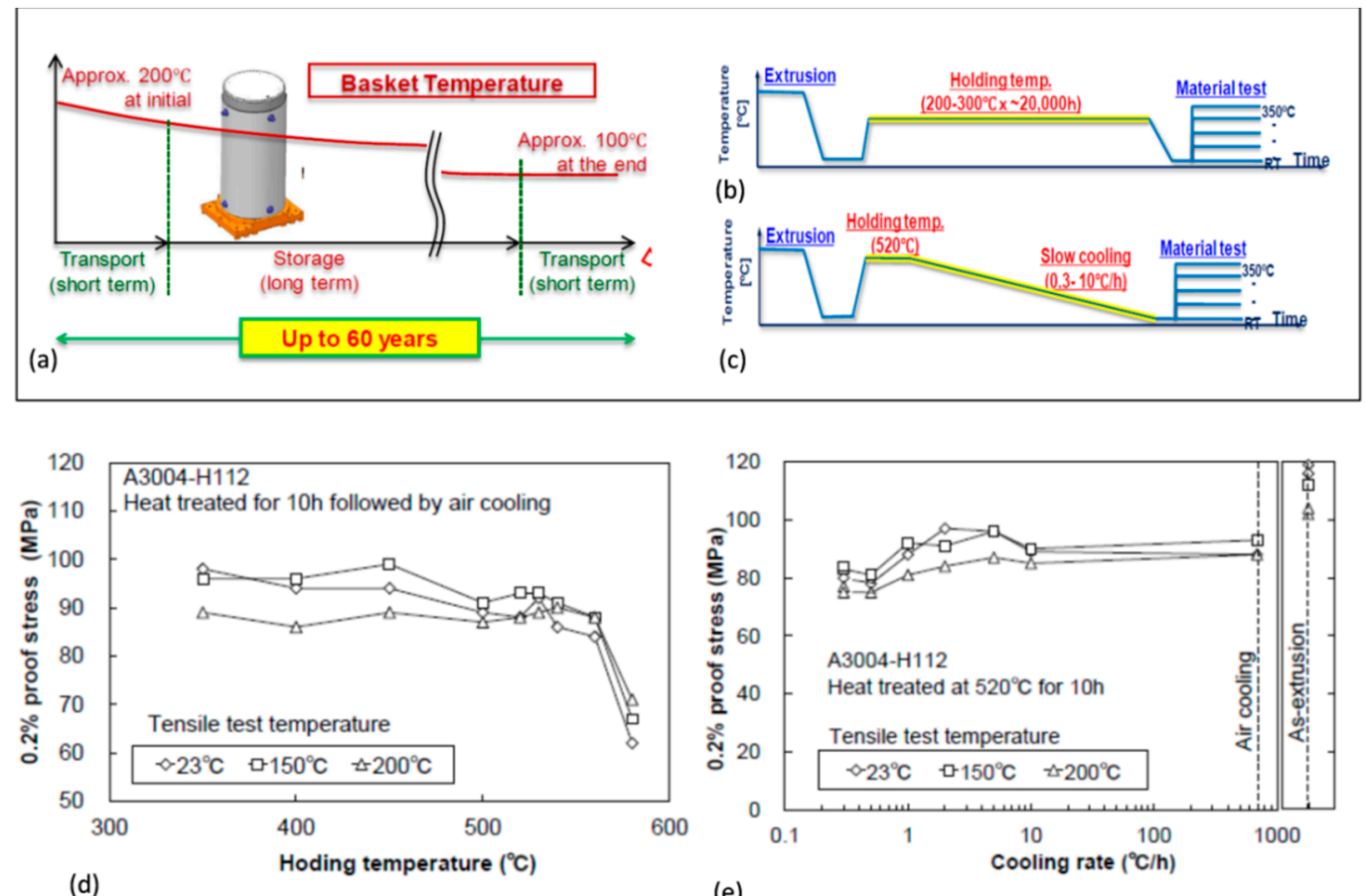

(e)

Figure 16. Evaluation of thermal stability of an aluminum alloy for long-term storage/transportation casks for spent fuel in nuclear power plants: (a) design requirements of temperature-time exposures; (b) long-term holding treatment parameters; (c) parameters of annealing and slow cooling treatments; (d,e) yield stress of the AA3004 H112 extruded alloy after treatment and testing at temperatures indicated $[6,16]$. 
A thermal treatment method was developed to assess the aluminum alloy properties in the basket application, anticipated after long-term storage for 60 years [16]. It consists of two alternate routes: (i) long-term overaging heat treatment at 250 and $300^{\circ} \mathrm{C}$ for up to $10^{4} \mathrm{~h}$ or (ii) slow cooling from high-temperature annealing at 350 to $580{ }^{\circ} \mathrm{C}$ for $10 \mathrm{~h}$ (Figure $16 \mathrm{~b}, \mathrm{c}$ ). The evaluation of the properties of the AA3004-H112 H112 hot-extruded Al-Mn alloy, Al-1-1.5Mn0.8-1.3Mg (wt.\%), after both treatments is shown in Figure 16d,e.

\section{Alloys Prone to Instability at Room or Slightly Elevated Temperatures}

This phenomenon refers to temperatures typically below $100^{\circ} \mathrm{C}$. Such a scenario applies to aircraft components that may become warm during service due to exposure to sun, aerodynamic heating, or heat transferred from engines. Temperatures from 70 to $85{ }^{\circ} \mathrm{C}$ are typically used to simulate the environment to which the wings and fuselage structures of commercial aircraft are exposed [8]. For a supersonic jet, due to air friction at a speed of Mach 2.05, the temperature on the skin of the airplane body is reported as $127^{\circ} \mathrm{C}$ [57]. A challenging factor is the long exposure time, as airplane materials are designed for a service time between 30 to 50 years. The aerospace applications have strict regulations, regarding thermal stability.

\subsection{Application of Aluminum Alloys for Aircraft Structure}

In today's aircraft industry, there is a general shift from metallic materials towards composites, but aluminum alloys still represent $\sim 60 \%$ by weight of the structural materials used. An exception is the Boeing 787 Dreamliner, which uses only 20\% aluminum. Although there are different selection criteria, aluminum alloys are also used in spacecraft structures, including space vehicles and satellites.

The typical alloys used for aircraft structure are Al-Li grades containing lithium to decrease the weight of aluminum, while improving its strength, toughness, corrosion resistance, and forming characteristics. Lithium contents up to $3 \mathrm{wt}$ \% exert a large effect on the modulus of aluminum with a $6 \%$ increase for every wt. $\% \mathrm{Li}$ added. In addition, every wt. $\% \mathrm{Li}$ added decreases the aluminum density by $3 \%$. Aircraft industry applications include wing leading and trailing edges, fuselage bulkhead webs, and internal framework parts. For example, the Airbus A350 XWB has parts made of steel and titanium, with almost $20 \%$ made from Al-Li alloys.

\subsection{Thermal Stability Concerns with Al-Li Grades}

A key question in controlling the thermal stability is how fast the properties evolve, which relates to the kinetics of phase transformations, primarily controlled by diffusion. A room temperature exposure of some aluminum alloys may result in natural aging, i.e., slight movements of solute atoms in the matrix, which modifies the material properties [58]. Aging of Al- Li alloys results in decomposition of solid solution of $\mathrm{Li}$ in $\mathrm{Al}$ and precipitation of $\mathrm{Al}_{3} \mathrm{Li}$ [59], which may lead to embrittlement during the long-term operation $[60,61]$.

Historically, the first (1950s and 1960s) and second (1980s) generations of Al-Li alloys tended to suffer from several problems, including poor ductility and fracture toughness, fatigue and fracture resistance, and unreliable corrosion resistance [62]. The second generation alloys AA2090, $\mathrm{Al}-\mathrm{Li}-\mathrm{Cu}$, and AA8090, $2091 \mathrm{Al}-\mathrm{Li}-\mathrm{Cu}-\mathrm{Mg}$, when exposed to elevated temperature of $\sim 70{ }^{\circ} \mathrm{C}$ undergo aging, causing an increase in strength and reduction in ductility and toughness that may lead to embrittlement. An explanation of embrittlement in the AA8090 alloy, considered the most successful of the second generation, includes a formation of $\delta$ AlLi phase at grain boundaries, segregation of Li atoms to grain boundaries, precipitation of small $\mathrm{Al}_{3} \mathrm{Li}$ particles, and precipitation effects related to $\mathrm{G}-\mathrm{P}$ zone formation [63]. An example of property change for the second generation Al-Li alloy AA1464, subjected to long-term exposure at $85^{\circ} \mathrm{C}$ and strengthening precipitates in third generation alloys, are shown in Figure 17a,b. 


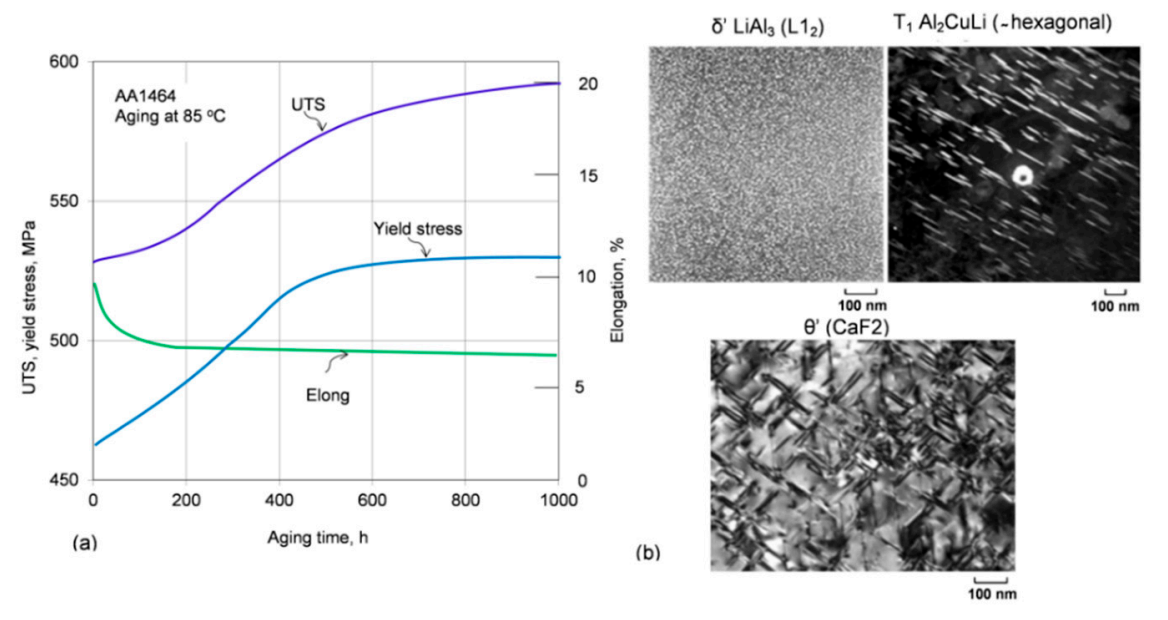

Figure 17. Tensile property change during long-term aging of 2nd generation Al-Li AA1464 alloys at $85^{\circ} \mathrm{C}$, showing an increase in strength and reduction in ductility (a) [61] and strengthening precipitates in third generation Al-Li alloys (b) [62].

The third generation Al-Li alloys, developed in the 1990s, with significantly reduced lithium content and other improvements, made them more attractive for modern aircraft and aerospace vehicles. For example, the Airbus A380 uses 3rd generation Al-Li alloys AA2099-T83 and AA2196-T8511 for floor beams, AA2196-T8511 for fuselage stringers, and AA2050-T84 for lower wing reinforcement [64]. Thermal stability of the AA2099 Al-Cu-Li T83 alloy, assessed in the temperature range 200 to $305^{\circ} \mathrm{C}$, through both hardness and tensile tests after overaging, showed better performance, compared to aluminum alloys specifically developed for high temperature applications, with the advantage of a considerable lower density [65]. Tests underlined the need to enhance the formation of $\mathrm{T}_{1}\left(\mathrm{Al}_{2} \mathrm{CuLi}\right)$ precipitates when high temperature strength is required. An addition of $0.29 \mathrm{wt} . \%$ Ce contributed to coarsening inhibition of $\mathrm{Al}_{2} \mathrm{CuLi}$ and refinement of Ce-containing intermetallic phase, $\mathrm{Al}_{8} \mathrm{Cu}_{4} \mathrm{Ce}$, which further improved the thermal stability at the medium-high temperature range (170 to $270{ }^{\circ} \mathrm{C}$ ) and high-temperature deformation uniformity of this alloy [66].

The Al- $\mathrm{Li}-\mathrm{Cu}-\mathrm{Zr}$ alloy, C458-T861 (Al-1.8Li-2.7Cu-0.3Mg-0.08Zr-0.3Mn-0.6Zn wt.\%), destined for use in space vehicles, tested at 83,135 , and $177^{\circ} \mathrm{C}$ for up to $1000 \mathrm{~h}$ showed good thermal stability of mechanical properties up to $135^{\circ} \mathrm{C}$. However, further increasing the temperature and time led to a reduction in the alloy fracture toughness [67].

\section{Stability of Alloys with a Nonequilibrium State}

The upper strength limit of bulk $\mathrm{Al}$ alloys achieved by conventional precipitation strengthening of $\sim 700 \mathrm{MPa}$ may be increased to over $1000 \mathrm{MPa}$ through grain refinement to nanocrystalline level and amorphization. Unfortunately, the nonequilibrium state with a low thermal stability of amorphous and nanostructured aluminum alloys limits their use at increased temperatures.

\subsection{Thermal Stability of Amorphous Alloys (Metallic Glasses)}

Al-based amorphous alloys represent an important group of amorphous materials with a high specific strength, combined with outstanding corrosion resistance and good ductility. It is of interest that their high strength at room temperature is accompanied by an ability of softening to viscous liquid states above the glass transition temperature, thus allowing thermoplastic forming to be conducted due to superplasticity [68].

In the 1970s, the alloys covered Al-transition metal binary systems, formed by splat quenching, and in the 1980s, the Al-(Fe, Co)-B alloys, cast by melt spinning. Later, they expanded to alloying with transition metals groups IV-VI with VII and VIII. The next expansion included Al-rare earth binary systems and Al-transition metals-rare earth combinations. The latter systems are the most 
popular at present due their high glass-forming ability and high strength. There are still technological barriers with manufacturing the Al-based bulk metallic glasses due to their rather low glass-forming ability, requiring very high critical cooling rates that are difficult to achieve in engineering practice at larger cross sections, often larger than just a few micrometers.

During heating, amorphous alloys easily transform to crystalline structures, losing their unique properties. Following crystallization, continued heating results in phase transformations with a generation of stable and metastable phases, until the alloy finally melts. For example, amorphous powders with compositions of Al85Y7Fe8, Al83Y7Fe8Ti2, and Al79Y7Fe8Ni3Ti2Nd1 (at.\%) exhibited crystallization temperatures of 342,446 , and $457^{\circ} \mathrm{C}$, respectively, with an increase by $115^{\circ} \mathrm{C}$ through microalloying [69].

An interesting feature of the crystallization behavior of amorphous aluminum alloys is that some compositions have a tendency to crystallize into nanometer-sized clusters or grains (Figure 18). The phenomenon can be explored for improving properties of amorphous structures. For example, the mechanical properties of bulk Al84Ni7Co3Dy6 (at.\%) alloys, produced by Spark Plasma Sintering of amorphous powder with a diameter of $25 \mu \mathrm{m}$ at temperatures above $400{ }^{\circ} \mathrm{C}$, are significantly enhanced by in situ crystallization of nanoscale intermetallic compounds during plasma sintering [70]. The Al-Ni-Co-Dy bulk alloys produced by plasma sintering at $400{ }^{\circ} \mathrm{C}$ exhibit a maximum strength of $1773 \mathrm{MPa}$ with $5.6 \%$ plastic strain. Increasing the sintering temperature to $430{ }^{\circ} \mathrm{C}$ led to higher plastic deformability of $7.2 \%$ at the expense of the lower maximum strength of $1255 \mathrm{MPa}$. The solute concentration played a key role in determining the size of the $\alpha-\mathrm{Al}$ phase during plasma sintering of the amorphous A184Ni7Co3Dy6 (at.\%) powder.

(a)

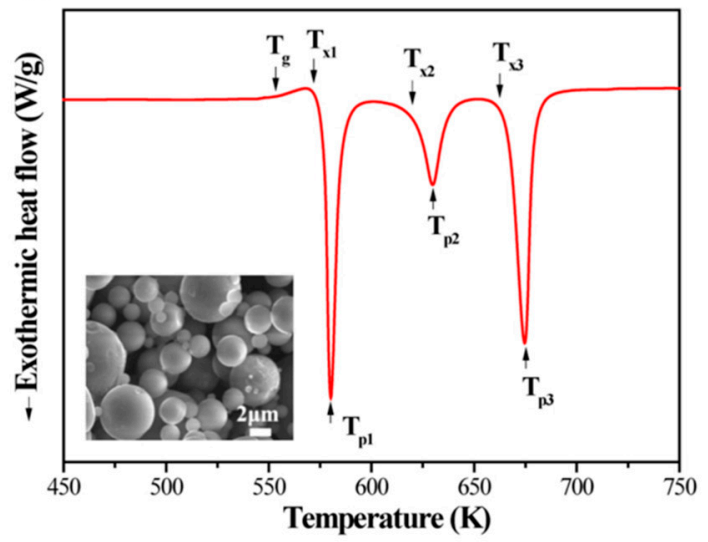

(b)

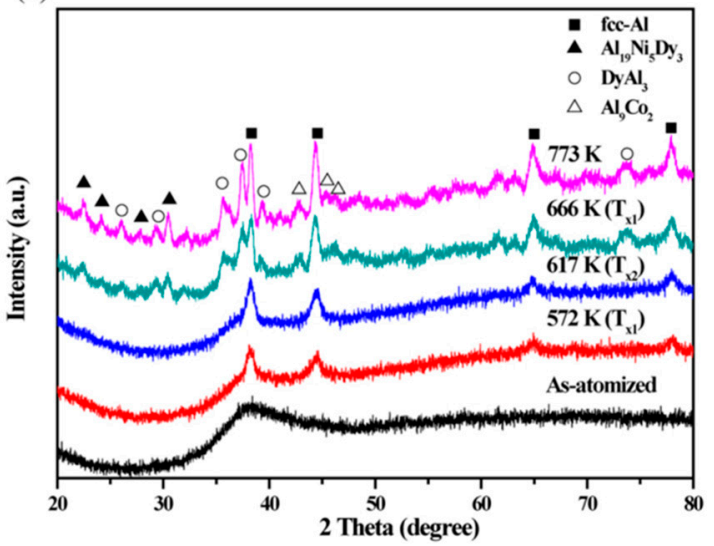

Figure 18. Thermal stability of amorphous Al84Ni7Co3Dy6 alloy in gas-atomized powder form: (a) DSC trace obtained during continuous heating of at a heating rate of $40 \mathrm{~K} / \mathrm{min}$ with inset showing the powder morphology; (b) XRD patterns after heating to $299,344,393$, and $500{ }^{\circ} \mathrm{C}$. Both techniques show crystallization phenomena of marked phases [70].

\subsection{Thermal Stability of Nanocrystalline Alloys}

Nanocrystalline materials have a high stored energy due to their large grain boundary area and, when subjected to heating, grains have a tendency to grow to minimize their energy by reducing the grain boundary area per unit volume [71]. The poor thermal stability of nanocrystalline materials arises from their high density of grain boundaries, which provides a high driving force for grain coarsening. Overall strategies that are proposed to stabilize the grain size with emphasis on thermodynamic stabilization and kinetic stabilization are discussed in [72].

Therefore, low thermal stability restricts the application expansion of nanocrystalline alloys. To improve their thermal stability, the mobility of grain boundaries should be reduced, for example, through alloying. The precipitation-hardened AA2024 (Al-4.2Cu-1.5Mg-0.6Mn-0.5Si) alloy, with nanocrystalline structure, generated through the single-pass Equal Channel Angular Pressing, preserved 
its properties at $120^{\circ} \mathrm{C}$ for up to $1000 \mathrm{~h}$ [73]. As shown in Figure 19, after long-term heating at 80 and $120^{\circ} \mathrm{C}$, a secondary hardening took place, whereas at $150{ }^{\circ} \mathrm{C}$, softening was accompanied by a slight secondary hardening. In contrast, at $200{ }^{\circ} \mathrm{C}$ fast softening occurred. As the major cause of the hardness loss, the increased coarsening rate of the equilibrium phase $\mathrm{S}\left(\mathrm{Al}_{2} \mathrm{CuMg}\right)$ accompanied by dislocation annihilation were identified. Moreover, the dislocation-rich structure and $\mathrm{Mg}$ clusters, remaining from the $S$ precipitate dissolution, eased the nucleation of $\Omega$ precipitates, which were responsible for the secondary hardening. The above transformation sequence differs from that described for the AA2024 commercial sheet [74].
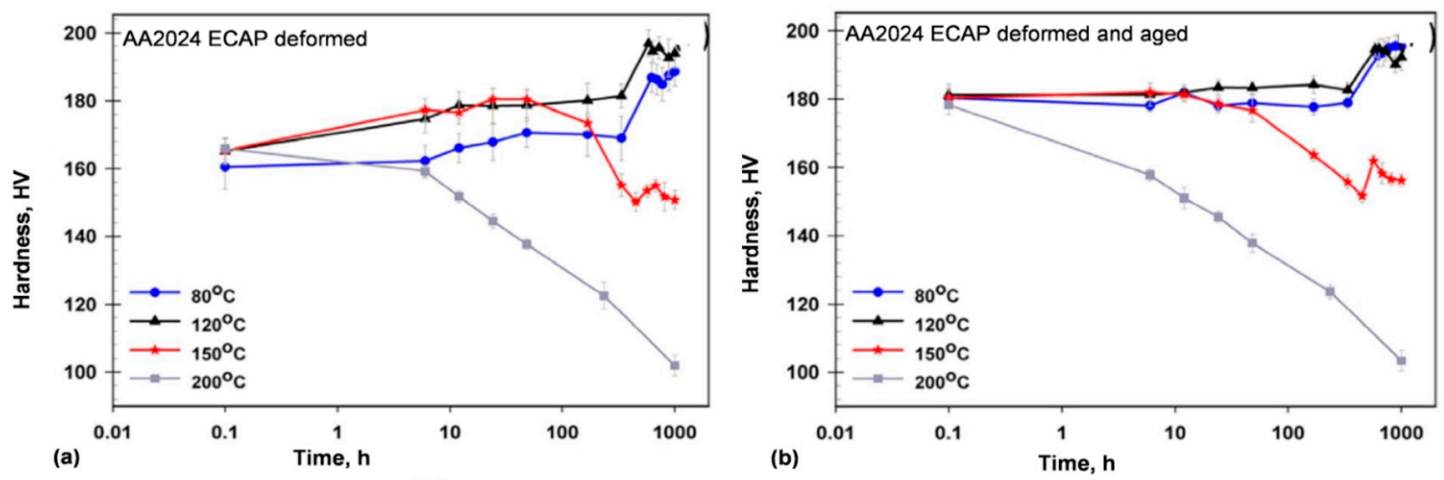

Figure 19. Thermal stability of nanocrystalline AA2024 alloy deformed by Equal Channel Angular Pressing (ECAP): (a) heated in as-deformed state; (b) heated after deformation and peak aging for $1 \mathrm{~h}$ at $190{ }^{\circ} \mathrm{C}$ [73].

As another example, the nanocrystalline structure of $\mathrm{Al}-\mathrm{Mg}-\mathrm{Sc}$ alloys, generated by Friction Stir Processing, was stabilized by the $\mathrm{Al}_{3}(\mathrm{Sc}, \mathrm{Zr})$ dispersoid phase up to $450{ }^{\circ} \mathrm{C}$ for $16 \mathrm{~h}$ [75]. In turn, in cold-worked Al-Fe-Si alloys, developed for electrical engineering purposes, the $\mathrm{Mn}-\mathrm{Ni}-\mathrm{Cr}$ fine dispersion phases were effective recrystallization barriers, preserving the microstructure up to $300{ }^{\circ} \mathrm{C}$ [76]. In another example, the nanocrystalline Al-10Fe-5Cr (wt.\%) bulk alloy preserved the compressive strength of $450 \mathrm{MPa}$ at $450{ }^{\circ} \mathrm{C}$ with such a high thermal stability being attributed to the formation of $\mathrm{Fe}$ and $\mathrm{Cr}$ containing phases with $\mathrm{Al}$, such as $\mathrm{Al}_{6} \mathrm{Fe}, \mathrm{Al}_{13} \mathrm{Fe}_{4}$, and $\mathrm{Al}_{13} \mathrm{Cr}_{2}$, in addition to the supersaturated solid solution of $\mathrm{Cr}$ and $\mathrm{Fe}$ in $\mathrm{Al}$ matrix [77].

The application of High Pressure Torsion to the Al-2.46Cu-1.48Mg-0.89Fe-0.92Ni (wt.\%) alloy led to grain refinement to $200 \mathrm{~nm}$, formation of high-angle grain boundaries and dynamic precipitation of $\mathrm{Al}_{9} \mathrm{FeNi}$ particles, with the strength preserved up to $225^{\circ} \mathrm{C}$ [78]. It is of interest that $0.5 \mathrm{~h}$ annealing at around $225^{\circ} \mathrm{C}$ reduced hardness to the level seen before deformation. Increasing the temperature up to $300^{\circ} \mathrm{C}$ resulted in the same hardness of both deformed and non-deformed alloys. Similarly, high pressure torsion led to an improvement of tensile strength of the AA2198-T8 Al-Li alloy, associated mainly with grain refinement and dislocation strengthening [79]. However, aging of that alloy at $175^{\circ} \mathrm{C}$ for $12 \mathrm{~h}$ caused a reduction in strength, indicating the low thermal stability. In contrast, the ultrafine grain AA8090 Al-Li alloy with an average grain size of $2 \mu \mathrm{m}$, obtained by Repetitive Corrugation and Straightening (RCS), was fairly stable during heating up to $300{ }^{\circ} \mathrm{C}$ [80].

Additions of Er to Al-Mg alloy powder improved its thermal stability through the combined effects of the solute/impurity drag and second-phase pinning, involving nanosize oxides, nitrides, and oxynitrides that impeded the grain boundary motion [47]. Small additions of the order of $0.1 \mathrm{wt} . \%$ Er were not effective and $\mathrm{Al}-\mathrm{Mg}$ powders showed the abnormal grain growth at $180{ }^{\circ} \mathrm{C}$. In contrast, the $0.5 \mathrm{wt}$.\% Er addition improved thermal stability, maintaining the grain size of approximately $20 \mathrm{~nm}$ up to $400{ }^{\circ} \mathrm{C}$. The controlled grain growth at higher temperatures resulted in an average grain size of $55 \mathrm{~nm}$ and a maximum observed grain size of $\sim 200 \mathrm{~nm}$ after one hour of annealing at $500{ }^{\circ} \mathrm{C}$. 


\section{Efforts to Increase the Upper Service Limit of High-temperature Grades}

\subsection{Development Drive for High-temperature Aluminum Alloys}

The vast application market and commercial opportunities create very strong drive for development of aluminum alloys with high-temperature capabilities. Despite of essential differences between the high-cost, high-end alloys for aerospace use and generally lower cost grades, required for large volume applications in ground transportation, both sectors fuel the critical research and development activities. The automotive interest is driven by new designs of combustion engines (both diesel and direct fuel injection gasoline engines), where an improvement in combustion efficiency requires the increased operating temperature up to $300{ }^{\circ} \mathrm{C}$ and internal pressure in and around the combustion chamber (Figure 20). Thus, aluminum alloys, capable of high-temperature strength and fatigue can increase performance and efficiency of combustion engine components through the lower weight and higher operating temperatures.
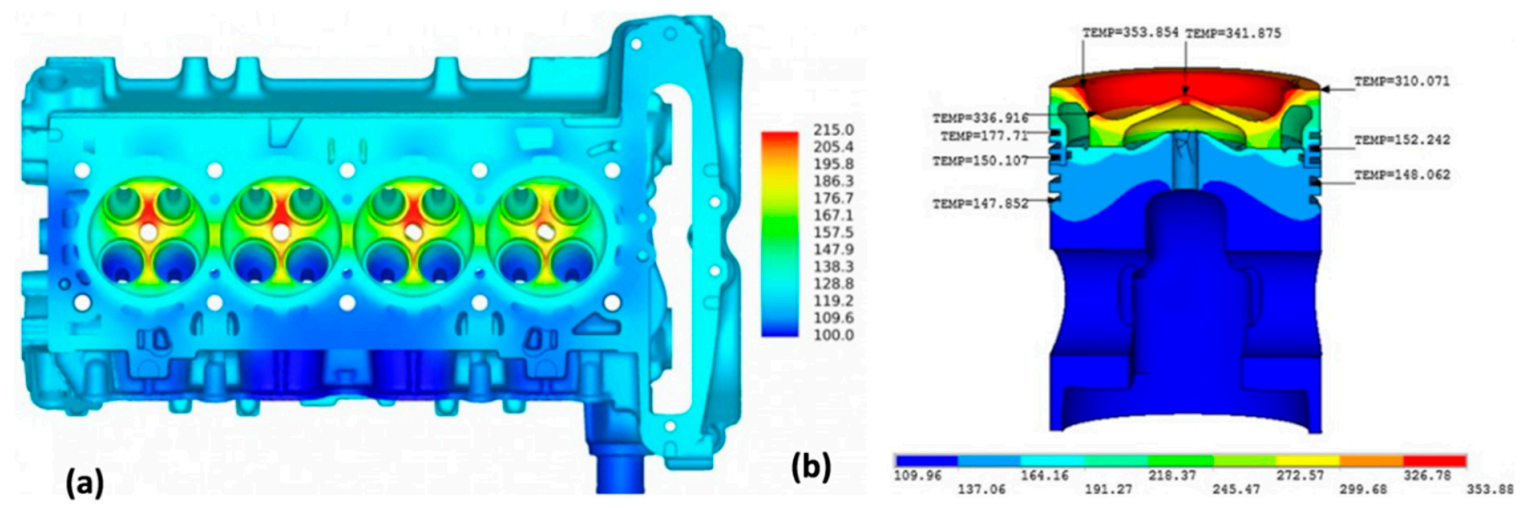

Figure 20. Computer simulation of temperature distribution within a combustion engine block with maximum temperature reaching $215^{\circ} \mathrm{C}$ (a) $[2,81]$ and thermal fields of a diesel engine piston with maximum temperature exceeding $350{ }^{\circ} \mathrm{C}(\mathbf{b})$ [82].

\subsection{Concepts of Alloy Design for High-Temperature Service}

A development of new Al alloys with high-temperature capabilities is not a trivial task and different directions are researched in academia and industry, including optimizing the conventional compositions and verifying the exotic solutions. During this search, an analogy is frequently made to nickel-based superalloys, which resist degradation of mechanical properties up to approximately $75 \%$ of their absolute melting temperature [83]. According to this concept, aluminum-based alloys should resist degradation up to $425^{\circ} \mathrm{C}$. The strengthening and thermal stability in Ni superalloys is achieved through ordered $\mathrm{Ni}_{3}(\mathrm{Al}, \mathrm{Ti})$ precipitates having the cubic $\mathrm{L1}_{2}$ structure, being isomorphous with the fcc Ni alloy $\gamma$ matrix. By analogy with that, the high-temperature aluminum alloys must contain a high volume fraction of a dispersed phase, which has $\mathrm{L}_{2}$ crystal structure and is thermodynamically stable at the intended service temperature. In this respect, trialuminide intermetallic compounds $\left(\mathrm{Al}_{3} \mathrm{M}\right)$ have a number of valuable features and are seen as perfect candidates in this role. The possible alloying elements are listed in Table A4, Appendix A.

\subsection{Copper and Silver in Heat-Resistant Aluminum Alloys}

As a potential structural material for use in aircraft structures operating at high temperatures, high strength aluminum alloys belonging to AA2XXX have been utilized for the past several decades. The alloys are commonly used for pistons and rotating aircraft parts due to their ability to work in higher temperature applications. During service at high temperature, stability of precipitates is still a major concern. 


\subsection{1. $\mathrm{Al}-\mathrm{Cu}-\mathrm{Mg}$}

The heat-resistant wrought aluminum alloy, designated as AA2618 (2618A), has been widely used in aerospace since the 1950s with extensive research conducted on its thermal stability [84]. In this alloy, the properties and thermal stability are controlled by $\mathrm{Cu}$ and $\mathrm{Mg}$ contents with high $\mathrm{Cu}$ content in solid solution accelerating the precipitation coarsening [85]. For 3.1-3.7 $\mathrm{Cu}$ and $1.2-2 \mathrm{Mg}$, strengthening by $\mathrm{S}^{\prime}\left(\mathrm{Al}_{2} \mathrm{CuMg}\right)$ yield stress of $465 \mathrm{MPa}(\mathrm{T} 8)$ and good thermal stability up to $200{ }^{\circ} \mathrm{C}$ exist. For $4.8-5.4 \mathrm{Ce}$ and $0-0.4 \mathrm{Mg}$, strengthening by $\theta^{\prime}\left(\mathrm{Al}_{2} \mathrm{Cu}\right)$ yields stress of $380 \mathrm{MPa}$ and good thermal stability up to $30{ }^{\circ} \mathrm{C}$ is valid. For $3.7-4.3 \mathrm{Cu}$ and $0.9-1.3 \mathrm{Mg}$, strengthening by $\mathrm{S}^{\prime}$ and $\theta^{\prime}$ yields stress of $470 \mathrm{MPa}$ but poor thermal stability of $150{ }^{\circ} \mathrm{C}$ was found (all values in wt.\%.).

\subsection{2. $\mathrm{Al}-\mathrm{Cu}-\mathrm{Mg}-\mathrm{Ag}$}

The $\mathrm{Al}-\mathrm{Cu}-\mathrm{Mg}$ system, with a high $\mathrm{Cu}-\mathrm{Mg}$ ratio and a minor addition of $\mathrm{Ag}$, is the base system for aerospace applications. Although there are differences between alloys from the $\mathrm{Al}-\mathrm{Cu}-\mathrm{Mg}-\mathrm{Ag}$ family, the tensile strength decreases gradually with increasing the thermal exposure time at $200-250{ }^{\circ} \mathrm{C}$. The combined addition of small concentrations of $\mathrm{Ag}$ and $\mathrm{Mg}$ to $\mathrm{Al}-\mathrm{Cu}$ alloys promotes precipitation of $\Omega$ phase that forms as thin, hexagonally shaped plate-like precipitates on $\{111\} \alpha$ matrix planes. The uniform dispersion of this precipitate as well as $\theta^{\prime}$ plates on the $\{001\}$ planes are considered to be the major contributor to alloy hardening. The thermal stability and coarsening resistance of microstructures dominated by $\Omega$ plates was found to coincide with relatively high levels of $\mathrm{Ag}$ and moderate $\mathrm{Mg}$ additions, with the latter limiting the competition for solute with S-phase precipitation [86].

The $\mathrm{Al}-\mathrm{Cu}-\mathrm{Mg}-\mathrm{Ag}$ alloy maintained a tensile strength of $434 \mathrm{MPa}$ after $1000 \mathrm{~h}$ at $150^{\circ} \mathrm{C}$, being $86 \%$ of that of the peak-aged alloy [87]. After exposure for $1000 \mathrm{~h}$ at $200{ }^{\circ} \mathrm{C}$ the tensile strength decreased to $307 \mathrm{MPa}$. The improved alloy from this family, Al6.5Cu0.3Mg0.5Ag (wt.\%) trademarked as $\mathrm{KS} 2000$, with high $\mathrm{Cu} / \mathrm{Mg}$ ratio of 20 , higher than in AA2618 Al1Fe2.5Cu1.5Mg1Ni (wt.\%), was developed by the refinement of chemistry, heat treatment, and refinement of grain size through the optimization of forging conditions [9]. The alloy maintained the yield stress of $375 \mathrm{MPa}$ after $100 \mathrm{~h}$ exposure at $150^{\circ} \mathrm{C}$, as compared to $330 \mathrm{MPa}$ achieved by AA2618-T61.

The possibility of $\mathrm{Al}-\mathrm{Cu}-\mathrm{Mg}-\mathrm{Ag}$ alloying with $\mathrm{Zr}$ and $\mathrm{Sc}$ led to nanoscale dispersoids of $\mathrm{Al}_{3}(\mathrm{Sc}, \mathrm{Zr})$ under solution treatment with no primary AlCuSc phase [88]. The dominant precipitation was still the $\Omega$ phase, formed on the $\{111\} \alpha$ planes and being susceptible to coarsening at $200{ }^{\circ} \mathrm{C}$, thus determining the alloy thermal stability.

\subsection{Rare Earth Metals in Aluminum Alloys}

Rare earth metals have attracted increasing interest during aluminum alloying not only as minor additives, but also as their major ingredients. There are examples with an application of mischmetal and individual elements with positive effects, no effects [89], and detrimental influence on properties of aluminum alloys [90]. Rare earth elements such as $\mathrm{La}, \mathrm{Ce}, \mathrm{Nd}$, and $\mathrm{Y}$ were tested with the $\mathrm{Al}-\mathrm{Si}$ matrix [91]; Er with $\mathrm{Al}-\mathrm{Mg}, \mathrm{Al}-\mathrm{Zn}-\mathrm{Mg}$, $\mathrm{Al}-\mathrm{Zn}-\mathrm{Mg}-\mathrm{Cu}, \mathrm{Al}-\mathrm{Li}$, and $\mathrm{Al}-\mathrm{Cu}$ grades [92]; or Sm with $\mathrm{Al}-\mathrm{Si}-\mathrm{Cu}$ grades [93]. Among rare earths, cerium and scandium are of particular interest for aluminum alloying, as emphasized in [94-96].

\subsubsection{Exploring Scandium to Improve Thermal Stability of Al}

Aluminum-scandium alloys have excellent mechanical properties at ambient and elevated temperatures due to the presence of coherent, nanoscale, $\mathrm{L}_{2}$-ordered $\mathrm{Al}_{3} \mathrm{Sc}$ precipitates with a gain in tensile strength per atomic percent of scandium higher than for any other alloying element added to aluminum. The key effects of scandium include (i) grain refinement during casting or welding, (ii) precipitation hardening from $\mathrm{Al}_{3} \mathrm{Sc}$ particles, and (iii) grain structure control from the $\mathrm{Al}_{3} \mathrm{Sc}$ phase. An addition of scandium in a combination with zirconium is particularly effective, which is linked to the core/shell structure of the $\mathrm{Al}_{3}(\mathrm{Sc}, \mathrm{Zr})$ dispersoids [94]. 
Due to unfavorable diffusivity of $\mathrm{Sc}$ in $\mathrm{Al}$, the thermal stability of alloys is rather moderate. For $\mathrm{Al}-5 \mathrm{Mg}-0.3 \mathrm{Sc}$ (wt.\%) alloys, heating at 300 to $450{ }^{\circ} \mathrm{C}$ resulted in increasing the $\mathrm{Al}_{3} \mathrm{Sc}$ coarsening rate by an order of magnitude for every $50{ }^{\circ} \mathrm{C}$ [97]. However, $\mathrm{Al}_{3} \mathrm{Sc}$ precipitates exhibited good coherency with the aluminum matrix, even after being annealed at $300-450{ }^{\circ} \mathrm{C}$ for $168 \mathrm{~h}$. Coarsening resistance of $\mathrm{Al}_{3} \mathrm{Sc}$ precipitates was described in $[98,99]$. Unfortunately, the prohibitive cost barrier accompanies an extraordinary improvement of aluminum properties by micro-additions of scandium.

\subsubsection{Influence of Other Rare Earths}

Similarly to Sc, the four heaviest rare earth elements, $\mathrm{Er}, \mathrm{Tm}, \mathrm{Yb}$, and $\mathrm{Lu}$, develop an $\mathrm{Al}^{-} \mathrm{Al}_{3} \mathrm{RE}$ eutectic reaction, with $\mathrm{Al}_{3} \mathrm{RE}$ having the stable $\mathrm{L1}_{2}$ crystal structure. The available data refer to experimental alloys, synthesized in small volumes in a laboratory environment. The binary aluminum alloys with $0.03-0.06$ at. $\% \mathrm{Yb}$ or Er, after aging produced the coherent, nanosized $\mathrm{Al}_{3} \mathrm{RE}$ precipitates [100]. Based on microhardness data from isochronal aging experiment, the Er precipitation started at $150{ }^{\circ} \mathrm{C}$ and an aging peak occurred at $275^{\circ} \mathrm{C}$ for $\mathrm{Al}-0.03 \mathrm{Er}$, while for $\mathrm{Al}-0.03 \mathrm{Yb}$ precipitation of $\mathrm{Yb}$ started at $100^{\circ} \mathrm{C}$ and an aging peak occurred at $250^{\circ} \mathrm{C}$. The significantly lower temperatures obtained for $\mathrm{Er}$ and $\mathrm{Yb}$ alloying as compared to the $\mathrm{Al}-0.12 \mathrm{wt} . \% \mathrm{Sc}$ alloy is explained through larger diffusivities in $\mathrm{Al}$ as compared to Sc. This claim, however, is not supported by diffusivity data in Table A3, Appendix A.

There are many examples of using the minor additions of mischmetal or Ce with both the experimental and commercial alloys [96]. In addition to some improvements in thermal stability, there is also evidence of no beneficial effect of Ce additions. For example, after alloying of the $\mathrm{A} 205 / \mathrm{TiB}_{2}$ composite with $0.2-1.5 \mathrm{wt} . \% \mathrm{Ce}$, no influence on thermal stability of the $\Omega$ phase, tested at $230{ }^{\circ} \mathrm{C}$ for up to $100 \mathrm{~h}$, was recorded [101]. It is claimed that cerium was located in the $\mathrm{CeTi}_{2} \mathrm{Al}_{20}$ phase and poisoned the matrix grain refinement by nucleating around the $\mathrm{TiB}_{2}$ particles.

\subsection{Features Specific for Cast Alloys}

In this report, no clear separation is made between wrought and cast alloys. Based on the chemical composition and manufacturing route provided, the alloy can easily be classified to which group it belongs. In this section, some features specific for development of cast alloys with high-temperature capabilities are described.

There are many benefits of using cast alloys to manufacture components for engineering applications; in contrast to the multistage manufacturing cycle, typical for wrought products, through casting, e.g., through modern high pressure die casting (HPDC). However, there are also disadvantages, with the most important one for structural applications being the component poor integrity. In addition to improving casting technology, including mold (die) design and selection of process parameters to control flow of molten metal during die filling, post-casting treatments may be used. One of them is hot isostatic pressing (HIP), aimed at eliminating pores and bonding pore surfaces together. In some applications, the pneumatic isostatic forging was an effective technology for improving mechanical properties in aluminum castings through healing defects in castings and controlling the microstructure [102]. In cast alloys, segregation, being also their inherent feature, may have detrimental effect on alloy thermal stability.

The graph in Figure 21 shows a strategy for selection of alloy matrix and alloying elements, when considering differences in their diffusivities in aluminum.

Four development criteria for cast, precipitation-strengthened aluminum alloys for high temperature applications were formulated: (i) solid state precipitation of $\mathrm{Al}_{3} \mathrm{M}$ with $\mathrm{L1}_{2}$ crystal structure; (ii) appropriate shape of solvus line to facilitate precipitation; (iii) low diffusivity in of $\mathrm{M}$ in $\mathrm{Al}$; and (iv) solid-liquid partition near unity to minimize segregation [83]. As in cast aluminum alloys eutectic is the essential component that provides the necessary fluidity in liquid state, to achieve a high thermal stability, the solidified eutectic structure should remain stable at service temperatures. The properties of potential alloying candidates are listed in Appendix A, Table A4. 


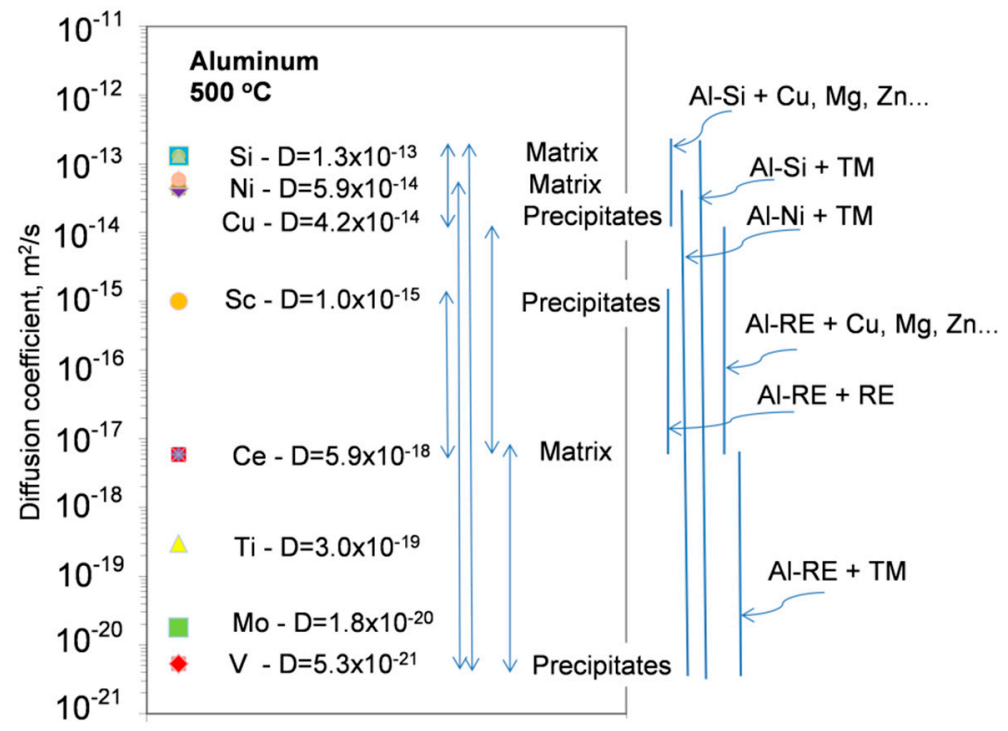

Figure 21. A development strategy of cast $\mathrm{Al}$ alloys with high temperature stability through combining of appropriate matrix (Al-Si, $\mathrm{Al}-\mathrm{Ni}, \mathrm{Al}-\mathrm{RE}$ ) and strengthening compounds (conventional elements, $\mathrm{RE}, \mathrm{TM}$ ). Strengthening can be effective after casting or/and after post-casting heat treatment. Diffusion coefficients of alloying elements in aluminum at $500{ }^{\circ} \mathrm{C}$ were calculated based on data in Tables A1-A3 in Appendix A. RE-rare earths; TM-transition metals.

\subsubsection{Improving Thermal Stability of Al-Si Matrix with Transition Metals}

The Al-Si cast alloys are the most commonly used, representing up to $90 \%$ of the total aluminum cast parts, produced for the automotive industry. The operating temperature of existing $\mathrm{Al}-\mathrm{Si}$ casting grades, for example, hypoeutectic $\mathrm{Al}-\mathrm{Si}-\mathrm{Cu}$ alloy $\mathrm{A} 380$ and $\mathrm{Al}-\mathrm{Si}-\mathrm{Mg}$, typically below $180{ }^{\circ} \mathrm{C}$, is becoming insufficient for modern designs of automotive engines.

Based on the diffusion coefficient criterion, the high temperature mechanical performance of traditional Al-Si alloys can be enhanced by alloying with transition metals, leading to formation of thermally stable and coarsening-resistant precipitates. Transition metals used in aluminum alloys, such as $\mathrm{Mn}, \mathrm{Fe}, \mathrm{Co}, \mathrm{Ni}, \mathrm{Cu}, \mathrm{Ag}$, and $\mathrm{Zn}$, form equilibrium phase diagrams of eutectic type, when $\mathrm{Cr}$, $\mathrm{Mo}, \mathrm{Ti}, \mathrm{Zr}$, and $\mathrm{V}$ form diagrams of peritectic type (Appendix A, Table A4). They exhibit low solid state solubility in aluminum with limits mostly from a fraction of 1 to less than $2 \mathrm{wt} . \%$, which sharply decreases with temperature. Moreover, the high solidus temperature, approaching melting point of $\mathrm{Al}$, leads to narrow solidification range of Al-TM solid solutions. Therefore, their tri-aluminides with the general chemical formula $\mathrm{Al}_{3} \mathrm{TM}$, formed within the aluminum matrix during artificial aging, have high thermal stability. There are data suggesting benefits of using combinations of two or more transition metals, additions of which widen the aluminum solid solution range [103].

\section{Al-Si-Based Alloys Strengthened with Zr, V, and Ti}

In aluminum alloys, individually added $\mathrm{V}$ forms the $\mathrm{Al}_{3} \mathrm{~V}$ dispersoids with an $\mathrm{Ll}_{2}$ structure in the metastable condition and a $\mathrm{D}_{22}$ structure in the equilibrium condition. The purpose of $\mathrm{Zr}$ additions is to form fine precipitates of intermetallic particles that inhibit recrystallization. It also forms a solid solution of $\mathrm{Zr}$ in $\mathrm{Al}$. The major role of $\mathrm{Ti}$ is to refine the grain of aluminum matrix. In case of cast alloys, the $\mathrm{Al}_{3} \mathrm{TM}$ intermetallics, acting as nuclei during solidification, may lead to grain refinement. At the same time, the primary $\mathrm{Al}_{3} \mathrm{Ti}$ and $\mathrm{Al}_{3} \mathrm{Zr}$ compounds that form during solidification negatively affect the ingot ductility. According to ternary Al-TM1-TM2 phase diagrams, some combinations of transition metals do not decrease their joint solid state solubility in aluminum and widen the range of existence of the aluminum solid solution [104]. Such combinations are also beneficial to suppress the precipitation of primary intermetallics during solidification, being detrimental to the alloy performance. 
A combination of $\mathrm{Zr}, \mathrm{V}$, and $\mathrm{Ti}$ additions with individual contents from 0.2 to 0.5 wt.\% was explored to modify the hypoeutectic Al7Si1Cu0.5Mg (wt.\%) cast alloy $[105,106]$. The objective was to modify its phase composition and aging characteristics, and create intermetallic phases with sufficiently high thermal stability to improve the alloy performance in potential applications for automotive engine blocks and cylinder heads. As shown in Figure 22, the results of isochronal aging, performed at temperatures up to $500{ }^{\circ} \mathrm{C}$, revealed that the peak aging hardness occurred at approximately $200{ }^{\circ} \mathrm{C}$. An assessment of the role of time shows that at $200^{\circ} \mathrm{C}$, solution-treated alloys with $\mathrm{Zr}-\mathrm{V}-\mathrm{Ti}$ increased hardness, reaching a peak value after roughly $1 \mathrm{~h}$ exposure; then hardness reduction was observed.
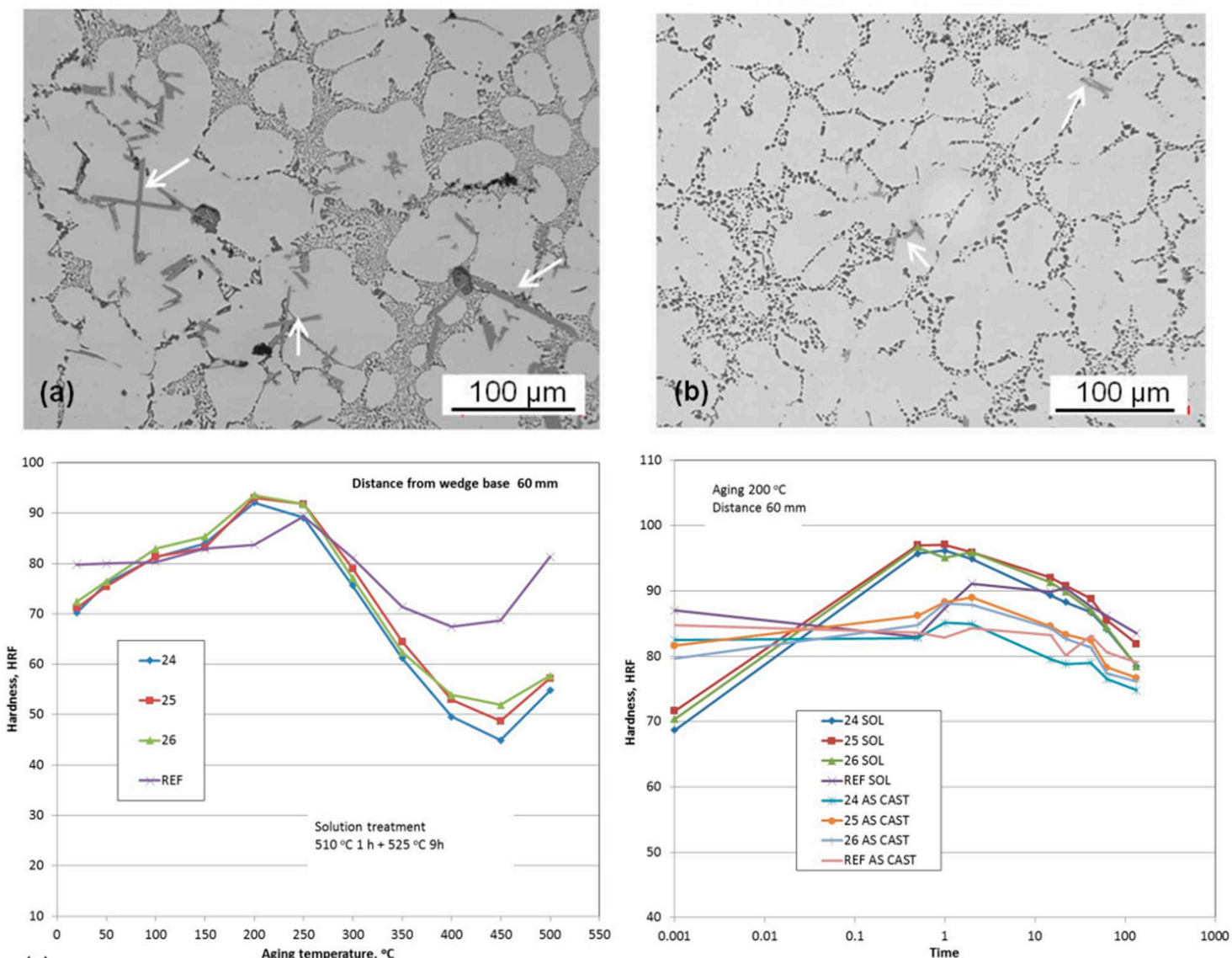

(c)

(d)

Figure 22. Microstructure of the Al7Si1Cu0.5Mg alloy modified with 0.47 wt. $\% \mathrm{Zr}, 0.21$ wt.\% Ti, $0.30 \mathrm{wt} . \% \mathrm{~V}$ in as-cast condition (a) and after T6 heat treatment (solutionizing $510{ }^{\circ} \mathrm{C}: 0.5 \mathrm{~h}+525^{\circ} \mathrm{C}$, $4.5 \mathrm{~h}$ water quench; aging $200^{\circ} \mathrm{C}, 1 \mathrm{~h}$ air cooling). Arrows indicate coarse phases containing transition metals $\mathrm{Ti}-\mathrm{Zr}-\mathrm{V}(\mathbf{b})$. Effect of aging temperature (c) and time (d) on hardness for various additions of transition metals. Figure legend: (24) 0.14 wt.\% Zr, 0.14 wt.\% Ti, 0.22 wt.\% V; (25) 0.42 wt.\% Zr, 0.18 wt.\% Ti, 0.17 wt.\% V; (26) 0.47 wt.\% Zr, 0.21 wt.\% Ti, 0.30 wt.\% V; (REF) A380 alloy.

Micro-additions of $\mathrm{Ti}, \mathrm{V}$, and $\mathrm{Zr}$ to the $\mathrm{Al}-7 \mathrm{Si}-1 \mathrm{Cu}-0.5 \mathrm{Mg}$ (wt.\%) cast alloy led to the formation of $(\mathrm{AlSi})_{\mathrm{x}}(\mathrm{TiVZr})$ phases with increased stability at high temperatures, thus positively affecting the alloy strength. The improvement in tensile and compressive strength was preserved up to $200{ }^{\circ} \mathrm{C}$ with more positive effect seen for the T6 state. The hardness curves show that the potential alloying benefits from transition metals $\mathrm{Zr}-\mathrm{V}-\mathrm{Ti}$ are not fully utilized. Being effective, they should exhibit much higher hardness advantage over temperature and time than the A380 alloy with $\mathrm{Cu}-\mathrm{Si}$ containing compounds.

Hardness tests do not reveal the entire picture of alloying with $\mathrm{Ti}, \mathrm{Zr}$, and $\mathrm{V}$ and benefits in improving thermal stability are shown through the higher creep rapture strength and much longer fatigue life than that of the A380 alloy, currently used by the automotive industry [107]. 


\section{Al-Si Alloys with Micro-Additions of Zr, V, Ti and Cr}

According to literature data [108], the presence of $\mathrm{Cr}$ in $\mathrm{Al}-\mathrm{Si}$ cast alloys changes the morphology of the $\beta$-AlFeSi phase from the needle-like to a fishbone-like $\alpha-\mathrm{Al}(\mathrm{Fe}, \mathrm{Cr}) \mathrm{Si}$ phase, leading to an improvement of ultimate strength. Unknown remains the synergy of simultaneous presence of $\mathrm{Ti}, \mathrm{Zr}$, $\mathrm{V}$, and $\mathrm{Cr}$. Thus, the objective of $\mathrm{Cr}$ additions was to verify how the $\mathrm{Cr}-\mathrm{Ti}-\mathrm{V}-\mathrm{Zr}$-rich phases influence the alloy properties at high temperatures [109]. To achieve this, the base Al7Si1Cu0.5Mg (wt.\%) alloy was modified with $0.39 \mathrm{wt} . \% \mathrm{Ti}, 0.25 \mathrm{wt} . \% \mathrm{Zr}, 0.39 \mathrm{wt} . \% \mathrm{~V}$, and $0.47 \mathrm{wt} . \% \mathrm{Cr}$. The alloy base used was the same as in previous section, thus allowing direct comparison of results.

A presence of additional transition metal $\mathrm{Cr}$ contributed to noticeable microstructural differences to those described for $\mathrm{Zr}-\mathrm{V}-\mathrm{Ti}$ additions. The Cr-containing phases included Al18.5Si7.3Cr2.6V (wt.\%) with needle shape and Al7.9Si8.5Cr6.8V4.1Ti (wt.\%) having hexagonal pipe shape, most likely falling into the general formula as $(\mathrm{AlSi})_{3}(\mathrm{CrV})$ and $(\mathrm{AlSi})_{3}(\mathrm{CrVTi})$, respectively.

The hardness changes versus aging time for different aging temperatures of the Al7Si1Cu0.5Mg alloy, modified with $\mathrm{Ti}-\mathrm{Zr}-\mathrm{V}-\mathrm{Cr}$, are shown in Figure 23. The solution treatment reduced the alloy hardness and, according to heat treatment observations, it looked more sensitive to the aging temperature rather than to the aging time. Based on comparison with alloys described in the previous section, it may be concluded that additions of transition metal $\mathrm{Cr}$ to $\mathrm{Zr}$, V, and Ti did not substantially change the thermal stability of the Al7Si1Cu0.5Mg base. It appears again that all transition metals were concentrated in coarse primary compounds, having low effectiveness in as-cast conditions. Also solution annealing was not able to dissolve them completely and drastically change their effectiveness after aging.

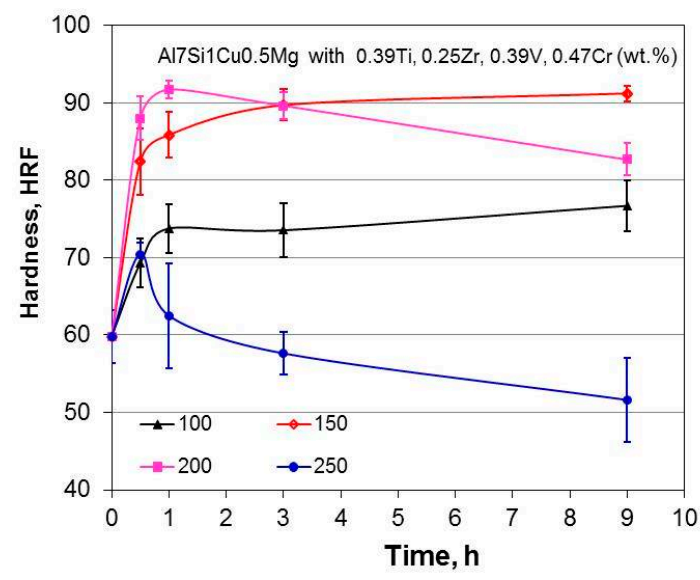

Figure 23. Hardness changes during aging of the Al7Si1Cu0.5Mg alloy modified with 0.39 wt.\% Ti, 0.25 wt. $\% \mathrm{Zr}, 0.39 \mathrm{wt} . \% \mathrm{~V}$, and $0.47 \mathrm{wt} . \% \mathrm{Cr}$. Solution treatment included heating at $510{ }^{\circ} \mathrm{C}$ for $0.5 \mathrm{~h}$ followed by $4.5 \mathrm{~h}$ at $525^{\circ} \mathrm{C}$ and water quench [109].

\section{Al-Si Alloys with Micro-Additions of Mo and Mn}

The presence of molybdenum in $\mathrm{Al}$ alloys leads to nanoscale dispersoid formation, which contributes to improved high-temperature strength and creep resistance. Micro-additions of Mo to commercial $\mathrm{Al}-\mathrm{Si}$ alloys slightly improve strength at room temperature, but substantially improve the alloy thermal stability with preserving properties up to $250^{\circ} \mathrm{C}$.

Another transition metal manganese has very low diffusion coefficient in aluminum and form high density of micron-size primary $\mathrm{Al}_{6} \mathrm{Mn}, \mathrm{Al}_{6}(\mathrm{Mn}, \mathrm{Fe})$, and $\mathrm{Al}(\mathrm{Mn}, \mathrm{Fe}) \mathrm{Si}$ precipitates in alloys containing $\mathrm{Si}$ and Fe. A combination of Mn with Mo provides strengthening through $\mathrm{Al}(\mathrm{Mn}, \mathrm{Mo}) \mathrm{Si}$ precipitates and looks promising in terms of Al thermal stability improvement. As reported in [110], Mo additions to the Al7Si0.5Cu0.3Mg alloy (wt.\%) led to formation of $\alpha-\mathrm{Al}(\mathrm{Fe}, \mathrm{Mo}) \mathrm{Si}$ and $\alpha-\mathrm{Al}(\mathrm{Fe}, \mathrm{Mn}, \mathrm{Mo}) \mathrm{Si}$ nanoprecipitates with and without Mn. 
In the as-cast state, the Al7Si1Cu0.5Mg (wt.\%) alloy with micro-additions of $0.20 \mathrm{wt} . \% \mathrm{Mn}$ and 0.19 wt.\% Mo was composed of dendritic $\alpha-\mathrm{Al}$; fibrous-like eutectic Si; and Cu-, Mg-, and Fe-based phases with Mo and Mn additions being present in the $\alpha-A 117 F e 3.2 M n 0.8 S i 2, A 165 C u 20 F e 6 M n 9$, Al13Fe8Mn33Mo, and Al0.78Fe4.8Mn0.27Mo4.15Si2 phases [111]. An example of the influence of artificial aging on alloy hardness is shown in Figure 24. The hardness test revealed that the Al7Si1Cu0.5Mg alloy with Mo and Mn was able to retain its hardness for maximum aging time of $75 \mathrm{~h}$ up to $200{ }^{\circ} \mathrm{C}$. There was some hardness reduction for temperatures of 200 and $250{ }^{\circ} \mathrm{C}$ but the evident softening was observed after exposures at temperature as high as at $300^{\circ} \mathrm{C}$. The overall conclusion is that the $\mathrm{Al}-\mathrm{Si}-\mathrm{Cu}-\mathrm{Mg}$ alloy with $\mathrm{Mo}-\mathrm{Mn}$ combined additions showed better hardness retention than achieved for the same base, modified with $\mathrm{Zr}, \mathrm{Ti}, \mathrm{V}$, and $\mathrm{Cr}$.

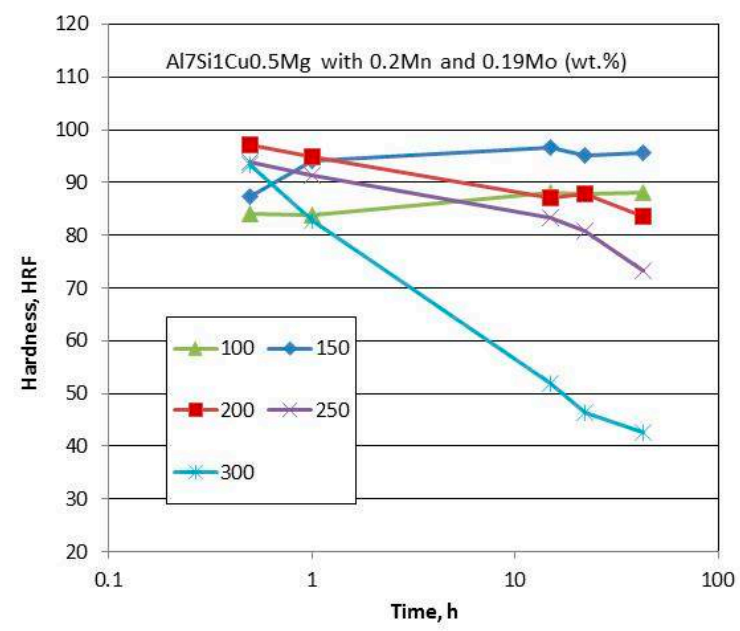

Figure 24. Hardness changes during aging of the Al7Si1Cu0.5Mg alloy modified with addition of $0.20 \mathrm{wt} . \% \mathrm{Mn}$ and $0.19 \mathrm{wt} . \%$ Mo. Solution treatment included heating at $510{ }^{\circ} \mathrm{C}$ for $0.5 \mathrm{~h}$ followed by $4.5 \mathrm{~h}$ at $525^{\circ} \mathrm{C}$ and water quench [111].

\subsubsection{A Search for Novel Matrix of Cast Aluminum Alloys}

An alloy designed for casting should contain the eutectic component, providing sufficient fluidity in molten state and strengthening dispersoids. The latter ones may form directly during solidification or they can precipitate as a result of a subsequent heat treatment. In practice, both forms of strengthening compounds often coexist. Therefore, thermal stability of the solidified eutectic and strengthening phases affects the alloy performance at increased temperatures.

\section{Eutectic Based on Al-Ni System}

The presently used Al-Si eutectic with low melting range limits the stability improvement [35]. To overcome this barrier, the $\mathrm{Al}-\mathrm{Al}_{3} \mathrm{Ni}$ eutectic was proposed [112-114] with better thermal stability, attributed, according to the work in [112], to the existence of a thin coherent layer of $\alpha-\mathrm{Al}$ surrounding each $\mathrm{Al}_{3} \mathrm{Ni}$ fiber. However, among other issues of $\mathrm{Ni}$, the fluidity of the $\mathrm{Al}-\mathrm{Al}_{3} \mathrm{Ni}$ eutectic, tested in the $\mathrm{Al}-6 \mathrm{Ni}-4 \mathrm{Mn}$ (wt.\%) alloy, was not as high as that of typical casting alloys, e.g., A390. The $\mathrm{Al}^{-} \mathrm{Al}_{3} \mathrm{Ni}$ eutectic matrix is also weak, so additional alloying is required to improve mechanical properties and to preserve the fiber thermal stability.

In an effort to improve strength, Sc was used in $[115,116]$. The eutectic in the Al-6wt.\%Ni alloy with $\mathrm{Al}_{3} \mathrm{Ni}$ microfiber morphology maintained its hardness at $300{ }^{\circ} \mathrm{C}$ for up to $672 \mathrm{~h}$. Additions of $0.4 \mathrm{wt}$. $\%$ Sc did not change the morphology of the $\mathrm{Al}_{3} \mathrm{Ni}$ microfibers and did not change the alloy thermal stability; the major effect of Sc was expressed through increased the alloy strength. The strengthening contributions of the $\mathrm{Al}_{3} \mathrm{Ni}$ and $\mathrm{Al}_{3} \mathrm{Sc}$ phases at ambient temperature are cumulative in the ternary alloys. The hardness curve of $\mathrm{Al}-6 \mathrm{Ni}-0.4 \mathrm{Sc}$ (wt. \%) at $300{ }^{\circ} \mathrm{C}$ was described via a superposition of the curves of Al-0.4Sc and Al-6Ni alloys, over the full aging time of 0-672 h. In another research, a new 
generation of heat-resistant aluminum alloys, based on Ni-containing eutectic, the Al-Ni-Mn-Fe-Si-Zr system, strengthened by the $\mathrm{Al}_{3} \mathrm{Zr}\left(\mathrm{L1}_{2}\right)$ nanoparticles, was developed [117]. The presence of Si widened the crystallization range, increasing the tendency of the alloy to form hot cracks during casting but having high thermal stability.

Eutectic Based on the Al-Ce System

A possibility of further improvement in thermal stability of aluminum alloys is anticipated through a substitution of nickel with a rare earth metal cerium, having the diffusion coefficient in aluminum lower by approximately four orders of magnitude than that for nickel [96]. At present, there is still no convincing evidence, supporting the Al-Ce system in this role.

The idea of using cerium for aluminum alloying with contents, reaching eutectic compositions, was introduced in 1912 [118], followed by research in 1920s [119-121] with a summary of early efforts given in [122]. Historically, exploring $\mathrm{Ce}$ as the major alloying element of $\mathrm{Al}$, where it forms the $\mathrm{Al}_{11} \mathrm{Ce}_{3}$ eutectic phase with melting point of $1251^{\circ} \mathrm{C}$, aimed at increasing the thermal stability of alloys [96]. According to recent statements [123], alloying with Ce helped retaining the mechanical properties of $\mathrm{Al}$ alloys at higher temperatures than that seen in $\mathrm{Ce}-$ free $\mathrm{Al}$ grades, with $\mathrm{Al}-\mathrm{Ce}$ showing complete hardness recovery at room temperature after exposures to temperatures as high as $500{ }^{\circ} \mathrm{C}$ for $1000 \mathrm{~h}$. There is research, however, documenting rather detrimental influence of heat on $\mathrm{Al}-\mathrm{Ce}$ system. As shown in Figure 25, conventionally cast Al-5wt.\%Ce binary alloy exhibited drastic reduction in strength at $500{ }^{\circ} \mathrm{C}$ and $20 \%$ hardness reduction after exposure for $150 \mathrm{~h}$ at $500{ }^{\circ} \mathrm{C}$.
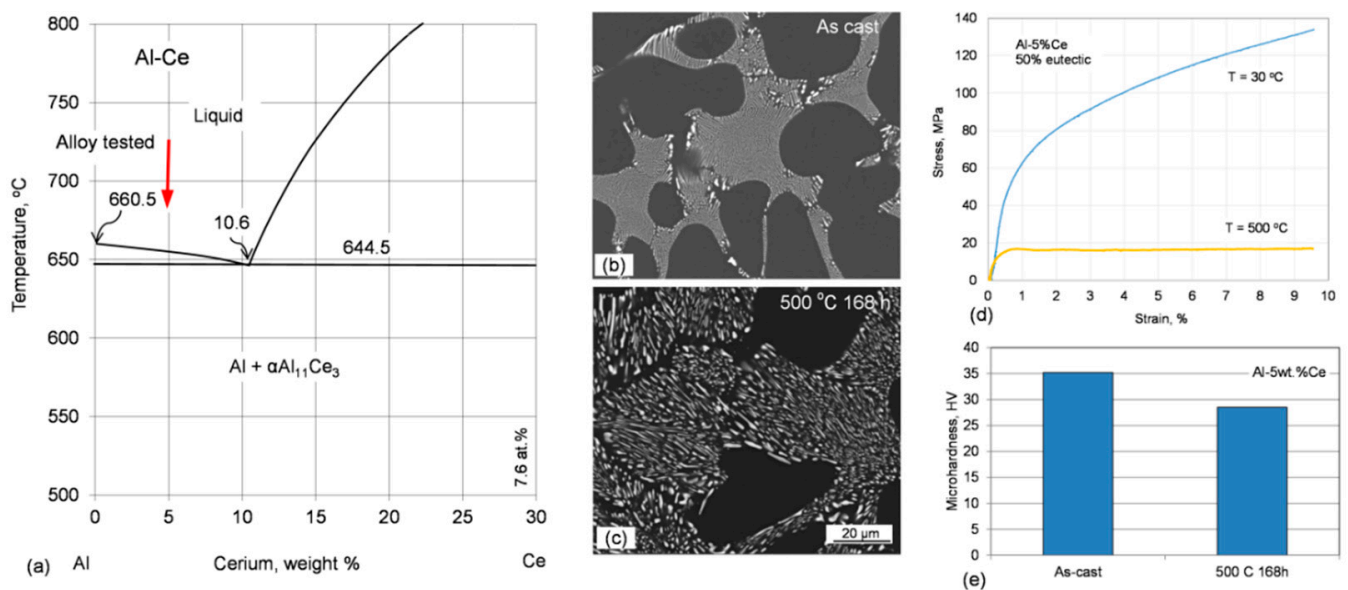

Figure 25. Thermal stability of Al-5 wt.\% Ce binary alloy: (a) portion of Al-Ce binary diagram showing location of commercially important eutectic [124]; (b) eutectic morphology after casting; (c) eutectic morphology after heating for $168 \mathrm{~h}$ at $500{ }^{\circ} \mathrm{C}$; (d) stress versus engineering strain plot for alloy compression at room and at $500{ }^{\circ} \mathrm{C}$; (e) hardness after casting and heating for $168 \mathrm{~h}$ at $500{ }^{\circ} \mathrm{C}$.

The hardness reduction was accompanied by a substantial change in the eutectic morphology with visible lamellae modifications. Moreover, the rapidly solidified Al-Ce and Al-Nd alloys, with $\mathrm{Ce}$ and $\mathrm{Nd}$ contents up to $22 \mathrm{wt}$.\%, experienced a substantial reduction in hardness, accompanied by morphological changes with a disappearance of lamellae after exceeding $300{ }^{\circ} \mathrm{C}$ (Figure 26) [125]. Another study, using the spun cast Al-8 wt.\% Ce and Al-20 wt.\% Ce alloys essentially confirmed the above observations. Although Al-Ce alloys preserved the initial hardness, when annealed at 200 or

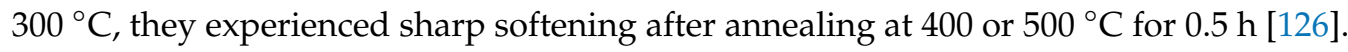



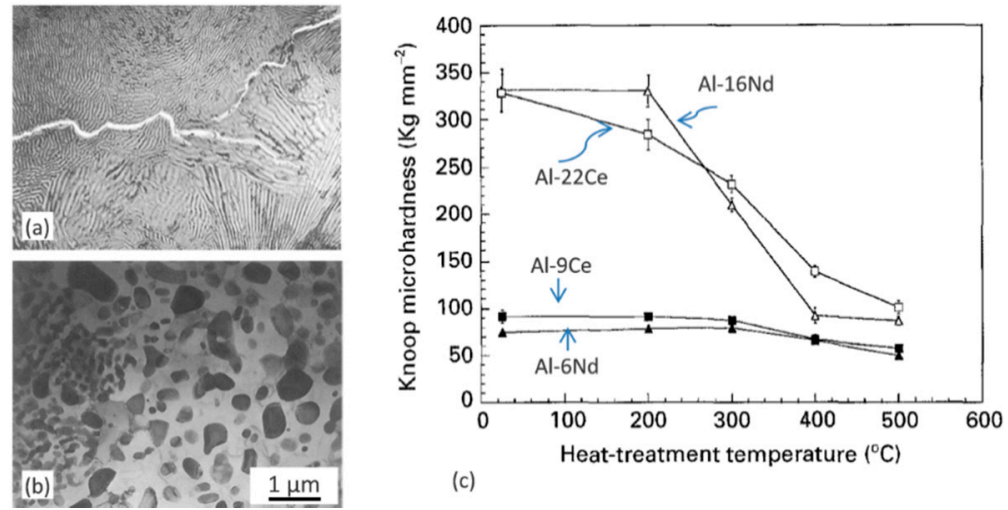

Figure 26. Thermal stability of rapidly solidified $\mathrm{Al}-\mathrm{Ce}$ and $\mathrm{Al}-\mathrm{Nd}$ alloys: (a) $\mathrm{Al}-22 \mathrm{Ce}$ as spun cast; (b) $\mathrm{Al}-22 \mathrm{Ce}$ after $2 \mathrm{~h}$ at $500{ }^{\circ} \mathrm{C}$, TEM images; (c) microhardness after heating at temperatures from 200 to $500{ }^{\circ} \mathrm{C}$ for $2 \mathrm{~h}$ (alloy compositions are in wt.\%) [125].

\section{Alloy Stability Improvement through Processing Techniques}

In addition to optimizing the alloy chemical composition, to improve thermal stability, parallel efforts are explored through alloy processing, such as rapid solidification, powder metallurgy, and additive manufacturing, engineering alloys in a liquid state, and post-casting treatments. They represent either modification of conventional or testing novel manufacturing routes or, as in the case of liquid metal engineering, an extra step within the conventional manufacturing sequence. Each technique exerts its unique impact on microstructural constituents, affecting the alloy performance at increased temperatures.

\subsection{Liquid Metal Engineering}

Liquid metal engineering refers to a variety of physical and/or chemical treatments of molten metals aimed at influencing their solidification characteristics [127]. It is generally accepted that exploring the synergy of melt chemistry and physical treatments, achieved through liquid metal engineering, allows creating the optimum conditions for nucleation and growth during solidification, positively affecting the quality of alloys.

\subsubsection{Refining Microstructure of Alloys Containing Transition Metals}

The detrimental feature of aluminum alloys modified with transition metals, having much higher melting points than aluminum, is that the intermetallic compounds that control thermal stability are generally coarse and therefore ineffective. Thus, an opportunity to refine the coarse compounds, using liquid metal treatment, offers a number of benefits through reducing the overheating temperature, required during melting, shortening the holding time in a molten state and shortening the holding times during post-casting heat treatment, or in some cases, eliminate a need for heat treatment altogether. A new mixing technology that explores an integration of gas injection into the shear zone with ultrahigh shear mixing, called Gas-enhanced Ultrahigh Shear Mixing (GE-UHS), allows refining the microstructure through affecting the alloy solidification mechanism (Figure 27) [128].

An application of the GE-UHS technology to molten aluminum alloys shows that injecting gas into a shear zone of the rotor/stator apparatus drastically magnified the alloy structural refinement, which substantially exceeded the individual effects, caused by gas flotation and ultrahigh shearing. For an experimental $\mathrm{Al}-7 \mathrm{Si}-1 \mathrm{Cu}-0.5 \mathrm{Mg}$ (wt.\%) alloy with microquantities ( 0.1 to $0.5 \mathrm{wt} . \%$ ) of $\mathrm{V}-\mathrm{Ti}-\mathrm{Zr}$, in addition to matrix grain size reduction by almost two orders of magnitude, the complex intermetallic compounds $(\mathrm{AlSi})_{\mathrm{x}}(\mathrm{TiVZr})$ with $\mathrm{DO}_{22} / \mathrm{DO}_{23}$ tetragonal crystal structure were refined [129]. Those compounds with transition metals are crucial for thermal stability but remain inherently coarse in conventional castings. 


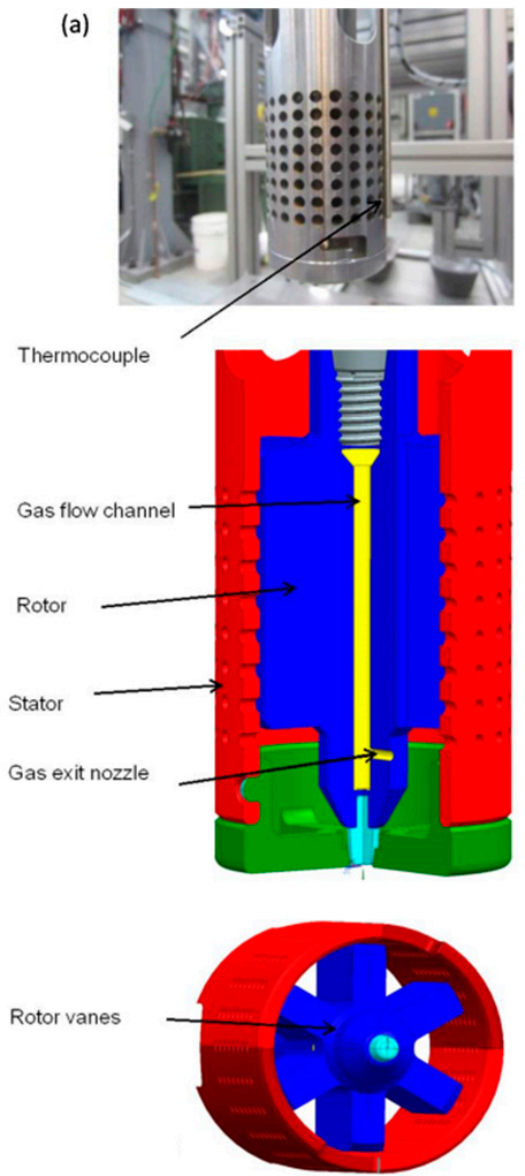

(b)
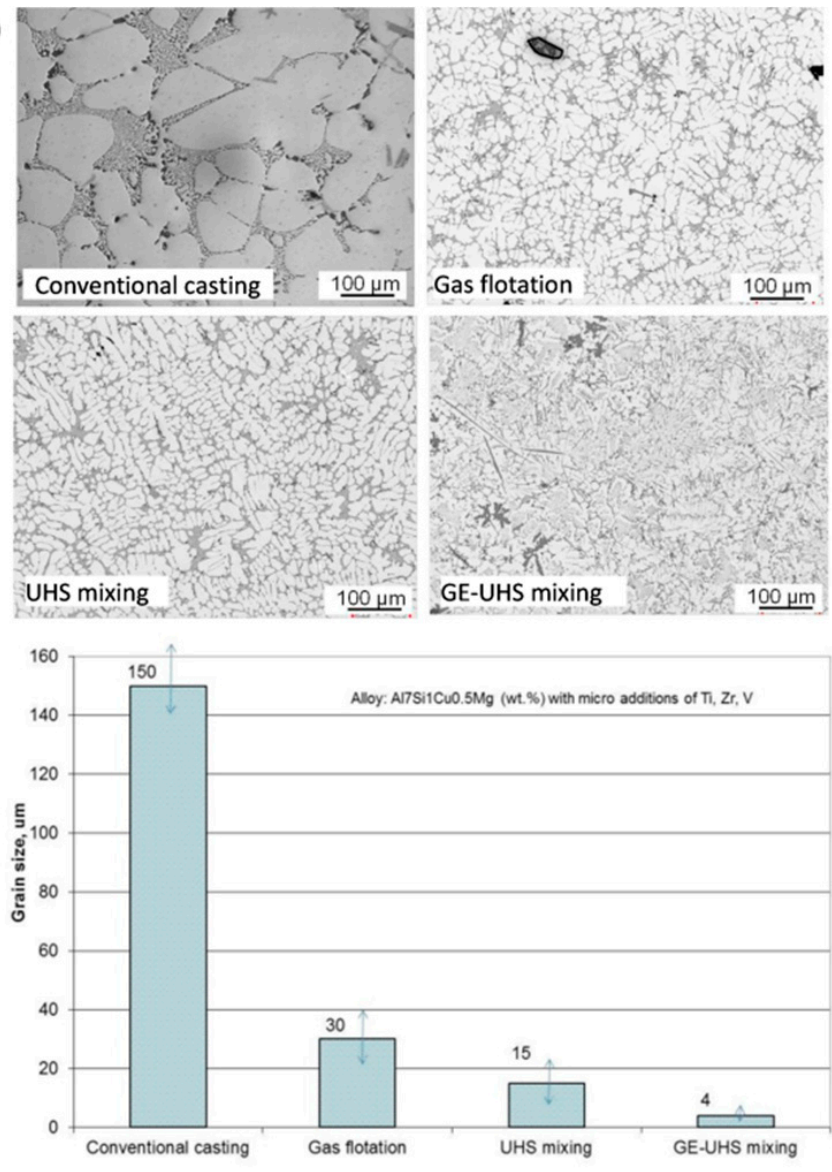

Liquid alloy treatment

Figure 27. Application of Gas-Enhanced Ultrahigh Shear Mixing for refining microstructure of Al7Si1Cu0.5Mg alloy with 0.47 wt.\% Zr, 0.21 wt.\% Ti, 0.30 wt.\% V: (a) mixing device; (b) microstructure after different treatments in liquid state with resultant grain size shown on histograms [129].

\subsubsection{Morphology Change of the Eutectic Phase in Alloys with Additions of Rare Earths}

For some alloys, liquid metal engineering may be the only option to refine the strategic strengthening compounds. An example is the Al-Ce alloy, where due to negligible solid state solubility of $\mathrm{Ce}$ in $\mathrm{Al}$, generation of strengthening precipitates through heat treatment is impossible. The key component of $\mathrm{Al}-\mathrm{Ce}$ binary alloys, which controls their thermal stability, is the $\mathrm{Al}-\mathrm{Al}_{11} \mathrm{Ce}_{3}$ eutectic. However, the $\mathrm{Al}_{11} \mathrm{Ce}_{3}$ eutectic phase with lamellar morphology provides limited strengthening to the alloy [124].

According to recent experiments, the eutectic morphology can be transformed from lamellar to more effective fiber-like, using an agitation of a molten alloy before solidification with a permanent magnet [130]. Modeling of the lamellar-to-fiber transition within the Jackson-Hunt framework, followed by experiments, using the $\mathrm{Al}-5 \mathrm{wt} . \% \mathrm{Ce}$ alloy, led to the fiber structure with improved mechanical properties. The alloy processing through permanent magnet stirring at $630^{\circ} \mathrm{C}$ exhibited increased mechanical strength retention and better performance than the other commercial aluminum heat-resistant alloys. Although, there is some ambiguity, regarding the alloy treatment temperature and its location in regards to the alloy liquidus, this example demonstrates that liquid metal engineering offers a new route to influencing the solidification morphology with a considerable advantage over directional solidification and laser additive manufacturing. 


\subsection{Rapid Solidification}

Rapid solidification technology is explored for decades with aluminum alloys, showing many advantages over conventional ingot casting. It improves the elevated temperature performance of aluminum alloys through high supersaturations of elements in the matrix. Several experimental materials with transition metals $\mathrm{Fe}$ and $\mathrm{Cr}$, produced through this route, have promising creep properties up to $350^{\circ} \mathrm{C}$ [131].

The rapid solidification was used to manufacture aluminum alloys for high temperature applications, including systems $\mathrm{Al}-\mathrm{Fe}-\mathrm{Ce}, \mathrm{Al}-\mathrm{Fe}-\mathrm{Cr}-(\mathrm{TM}), \mathrm{Al}-\mathrm{Cr}-\mathrm{Zr}(\mathrm{Mn})$, and $\mathrm{Al}-\mathrm{Fe}-\mathrm{V}(\mathrm{Mo})-\mathrm{Si}$ [132]. The best examples of green products show strength of 550-600 MPa at room temperature and at least $200-250 \mathrm{MPa}$ at $300^{\circ} \mathrm{C}$. The strength of Al-Fe-Cr-(TM) alloys with a high volume content of quasicrystals is approximately $100 \mathrm{MPa}$ higher at 20 and $300{ }^{\circ} \mathrm{C}$, while their elongation is 50 to $67 \%$ lower than typically seen in other aluminum alloys. In particular, in the $\mathrm{Al}-8.8 \mathrm{Fe}-3.7 \mathrm{Ce}$ (wt.\%) alloy, processed through arc melting and rapid solidification and followed by extrusion, led to formation of metastable phases in addition to equilibrium structures $\mathrm{Al}_{6} \mathrm{Fe}, \mathrm{Al}_{10} \mathrm{Fe}_{2} \mathrm{Ce}$, and $\mathrm{Al}_{20} \mathrm{Fe}_{5} \mathrm{Ce}$ [133]. The $\mathrm{Al}_{20} \mathrm{Fe}_{5} \mathrm{Ce}$ phase was a decagonal quasicrystal while the $\mathrm{Al}_{10} \mathrm{Fe}_{2} \mathrm{Ce}$ phase was determined to have an orthorhombic crystal structure belonging to space group $\mathrm{C} m m m, \mathrm{C} m m 2$, or $\mathrm{C} 222$.

\subsection{Mechanical Alloying-Alloy Consolidation from Fine Powders}

Mechanical alloying is widely used to produce nanostructured aluminum alloys for high-temperature applications, including compositions with transition metals, where having the fine and homogenous microstructure is difficult to obtain after conventional casting. The process is generally implemented through a combination of gas atomization, ball milling, and hot pressing. Examples of alloys include both standard and unique compositions such as Al86Ni7Y4.5Co1La1.5 (at. \%) [134], 70.0Al-22 Fe-8.0Ti (wt.\%), 69.0Al-22 Fe-8.0Ti (wt.\%) with 1.0 nano- $\mathrm{Y}_{2} \mathrm{O}_{3}$, and 69.0Al-22 $\mathrm{Fe}-8.0 \mathrm{Ti}$ (wt. $\%$ ) with $1 \mathrm{wt} . \%$ nano- $\mathrm{TiO}_{2}$ [135].

The powder metallurgy with devitrification and consolidation of amorphous/crystalline powders was also used to manufacture A184Ni7Gd6Co3 (at.\%) alloys with a unique hybrid microstructure, composed of isolated nanoscale fcc-Al grains and intermetallic compounds [25]. The high strength at both room and high temperatures is attributed mainly to the composite structure and the effect of confinement between the nanosized $\mathrm{Al}$ and intermetallic phases. As a result of the confining effect, the premature brittle fracture of the intermetallics and the nanocrystalline $\mathrm{Al}$ could effectively be suppressed, thus offering the possibility to deform plastically and to exhibit intrinsic strength rather than the flaw-controlled strength. An example of properties of the Al84Ni7Gd6Co3 (at.\%) alloy are shown in Figure 28.

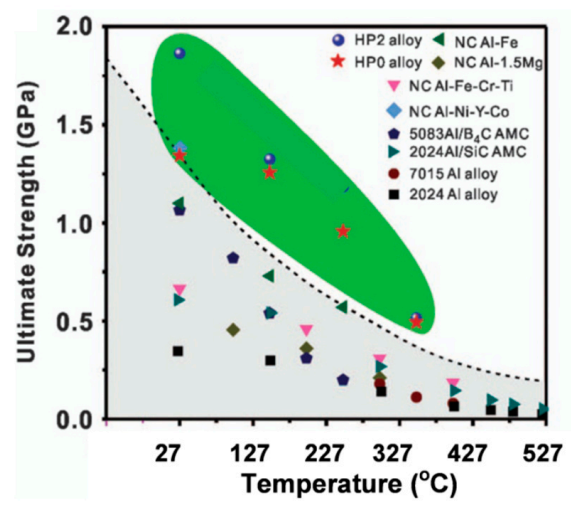

Figure 28. Thermal stability of the Al84Ni7Gd6Co3 (at.\%) alloy, produced by a combination of gasification, ball milling and hot pressing as compared to other alloys taken from the literature. $\mathrm{HPO}$ - hot pressing at $640 \mathrm{MPa}$ and $\mathrm{T}_{\mathrm{HP}}=500{ }^{\circ} \mathrm{C}$ using gas-atomized powders; $\mathrm{HP} 2$-powders milled for $50 \mathrm{~h}$ (HP1) and $100 \mathrm{~h} \mathrm{[25].}$ 
The combined mechanical alloying and powder consolidation was also found effective during manufacturing of the $\mathrm{Al}(\mathrm{Mg})-\mathrm{NiO}$ composites with very fine grain matrix [136]. During processing, transformation of $\mathrm{NiO}$ particles into thermodynamically stable $\mathrm{Al}_{3} \mathrm{Ni}$ and $\mathrm{MgAl}_{2} \mathrm{O}_{4}$ compounds in the $\mathrm{Al}(\mathrm{Mg})-\mathrm{NiO}$ composite extruded at $400{ }^{\circ} \mathrm{C}$ is responsible for the flow stress decrease, observed for a wide range of deformation temperatures. Therefore, the effect of preliminary annealing at $600{ }^{\circ} \mathrm{C}$ on the flow stress versus deformation temperature characteristics was very limited, because the chemical reaction occurred during the hot extrusion of the composite, i.e., before composite annealing.

\subsection{Additive Manufacturing}

Additive manufacturing (3D printing) covers a variety of computer-controlled processes, where a material is deposited layer by layer and solidifies to create a three-dimensional object. Selective laser melting and electron beam melting represent the major technologies of additive manufacturing. The key feature of selective laser melting, where manufacturing is conducted by repeated melting and solidification of a metal powder by laser, is its cooling rate, being much faster than that experienced during conventional casting [137].

In addition to refining structure due to a rapid solidification, multipass laser additive manufacturing can trigger precipitation hardening, thus replacing heat treatment. Conventional processing involves controlled ageing, during which the ordered and coherent $\mathrm{Al}_{3} \mathrm{Sc}$ precipitates form from a Sc-supersaturated solid solution. In [138], the intrinsic heat treatment that explores the deposition energy was used to trigger in situ precipitation of $\mathrm{Al}_{3} \mathrm{Sc}$ during laser additive manufacturing. As the intrinsic heat treatment causes precipitates coarsening, thereby reducing their strengthening effect, the alternative solidification conditions were implemented to exploit the intrinsic heat treatment to form the $\mathrm{Zr}$-rich shell around the $\mathrm{Al}_{3} \mathrm{Sc}$ precipitates.

As shown in Figure 29, a presence of the $\mathrm{Zr}$ shell prevents the precipitate coarsening. This approach is applicable to a wide range of precipitation-hardened alloys, used in laser additive manufacturing.
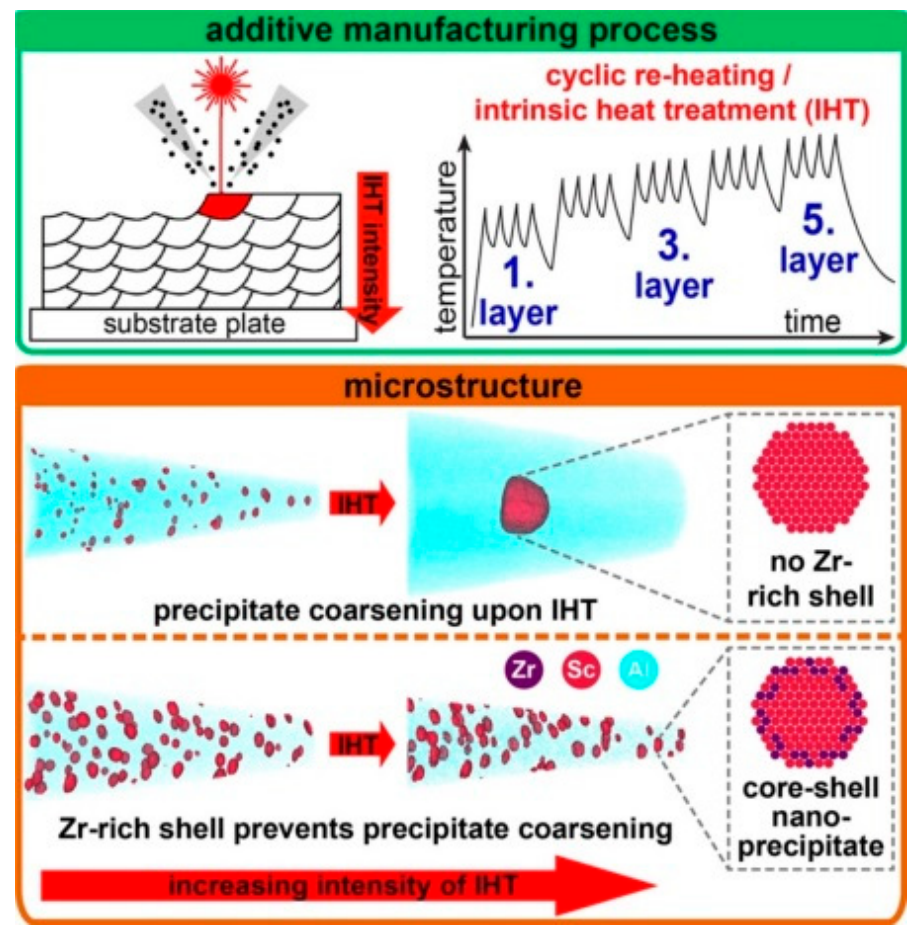

Figure 29. Control of thermally stable core-shell nanoprecipitates in additively manufactured $\mathrm{Al}-\mathrm{Sc}-\mathrm{Zr}$ alloys [138]. 
In general, laser-printed metals do not tend to match the mechanical properties and thermal stability of conventionally manufactured alloys. However, laser additive manufacturing can also produce high-performance and near-net shape parts of aluminum matrix composite with higher specific strength, better wear resistance, and more outstanding physical properties than aluminum alloys, which are widely used in automotive and aerospace fields [139]. It should be kept in mind that a single-pass laser melting creates microstructural effects similar to those achieved during rapid solidification.

Laser melting overcomes a challenge of manufacturing the aluminum matrix nano-composites with a high density of dispersed nanoparticles. The laser printed aluminum nano composites with a thickness of around $300 \mu \mathrm{m}$, reinforced with 35 vol.\% TiC reached a yield stress of up to $1000 \mathrm{MPa}$, elongation over 10\%, and Young's modulus of approximately $200 \mathrm{GPa}$ [140].

As shown in Figure 30, hardness of the composite over wide temperature range exceeds values obtained for other metallic materials listed there. An improvement in the composite performance is attributed to the high density of uniformly dispersed nanoparticles, strong interfacial bonding between particles and matrix, and fine grain sizes of $\sim 330 \mathrm{~nm}$. Similar benefits of selective laser melting were recorded after deposition of AlSi10Mg (wt.\%) composites with additions of $\mathrm{TiB}_{2}$ reinforcement [141].
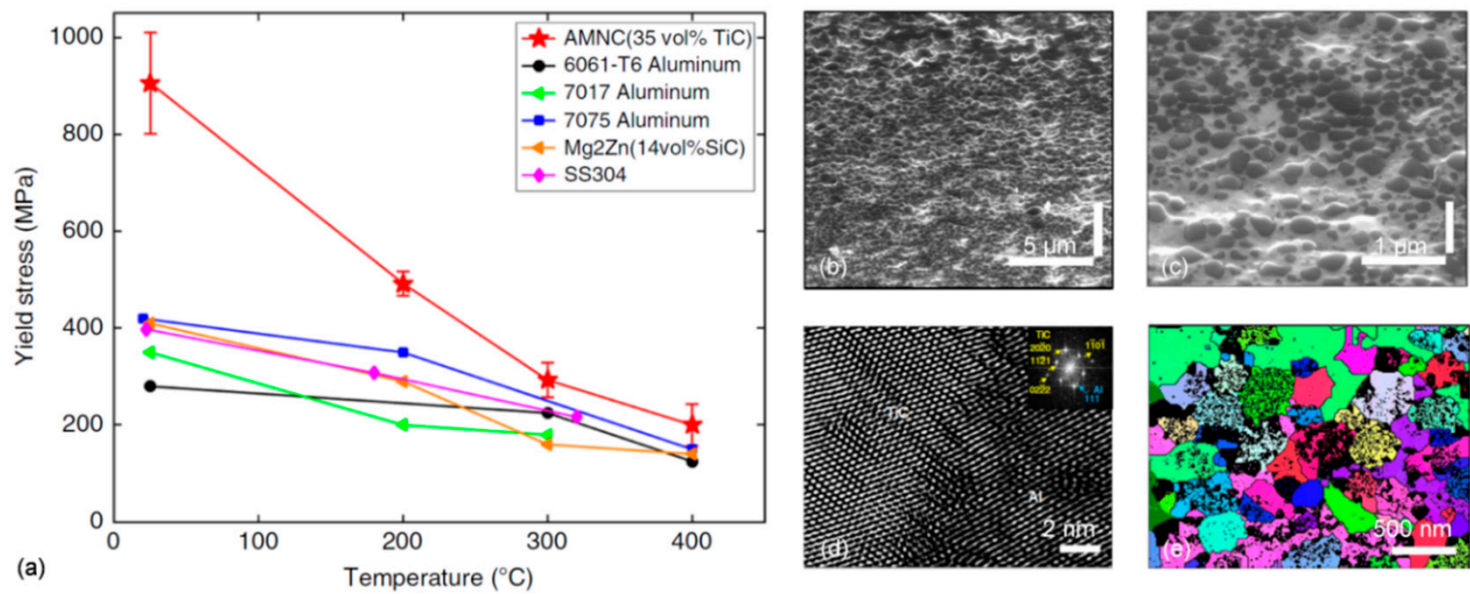

Figure 30. Mechanical behavior and microstructure of laser-deposited Al-matrix nanocomposites (AMNC) at elevated temperature: (a) yield strength of nanocomposite (35 vol.\% $\mathrm{TiC}$ ) at 25, 200, and $400{ }^{\circ} \mathrm{C}$ in comparison with other materials; $(\mathbf{b}, \mathbf{c})$ SEM images showing TiC nanoparticles uniformly distributed in matrix; (d) FFT-filtered high-resolution TEM image showing good bonding between TiC nanoparticle and $\mathrm{Al}$; (e) grain map showing orientation distribution [140].

To better exploit the advantages of additive manufacturing and optimize the functionality of the customized components, alloys specifically developed for this manufacturing route are required. At present, the majority of additive manufacturing of aluminum-based alloys involves commercial grades such as AlSi7Mg, AlSi12, and AlSi10Mg (wt.\%), designed for conventional casting. An attempt is shown in Figure 31, where novel Al-Mn-Sc alloys were evaluated by selective laser melting [142]. Due to formation of the primary $\mathrm{Al}_{3}(\mathrm{Sc}, \mathrm{Zr})$ particles at the molten pool boundaries, the $\mathrm{Al}-\mathrm{Mn}-\mathrm{Sc}$ alloys developed a fine columnar-equiaxed bimodal grain structure with high thermal stability. Additions of transition metal $\mathrm{Mn}$, forming $\mathrm{Al}_{6} \mathrm{Mn}$ likely through the solute rejection from the solidification front and nucleation at the grain and subgrain boundaries or dislocation walls, contributed to thermal stability improvement. 

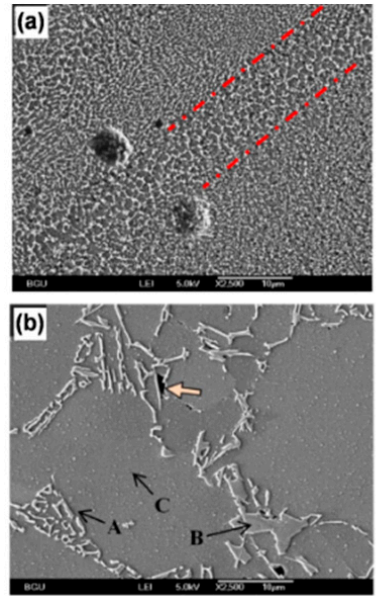

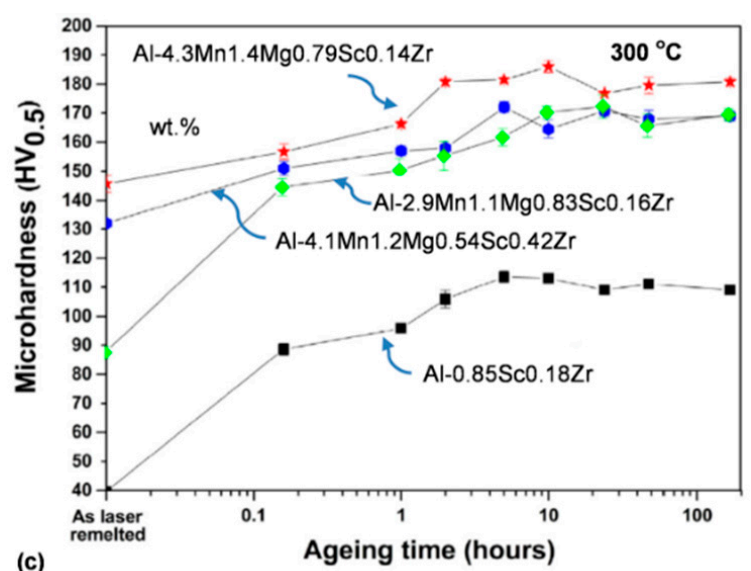

(c)

Ageing time (hours)

Figure 31. Refinement of microstructure of AlSi10Mg alloy after selective laser melting (a) as compared to the conventionally cast state $(\mathbf{b}), \mathrm{A}-\mathrm{Al}-\mathrm{Si}$ eutectic, $\mathrm{B}-\mathrm{Si}$ dispersion, $\mathrm{C}-\mathrm{Fe}$-containing intermetallics [143]; (c) aging responses of laser remelted $\mathrm{Al}-\mathrm{Mn}-\mathrm{Sc}$ and $\mathrm{Al}-\mathrm{Sc}-\mathrm{Zr}$ alloys at $300{ }^{\circ} \mathrm{C}$ [142].

The combination of processing through selective laser melting and alloying with Fe improved the high-temperature strength and ductility of $\mathrm{Al}-11.6 \mathrm{Si}-0.97 \mathrm{Cu}-0.96 \mathrm{Mg}-1 \mathrm{Ni}$ (wt.\%) alloys [144]. According to microstructural observations the improvement was caused by the dispersion of fine rod-shaped $\mathrm{Fe}-\mathrm{Si}-\mathrm{Ni}$ particles, which replaced the cell-like structure of eutectic $\mathrm{Si}$, typical for the conventionally cast state. Selective laser melting was also found effective to fabricate components from the heat-resistant $\mathrm{Al}-8.5 \mathrm{Fe}-1.3 \mathrm{~V}-1.7 \mathrm{Si}$ (wt.\%) aluminum alloy with a microhardness of $246 \mathrm{HV} 0.1$ [145]. The nanosize spheroidal $\mathrm{Al}_{12}(\mathrm{Fe}, \mathrm{V})_{3} \mathrm{Si}$ particles, homogeneously distributed in the $\mathrm{Al}$ matrix, were developed in the heat affected zone, while the rectangle-like $\mathrm{Al}_{\mathrm{m}} \mathrm{Fe}$ phase with $\mathrm{m}=4.0-4.4$ and $100-500$ $\mathrm{nm}$ in size was formed in the border re-melting zone.

In addition to experimental alloys, there are also commercial ones, designed for additive manufacturing. An example is the second-generation aluminum-magnesium-scandium ( $\mathrm{Al}-\mathrm{Mg}-\mathrm{Sc})$ alloy, referred to as Scalmalloy ${ }^{\circledR}$, developed by Airbus research center as a high-strength lightweight alloy for selective laser melting [146]. The alloy with a specific weight of $2.67 \mathrm{~g} / \mathrm{cm}^{3}$ offers tensile strength of $520 \mathrm{MPa}$ with elongation of $13 \%$ and the microstructure stable up to $250^{\circ} \mathrm{C}$.

\section{Thermal Stability and Exposure to Accidental Fire}

In case of accidental fire hazards a metal might be exposed to enormously high temperatures. Due to relatively low melting temperature of aluminum alloys as compared to steel, often coexisting in a design, the outcome may be catastrophic for the former (Figure 32). For aluminum, however, much higher heat input is necessary to bring the same mass of metal to a given temperature, compared with steel. This is caused by high thermal conductivity of aluminum, being about four times that of steel and its specific heat twice that of steel, resulting in higher heat transfer away from the source.

\subsection{Fire Initiation-Thermic Sparking}

Aluminum is non-sparking in all environments if struck against aluminum, stainless steel, or any other material. The purpose in using non-sparking metals is to prevent ignition of combustible or explosive materials from an impact-generated spark. There is, however, one known exception: when unpainted or uncoated aluminum is struck by or strikes rusty ferrous metals, sparks may result [147]. Therefore, to avoid any possibility of sparking, where it is likely that aluminum may be struck by rusty ferrous metals, protective coatings such as paint are recommended.

Even if pure, non-ferrous aluminum is used, sparks can occur during an aluminothermic reaction, also called a thermic reaction. Such a reaction occurs when an aluminum particle and a metal oxide, such as rust, are ignited by a heat source and chemically burn as a "Class D" fire (i.e., combustible metal). 
AA5083, $2000 \mathrm{~s}$ Thermal damage (no load)

Thermomechanical damage

Figure 32. Comparison of $(\mathbf{a}-\mathbf{c})$ thermally and $(\mathbf{d}-\mathbf{f})$ thermomechanically damaged 5083-H116 alloy exposed for $2000 \mathrm{~s}$. The shown conditions are (a) $200{ }^{\circ} \mathrm{C}$, (b) $300{ }^{\circ} \mathrm{C}$, (c) $400{ }^{\circ} \mathrm{C}$, (d) $200{ }^{\circ} \mathrm{C}, 140 \mathrm{MPa}, \varepsilon=$ $15 \%$, (e) $300{ }^{\circ} \mathrm{C}, 50 \mathrm{MPa}, \varepsilon=100 \%$ and (f) $400{ }^{\circ} \mathrm{C}, 17 \mathrm{MPa}, \varepsilon=143 \%$. The rolling/loading direction for all micrographs is along the long axis of the page [10].

\subsection{Exposure to Temperatures Exceeding the Melting Range}

The solid bulk aluminum alloys exposed in air to temperatures exceeding the liquidus convert to molten state but are not subjected to burning, generating smoke or hazardous fumes. After fire is extinguished the metal remains as a re-solidified pool. Similarly, temperatures leading to semisolid state will result in an integrity lost by a design. The resistance of aluminum to burning is controlled by a number of national standards including ASTM. This is in contrast to fine powders or flakes of aluminum, which are highly flammable and oxidize exothermically. The ignition behavior of aluminum powder is similar to other finely divided materials including iron and titanium, which also readily oxidize exothermically while in the powder form.

\subsection{Deterioration of Alloy Mechanical Properties during Fire}

When structural collapse does not occur as a result of a fire, there is a need to evaluate the residual properties of overheated material to assess whether the structures should be dismantled, repaired, or directly reused. The influence of fire on mechanical properties depends on temperature and exposure time. The key difference from thermal stability issues discussed in this report is that alloys exposed to fire may not be designed at all for high temperature service. Therefore, even relatively low temperature such as $150^{\circ} \mathrm{C}$ may lead to very poor performance during fire and the permanent property deterioration after fire.

There are a number of studies where the heat exposure on aluminum alloys that are not designed for high-temperature service, were evaluated. The objective was to accurately assess the post-fire performances of aluminum alloy structures. The models with predictive equations were developed, combining an influence of hardening factors and temperature on the material stress-strain relationship [148].

An example of research where an existing constitutive model for creep was modified in order to be used for fire-exposed alloys involved AA5083-O/H111 and AA6060-T66 grades [149]. For temperature range of 170 to $380^{\circ} \mathrm{C}$ the model predicted properties for the 5xxx series alloys. The same AA5083-H116 and AA6061-T651 marine-grade aluminum alloys were subject of extensive mechanical testing to determine the residual mechanical behavior after fire exposure [150] (Figure 33). The constitutive 
models were developed as a series of sub-models to predict (i) microstructural evolution, (ii) residual yield strength, and (iii) strain hardening after fire exposure. The properties of AA5000 series following a simulated fire exposure were evaluated in [151]. The 5xxx series alloys with different tempers resulted in residual strengths between 85 and $157 \mathrm{MPa}$ following the fire exposure. Most alloys exhibited structural recovery between 100 to $280{ }^{\circ} \mathrm{C}$ followed by recrystallization between 300 to $340{ }^{\circ} \mathrm{C}$. However, the AA5456-H116 alloy, which has the highest magnesium content, maintained $60 \%$ of room temperature yield strength. This alloy underwent recovery but did not have a clear recrystallization, preserving strength. Another study [152] found that the mechanical properties of AA6061-T6 were drastically reduced after exposure to temperatures exceeding $300{ }^{\circ} \mathrm{C}$. For AA7075-T73, reduction in properties took place at lower temperature of $200{ }^{\circ} \mathrm{C}$. An additional factor affecting post-fire mechanical properties of these two grades was a cooling rate from a relatively high fire temperature.
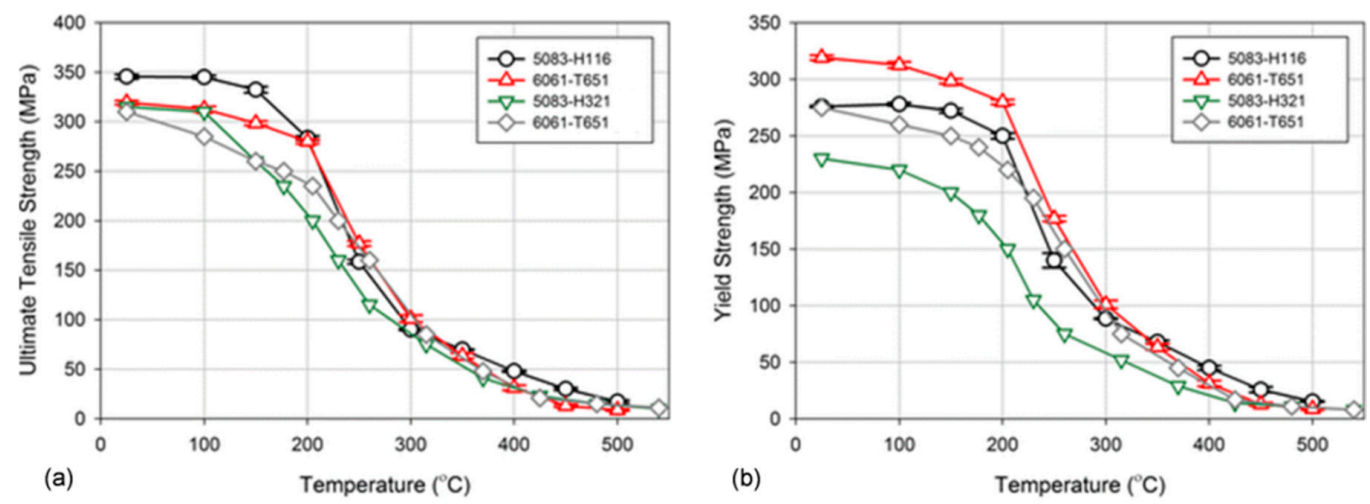

Figure 33. Degradation of tensile properties of 5083-H116 and 6061-T651 alloys during exposures to heat, expressed through ultimate tensile strength (a) and yield stress (b) [10].

\section{Concluding Remarks}

Thermal stability is becoming the next frontier for aluminum alloys; understanding and overcoming limitations in this area would lead to substantial expansion in their structural applications, especially in aerospace and automotive sectors.

As practically all aluminum alloys are thermally unstable, with their properties being affected, to some extent, by service temperature and time, thermal stability is of concern throughout the entire temperature range of their applications. This includes grades essentially used at room temperatures, as is the case with aircraft components that may become warm due to exposure to sun, due to aerodynamic heating or heat transferred from engines, which can deteriorate alloys properties over years of service.

The major challenge in thermal stability of aluminum is, however, in increasing the upper service limit of high-temperature grades. There are efforts to develop new alloys with thermally stable microstructure through alloying aluminum with a variety of elements, in particular, transition, and rare earth metals. In parallel, there are efforts to generate more stable microstructure through novel processing routes, such as rapid solidification, powder metallurgy, mechanical alloying and additive manufacturing, engineering alloys in a liquid state prior to casting, and post-casting treatments.

The ultimate goal is to overcome the present knowledge and manufacturing barriers and develop aluminum alloys with superior properties that remain stable across the temperature and time space, required by modern designs.

Funding: This research was funded by the Program of Energy Research and Development (PERD) of Natural Resources Canada.

Conflicts of Interest: The author declares no conflicts of interest. 


\section{Appendix A. Diffusivities and Phase Diagram Data for Alloying Elements in Aluminum}

Arrhenius equation for diffusion coefficient:

$\left.\mathrm{D}=\mathrm{D}_{\mathrm{o}} \exp (-\mathrm{Q}) / \mathrm{RT}\right), \mathrm{R}=8.314 \mathrm{Jmol}^{-1} \mathrm{~K}^{-1}$

D values at $500{ }^{\circ} \mathrm{C}$ were calculated in this work based on data cited in table

Table A1. Measured diffusivities of selected elements along with Al self-diffusion (data calculated are indicated).

\begin{tabular}{|c|c|c|c|c|c|c|c|}
\hline \multirow{2}{*}{$\begin{array}{c}\text { Element } \\
-\end{array}$} & \multirow{2}{*}{$\begin{array}{c}\text { Group-Period } \\
-\end{array}$} & \multirow{2}{*}{$\frac{\text { Pre-Exponential, } \mathrm{D}_{\mathrm{o}}}{\mathrm{m}^{2} \mathrm{~s}^{-1}}$} & \multicolumn{2}{|c|}{ Activation Enthalpy, Q } & \multirow{2}{*}{$\frac{\mathrm{D} \text { at } 500{ }^{\circ} \mathrm{C}(773 \mathrm{~K})}{\mathrm{m}^{2} \mathrm{~s}^{-1}}$} & \multirow{2}{*}{$\frac{\text { Temp. Range, }{ }^{\circ} \mathrm{C}}{-}$} & \multirow{2}{*}{$\begin{array}{c}\text { References } \\
-\end{array}$} \\
\hline & & & $\mathrm{kJmol}^{-1}$ & eVatom $^{-1}$ & & & \\
\hline \multirow{3}{*}{$\mathrm{Al}_{\text {self }}$} & \multirow{3}{*}{$13-2$} & $1.37 \times 10^{-5}$ & 124 & 1.29 & $5.7 \times 10^{-14}$ & $227-527$ & [153] \\
\hline & & $1.71 \times 10^{-5}$ & 142 & 1.47 & $4.34 \times 10^{-14}$ & $450-650$ & [32] \\
\hline & & $6.6 \times 10^{-6}$ & 124 & 1.29 & $2.75 \times 10^{-14}$ & Calculated & [154] \\
\hline \multirow{2}{*}{$\mathrm{Li}$} & \multirow{2}{*}{$1-1$} & $3.7^{+1.30}-0.28 \times 10^{-5}$ & $126.1 \pm 5.2$ & $1.31 \pm 0.05$ & $1.11 \times 10^{-13}$ & $150-240$ & [155] \\
\hline & & $4.5 \times 10^{-4}$ & 139.3 & 1.44 & $1.73 \times 10^{-13}$ & $310-597$ & [156] \\
\hline \multirow{3}{*}{$\mathrm{Si}$} & \multirow{3}{*}{$14-2$} & $2.02^{+0.97}-0.66 \times 10^{-4}$ & $136 \pm 3$ & 1.41 & $1.3 \times 10^{-13}$ & $480-620$ & [35] \\
\hline & & $8.3 \times 10^{-7}$ & 78.53 & 0.81 & $4.32 \times 10^{-13}$ & $475-550$ & [157] \\
\hline & & $1.19 \times 10^{-5}$ & 122 & 1.27 & $6.75 \times 10^{-14}$ & Calculated & [158] \\
\hline \multirow{4}{*}{$\mathrm{Mg}$} & \multirow{4}{*}{$2-2$} & $6.23 \times 10^{-5}$ & $115 \pm 1.15$ & $1.19 \pm 0.012$ & $1.05 \times 10^{-13}$ & - & [159] \\
\hline & & $1.0 \times 10^{-4}$ & 131 & $1.35 \pm 0.05$ & $1.40 \times 10^{-13}$ & - & [160] \\
\hline & & $1.49 \times 10^{-5}$ & 121 & 1.25 & $9.92 \times 10^{-14}$ & - & [161] \\
\hline & & $6.6 \times 10^{-5}$ & $124 \pm 1.45$ & $1.29 \pm 0.015$ & $2.75 \times 10^{-13}$ & - & [162] \\
\hline
\end{tabular}

Table A2. Measured diffusivities for transition elements in aluminum (data calculated are indicated).

\begin{tabular}{|c|c|c|c|c|c|c|c|}
\hline \multirow{2}{*}{$\begin{array}{c}\text { Element } \\
-\end{array}$} & \multirow{2}{*}{$\begin{array}{c}\text { Group-Period } \\
-\end{array}$} & \multirow{2}{*}{$\begin{array}{c}\text { Pre-Exponential } D_{0} \\
\mathrm{~m}^{2} \mathrm{~s}^{-1}\end{array}$} & \multicolumn{2}{|c|}{ Activation Enthalpy, Q } & \multirow{2}{*}{$\begin{array}{c}\mathrm{D} \text { at } 500^{\circ} \mathrm{C}(773 \mathrm{~K}) \\
\mathrm{m}^{2} \mathrm{~s}^{-1}\end{array}$} & \multirow{2}{*}{$\begin{array}{c}\text { Temp Range, }{ }^{\circ} \mathrm{C} \\
-\end{array}$} & \multirow{2}{*}{$\begin{array}{c}\text { Reference } \\
-\end{array}$} \\
\hline & & & $\mathrm{kJmol}^{-1}$ & eVatom $^{-1}$ & & & \\
\hline \multirow{2}{*}{$\mathrm{Ti}$} & \multirow{2}{*}{$4-3$} & $1.12 \times 10^{-1}$ & 261.5 & 2.71 & $2.38 \times 10^{-19}$ & - & [163] \\
\hline & & $9 \times 10^{-5}$ & 223.8 & 2.32 & $6.77 \times 10^{-20}$ & Calc & [36] \\
\hline $\mathrm{Zr}$ & $4-4$ & $7.28^{+10.4}{ }_{-4.29} \times 10^{-2}$ & 242 & 2.51 & $3.2 \times 10^{-18}$ & $531-640$ & [164] \\
\hline \multirow{3}{*}{ V } & \multirow{3}{*}{$5-3$} & $6.05 \times 10^{-12}$ & 82.0 & 0.85 & $1.74 \times 10^{-17}$ & - & [165] \\
\hline & & $1.6 \times 10^{0}$ & 303 & 3.14 & $5.35 \times 10^{-21}$ & - & [163] \\
\hline & & $1 \times 10^{-4}$ & 241 & 2.50 & $5.18 \times 10^{-21}$ & Calc & {$[36]$} \\
\hline $\mathrm{Nb}$ & $5-4$ & $1.66 \times 10^{-11}$ & 82.22 & 0.85 & $4.61 \times 10^{-17}$ & $350-480$ & [166] \\
\hline \multirow{4}{*}{$\mathrm{Cr}$} & \multirow{4}{*}{$6-3$} & $3.01 \times 10^{-11}$ & 64.4 & 0.67 & $1.0 \times 10^{-15}$ & $250-605$ & [167] \\
\hline & & 10 & 282 & 2.92 & $8.78 \times 10^{-19}$ & - & [168] \\
\hline & & $6.75 \times 10^{-1}$ & 261.5 & 2.71 & $1.44 \times 10^{-18}$ & - & [161] \\
\hline & & $7 \times 10^{-5}$ & 199.7 & 2.07 & $2.24 \times 10^{-18}$ & Calc & {$[36]$} \\
\hline Mo & $6-4$ & $1.4 \times 10^{-3}$ & 250 & 2.59 & $1.79 \times 10^{-20}$ & - & [169] \\
\hline \multirow{4}{*}{ Mn } & \multirow{4}{*}{$7-3$} & $1.04 \times 10^{-2}$ & 211 & 2.19 & $5.73 \times 10^{-17}$ & $460-660$ & [170] \\
\hline & & $2.2 \times 10^{-5}$ & 120.5 & 1.25 & $1.58 \times 10^{-13}$ & $450-650$ & [32] \\
\hline & & $1.35 \times 10^{-2}$ & 211 & 2.19 & $7.44 \times 10^{-17}$ & - & [161] \\
\hline & & $2 \times 10^{-5}$ & 166.9 & 1.73 & $1.05 \times 10^{-16}$ & Calc & [36] \\
\hline \multirow{4}{*}{$\mathrm{Fe}$} & \multirow{4}{*}{$8-3$} & $4.1 \times 10^{-13}$ & 58.16 & 0.61 & $5.0 \times 10^{-17}$ & $350-630$ & [171] \\
\hline & & $7.7 \times 10^{-1}$ & 221 & 2.29 & $8.95 \times 10^{-16}$ & - & [168] \\
\hline & & $1.35 \times 10^{-2}$ & 190 & 2.00 & $1.95 \times 10^{-15}$ & - & [172] \\
\hline & & $3 \times 10^{-5}$ & 145.7 & 1.51 & $4.28 \times 10^{-15}$ & Calc & [36] \\
\hline \multirow{4}{*}{ Co } & \multirow{4}{*}{$9-3$} & $1.41 \pm 1.37 \times 10^{-2}$ & $168.8 \pm 6.75$ & $1.75 \pm 0.07$ & $5.52 \times 10^{-14}$ & - & [173] \\
\hline & & $1.1 \times 10^{-10}$ & 83.26 & 0.86 & $2.6 \times 10^{-16}$ & $350-630$ & [171] \\
\hline & & $1.93 \times 10^{-2}$ & 168 & 1.75 & $8.57 \times 10^{-14}$ & - & {$[161,168]$} \\
\hline & & $1.6 \times 10^{-6}$ & 112.9 & 1.17 & $3.75 \times 10^{-14}$ & Calc & [36] \\
\hline \multirow{4}{*}{$\mathrm{Ni}$} & \multirow{4}{*}{$10-3$} & $4.4 \pm 3.1 \times 10^{-4}$ & $146 \pm 5.8$ & $1.51 \pm 0.06$ & $5.99 \times 10^{-14}$ & - & [173] \\
\hline & & $2.9 \times 10^{-12}$ & 65.69 & 0.68 & $1.0 \times 10^{-16}$ & $350-630$ & [171] \\
\hline & & $4.1 \times 10^{-4}$ & 144.7 & 1.50 & $6.83 \times 10^{-14}$ & - & [161] \\
\hline & & $2 \times 10^{-4}$ & 137.0 & 1.42 & $1.1 \times 10^{-13}$ & Calc & [36] \\
\hline \multirow{4}{*}{$\mathrm{Cu}$} & \multirow{4}{*}{$11-3$} & $6.47 \times 10^{-5}$ & $135.0 \pm 1.12$ & $1.40 \pm 0.011$ & $4.88 \times 10^{-14}$ & - & [174] \\
\hline & & $4.37 \times 10^{-6}$ & 120 & 1.25 & $3.39 \times 10^{-14}$ & - & [158] \\
\hline & & $2.9 \times 10^{-5}$ & $130 \pm 6.7$ & $1.35 \pm 0.07$ & $4.76 \times 10^{-14}$ & - & [175] \\
\hline & & $4.44 \times 10^{-5}$ & 113.8 & 1.18 & $9.06 \times 10^{-13}$ & Calc & [176] \\
\hline $\mathrm{Ag}$ & $11-4$ & $1.18 \times 10^{-5}$ & $116.4 \pm 0.59$ & $1.21 \pm 0.006$ & $1.61 \times 10^{-13}$ & - & [174] \\
\hline \multirow{3}{*}{$\mathrm{Zn}$} & \multirow{3}{*}{$12-3$} & $2.59 \times 10^{-5}$ & $120.7 \pm 0.56$ & $1.25 \pm 0.006$ & $1.80 \times 10^{-13}$ & - & [174] \\
\hline & & $2.0 \pm 0.8 \times 10^{-5}$ & $120.7 \pm 1.92$ & $1.25 \pm 0.02$ & $1.39 \times 10^{-13}$ & - & [173] \\
\hline & & $1.0 \times 10^{-4}$ & 130 & 1.34 & $1.6 \times 10^{-13}$ & - & {$[177]$} \\
\hline
\end{tabular}


Table A3. Measured diffusivities for rare-earth elements in aluminum (data calculated are indicated).

\begin{tabular}{|c|c|c|c|c|c|c|c|}
\hline \multirow{2}{*}{$\begin{array}{c}\text { Element } \\
-\end{array}$} & \multirow{2}{*}{$\begin{array}{c}\text { Group-Period } \\
-\end{array}$} & \multirow{2}{*}{$\frac{\text { Pre-Exponential, } \mathrm{D}_{\mathrm{o}}}{\mathrm{m}^{2} \mathrm{~s}^{-1}}$} & \multicolumn{2}{|c|}{ Activation Enthalpy, Q } & \multirow{2}{*}{$\begin{array}{c}\mathrm{D} \text { at } 500^{\circ} \mathrm{C} \\
(773 \mathrm{~K})\end{array}$} & \multirow{2}{*}{$\frac{\text { Temp Range, }{ }^{\circ} \mathrm{C}}{-}$} & \multirow{2}{*}{$\begin{array}{c}\text { Reference } \\
-\end{array}$} \\
\hline & & & $\mathrm{kJmol}^{-1}$ & eVatom $^{-1}$ & & & \\
\hline \multirow{6}{*}{ Sc } & \multirow{6}{*}{$3-3$} & $1.90 \times 10^{-4}$ & $164 \pm 9$ & $1.7 \pm 0.09$ & $1.57 \times 10^{-15}$ & $300-400$ & [99] \\
\hline & & $7.2 \pm 6.0 \times 10^{-4}$ & $176 \pm 9$ & $1.92 \pm 0.09$ & $9.20 \times 10^{-16}$ & $400-450$ & [41] \\
\hline & & $5.31 \times 10^{-4}$ & 173 & 1.79 & $1.1 \times 10^{-15}$ & $540-655$ & {$[178,179]$} \\
\hline & & $2.34 \pm 2.16 \times 10^{-4}$ & $167 \pm 6$ & $1.73 \pm 0.06$ & $1.37 \times 10^{-15}$ & $475,550,625$ & [180] \\
\hline & & $2.65 \pm 0.84 \times 10^{-4}\left(^{*}\right)$ & $168 \pm 2$ & $1.74 \pm 0.02$ & $1.17 \times 10^{-15}$ & - & [180] \\
\hline & & $5.0 \times 10^{-5}$ & 165.9 & 1.72 & $3.08 \times 10^{-16}$ & Calculated & [36] \\
\hline $\mathrm{La}$ & Lan & $1.3 \times 10^{-10}$ & 113.0 & 1.17 & $3.00 \times 10^{-18}$ & - & [39] \\
\hline \multirow{2}{*}{$\mathrm{Ce}$} & \multirow{2}{*}{ Lan } & $1.89 \times 10^{-10}$ & 111.3 & 1.15 & $5.69 \times 10^{-18}$ & $450-630$ & [39] \\
\hline & & $4.0 \times 10^{-9}$ & 130.2 & 1.35 & $6.3 \times 10^{-18}$ & Calculated & [181] \\
\hline $\operatorname{Pr}$ & Lan & $3.58 \times 10^{-11}$ & 99.9 & 1.04 & $6.35 \times 10^{-18}$ & $520-630$ & [39] \\
\hline $\mathrm{Nd}$ & Lan & $4.80 \times 10^{-11}$ & 105.0 & 1.08 & $3.85 \times 10^{-18}$ & $450-630$ & [39] \\
\hline $\mathrm{Sm}$ & Lan & $3.45 \times 10^{-11}$ & 95.7 & 0.99 & $1.18 \times 10^{-17}$ & - & [39] \\
\hline
\end{tabular}

$\left({ }^{*}\right)$ results of combining measurements in $[157,180]$ with literature data.

Additional diffusion data:

$D_{Y}=3.56 \times 10^{-17} \mathrm{~m}^{2} \mathrm{~s}^{-1}$ at $600{ }^{\circ} \mathrm{C}[182]$

$\mathrm{D}_{\mathrm{Er}}=(4 \pm 2) \times 10^{-19} \mathrm{~m}^{2} \mathrm{~s}^{-1}$ at $300^{\circ} \mathrm{C}$ [100]

$\mathrm{D}_{\mathrm{Yb}}=(6 \pm 2) \times 10^{-17} \mathrm{~m}^{2} \mathrm{~s}^{-1}$ at $300^{\circ} \mathrm{C}[100]$

Table A4. Phase diagram data for alloying elements with aluminum.

\begin{tabular}{|c|c|c|c|c|c|c|c|c|c|c|}
\hline Element & Group-Period & Density & $\begin{array}{c}\text { Melting } \\
\text { Point }\end{array}$ & $\begin{array}{l}\text { Al-X Phase } \\
\text { Diagram }^{(3)}\end{array}$ & $\begin{array}{l}\text { React } \\
\text { Temp. }\end{array}$ & $\begin{array}{c}\text { Eutectic } \\
\text { Point }\end{array}$ & $\begin{array}{c}\text { Solid } \\
\text { Solubility }\end{array}$ & $\begin{array}{c}\text { Solid } \\
\text { Solubility }\end{array}$ & $\begin{array}{c}\text { Phase } \\
\text { Formed }\end{array}$ & $\begin{array}{c}\text { Major } \\
\text { Reference }\end{array}$ \\
\hline- & - & $\mathrm{g} / \mathrm{cm}^{3}$ & ${ }^{\circ} \mathrm{C}$ & - & ${ }^{\circ} \mathrm{C}$ & wt.\% & at. $\%$ & wt. $\%$ & - & - \\
\hline \multicolumn{11}{|c|}{ Non-transition elements } \\
\hline $\mathrm{Li}$ & $1-1$ & 0.534 & 180.5 & Eut & 596 & 7.51 & 14.5 & 4.18 & $\mathrm{Al}_{3} \mathrm{Li}$ & [183] \\
\hline $\mathrm{Mg}$ & $2-2$ & 1.74 & 650 & Eut & 450 & 19.51 & 18.9 & 9.55 & $\mathrm{Al}_{3} \mathrm{Mg}_{2}$ & [184] \\
\hline $\mathrm{Ca}$ & $2-3$ & 1.55 & 842 & Eut & 616 & 7.68 & 0.05 & 0.07 & $\mathrm{Al}_{4} \mathrm{Ca}$ & [185] \\
\hline $\mathrm{Sr}$ & $2-4$ & 2.64 & 777 & Eut & 654 & $\sim 1.5$ & $<0.05$ & $<0.16$ & $\mathrm{Al}_{4} \mathrm{Sr}$ & [186] \\
\hline $\mathrm{Si}$ & $14-2$ & 2.33 & 1414.6 & Eut & 577 & 12.6 & 1.49 & 1.55 & $\mathrm{Si}$ & [187] \\
\hline \multicolumn{11}{|c|}{ Transition metals } \\
\hline $\mathrm{Ti}$ & $4-3$ & 4.51 & 1670 & Per & 665.4 & - & 0.78 & 1.38 & $\mathrm{Al}_{3} \mathrm{Ti}$ & [188] \\
\hline $\mathrm{Zr}$ & $4-4$ & 6.52 & 1854 & Per & 660.8 & - & 0.08 & 0.28 & $\mathrm{Al}_{3} \mathrm{Zr}$ & [189] \\
\hline $\mathrm{Hf}$ & $4-5$ & 13.3 & 2233 & Per & 662.2 & - & 0.19 & 1.22 & $\mathrm{Al}_{3} \mathrm{Hf}$ & [190] \\
\hline $\mathrm{V}$ & $5-3$ & 6.00 & 1910 & Per & 664 & - & 0.33 & 0.63 & $\mathrm{Al}_{3} \mathrm{~V}$ & {$[191,192]$} \\
\hline $\mathrm{Nb}$ & $5-4$ & 8.57 & 2477 & Per & 661.4 & - & 0.05 & $0.75^{(1)}$ & $\mathrm{Al}_{3} \mathrm{Nb}$ & [193] \\
\hline $\mathrm{Ta}$ & $5-5$ & 16.4 & 3017 & Per & 668.0 & - & 0.04 & 0.27 & $\mathrm{Al}_{3} \mathrm{Ta}$ & [194] \\
\hline $\mathrm{Cr}$ & $6-3$ & 7.15 & 1907 & Per & 661.5 & - & 0.37 & 0.72 & $\mathrm{Al}_{7} \mathrm{Cr}$ & [195] \\
\hline Mo & $6-4$ & 10.2 & 2622 & Per & 661 & - & 0.17 & $0.6^{(1)}$ & $\mathrm{Al}_{12} \mathrm{Mo}$ & {$[193,196]$} \\
\hline $\mathrm{W}$ & $6-5$ & 19.3 & 3414 & Per & $660.5^{(2)}$ & - & 0.18 & $1.2^{(1)}$ & $\mathrm{Al}_{12} \mathrm{~W}$ & [193] \\
\hline $\mathrm{Mn}$ & $7-3$ & 7.3 & 1246 & Eut & 658 & 1.21 & 0.67 & 1.35 & $\mathrm{Al}_{6} \mathrm{Mn}$ & {$[197,198]$} \\
\hline $\mathrm{Fe}$ & $8-3$ & 7.87 & 1538 & Eut & 655 & 1.8 & 0.02 & 0.04 & $\mathrm{Al}_{3} \mathrm{Fe}$ & {$[199,200]$} \\
\hline Co & $9-3$ & 8.86 & 1495 & Eut & 657 & 0.98 & 0.01 & 0.02 & $\mathrm{Al}_{9} \mathrm{Co}_{2}$ & {$[201,202]$} \\
\hline $\mathrm{Ni}$ & $10-3$ & 8.90 & 1455 & Eut & 639.9 & 6.1 & 0.11 & 0.13 & $\mathrm{Al}_{3} \mathrm{Ni}$ & [203] \\
\hline $\mathrm{Cu}$ & $11-3$ & 8.96 & 1084.6 & Eut & 548.2 & 32.7 & 2.33 & 5.67 & $\mathrm{Al}_{2} \mathrm{Cu}$ & [204] \\
\hline $\mathrm{Ag}$ & $11-4$ & 10.5 & 962 & Eut & 566 & 70.58 & 23.8 & 55.53 & $\mathrm{Al}_{2} \mathrm{Ag}$ & [205] \\
\hline $\mathrm{Zn}$ & $12-3$ & 7.14 & 419.5 & Eut & 277 & 77.7 & 67 & 83 & $\mathrm{Zn}$ & {$[206,207]$} \\
\hline \multicolumn{11}{|c|}{ Rare earth metals } \\
\hline Sc & $3-3$ & 2.99 & 1541 & Eut & 660 & 0.47 & 0.23 & 0.38 & $\mathrm{Al}_{3} \mathrm{Sc}$ & [208] \\
\hline$Y$ & $3-4$ & 4.47 & 1522 & Eut & 639 & 9.25 & 0.05 & 0.16 & $\mathrm{Al}_{3} \mathrm{Y}$ & [209] \\
\hline $\mathrm{La}$ & Lan & 6.15 & 920 & Eut & 628 & 15.7 & 0.01 & 0.05 & $\mathrm{Al}_{11} \mathrm{La}_{3}$ & {$[210,211]$} \\
\hline $\mathrm{Ce}$ & Lan & 6.77 & 799 & Eut & 644.5 & 10.6 & $\sim 0.01$ & $\sim 0.05$ & $\mathrm{Al}_{11} \mathrm{Ce}_{3}$ & {$[124,212]$} \\
\hline $\mathrm{Nd}$ & Lan & 7.01 & 1024 & Eut & 641 & $\sim 12$ & $<0.2$ & 0.04 & $\mathrm{Al}_{11} \mathrm{Nd}_{3}$ & {$[213,214]$} \\
\hline Er & Lan & 9.07 & 1529 & Eut & 655 & $\sim 6$ & $<0.05$ & $<0.3$ & $\mathrm{Al}_{3} \mathrm{Er}$ & {$[100,200]$} \\
\hline $\mathrm{Yb}$ & Lan & 6.90 & 824 & Eut & 625 & 21.1 & 0.02 & 0.16 & $\mathrm{Al}_{3} \mathrm{Yb}$ & [100] \\
\hline Th & Lan & 11.7 & 1750 & Eut & 630 & 20.44 & 0 & 0 & $\mathrm{Al}_{7} \mathrm{Th}_{2}$ & [215] \\
\hline
\end{tabular}

(1) supersaturated, cooling rate $10^{3}-10^{4} \mathrm{deg} / \mathrm{s}$; (2) aluminum melting point- $660.452{ }^{\circ} \mathrm{C}$; (3) Type of the binary Al-X phase diagram: Eut—eutectic reaction, Per-peritectic reaction. 


\section{References}

1. Starke, E.; Staley, J. Application of modern aluminum alloys to aircraft. Prog. Aerosp. Sci. 1996, 32, 131-172. [CrossRef]

2. Czerwinski, F.; Kasprzak, W.; Sediako, D.; Emadi, D.; Shaha, S.; Friedman, J.; Chen, D. High-temperature aluminum alloys for automotive powertrains. Adv. Mater. Process. 2016, 174, 16-20.

3. Matthews, S. Thermal Stability of Solid Solution Strengthened High. Performance Alloys; Cabot Corporation, Technology Division: Kokomo, Indiana, 1974; pp. 215-226.

4. Farrell, K. Assessment of Aluminum Structural Materials for Service within the ANS Reflector Vessel ORNL/TM-13049; ORNL/US Department of Energy: Oak Ridge, TN, USA, 1995.

5. Boeing Commercial Airplanes. Boeing. Available online: https://www.boeing.com/commercial/737ng/ (accessed on 18 June 2020).

6. Ishiko, D.; Kawahara, Y.; Maeguchi, T.; Yamamoto, R.; Kishimoto, J. Mechanical Properties of Aluminum Alloys for Transport and Storage Casks. Mitsubishi Heavy Industry Ltd. Available online: https://www-pub. iaea.org/iaeameetings/cn226p/Session4/ID78Kishimoto.pdf (accessed on 15 June 2020).

7. Czerwinski, F.; Birsan, G.; Benkel, F.; Kasprzak, W.; Walker, M.; Smith, J.; Trinowski, D.; Mousalem, I. Developing casting core technology for high pressure die casting. Adv. Mater. Process. 2017, 175, 18-20.

8. Polmear, I.; Pons, G.; Barbaux, Y.; Octor, H.; Sanchez, C.; Morton, A.; Borbidge, W.; Rogers, S.A. After Concorde: Evaluation of creep resistant Al-Cu-Mg-Ag alloys. J. Mater. Sci. Technol. 2013, 15, 861-868. [CrossRef]

9. Tanaka, T.; Kamitakahara, Y. Highly Heat-Resistant Aluminum Alloy “KS2000”. KOBELCO Technol. Rev. 2017, 35, 28-33.

10. Summers, P.; Chen, Y.; Rippe, C.; Allen, B.; Mouritz, A.; Case, S.; Lattimer, B. Overview of aluminum alloy mechanical properties during and after fires. Fire Sci. Rev. 2015, 4, 3. [CrossRef]

11. Coker, E. The Oxidation of Aluminum at High. In Temperature Studied by Thermogravimetric Analysis and Differential Scanning Calorimetry; SAND2013-8424; Sandia National Laboratories: Albuquerque, NM, USA, 2013.

12. Czerwinski, F. Controlling the ignition and flammability of magnesium for aerospace applications. Corros. Sci. 2014, 86, 1-16. [CrossRef]

13. Czerwinski, F. The reactive element effect on high temperature oxidation of magnesium. Int. Mater. Rev. 2015, 59, 264-296. [CrossRef]

14. Smeltzer, W.W. Oxidation of an aluminum 3pct magnesium alloy in the temperature range $200-250^{\circ} \mathrm{C}$. J. Electrochem. Soc. 1958, 105, 67-71. [CrossRef]

15. Tenorio, J.; Espinosa, D. High-temperature oxidation of Al-Mg alloys. Oxid. Met. 2000, 53, 361-373. [CrossRef]

16. Maeguchi, T.; Kawahara, Y.; Yamamoto, R.; Hase, T. Study for evaluation method of design strength of aluminum alloy for basket material. In Proceedings of the 19-th International Symposium on the Packaging and Transportation of Radioactive Materials PATRAM 2019, New Orleans, LA, USA, 4-9 August 2019.

17. Farrell, K.; King, R.; Jostons, A. Examination of Irradiated 6061 Alumuminum HFIR Target. Holder ORNL-TM-4139; US Atomic Energy Commissiony: Oak Ridge, TN, USA, 1973.

18. Mostovshchikov, A.; Ilyin, A.; Chumerin, P. The influence of microwave radiation on the thermal stability of aluminum nanopowder. Tech. Phys. Lett. 2016, 42, 344-346. [CrossRef]

19. Lavernia, E.; Srivatsan, T.; Mohamed, F. Strength, deformation, fracture behaviour and ductility of aluminium-lithium alloys. J. Mater. Sci. 1990, 25, 1137-1158. [CrossRef]

20. Dieter, G. Mechanical Metallurgy; McGraw-Hill Inc.: New York, NY, USA, 1976.

21. Friedel, J. Dislocation in Crystals; Pergamon Press: London, UK, 1967.

22. Marthinsen, K.; Nes, E. A general model for metal plasticity. Mater. Sci. Eng. A 1997, 234-236, 1095-1998. [CrossRef]

23. Embury, J.; Lloyd, D.; Ramachandran, R. 22-Strengthening mechanisms in aluminum alloys. Treatise Mater. Sci. Technol. 1989, 31, 579-601.

24. Furukawa, M.; Miura, Y.; Nemoto, M. Strengthening mechanisms in Al-Li alloys containing coherent ordered precipitates. Trans. Jpn. Inst. Met. 1985, 26, 230-235. [CrossRef] 
25. Wang, Z.; Qu, R.; Scudino, S.; Sun, B.; Prashanth, K.; Luzgin, D.; Eckert, J. Hybrid nanostructured aluminum alloy with super-high strength. NPG Asia Mater. 2015, 7, e229. [CrossRef]

26. Abd El-Aty, A.; Xu, Y.; Guo, X.; Zhang, S.H.; Ma, Y.; Chen, D. Strengtheing mechanism, deformation behavior and anisotropic mechanical properties of Al-Li alloys: A review. J. Adv. Res. 2018, 10, 49-67. [CrossRef]

27. Srivatsan, T.; Lavernia, E.; Prasad, E.; Kutumbaro, V. Quasi-static strength deformation and fracture behavior of AL-Li alloys. In Aluminum-Lithium Alloys:Processing, Properties, and Applications; Prasad, E., Gokhale, E., Wanhill, H., Eds.; Butterworth-Heinemann, Elsevier: Oxford, UK, 2014; pp. 305-339.

28. Qiao, X.; Gao, N.; Starink, M. A model of grain refinement and strengthening of Al alloys due to cold severe plastic deformation. Phil. Mag. 2012, 92, 446-470. [CrossRef]

29. Wen, H.; Hu, T.; Topping, T.D.; Isheim, D.; Seidman, D.N.; Lavernia, E.J.; Schoenung, J.M. Mechanical behavior and strengthening mechanisms in ultrafine grain precipitation-strengthened aluminum alloy. Acta Mater. 2014, 62, 141-155.

30. Connelly, N.; Hartshorn, R.; Damhus, T.; Hutton, A. Nomenclature of Inorganic Chemistry: IUPAC Recommendations 2005; Nomenclature of Inorganic Chemistry; IUPAC International Union of Pure and Applied Chemistry, RSC Publishing: Norfolk, UK, 2005; p. 51.

31. Wells, W.; Wells, V. Patty's Toxicology, The Lanthanides, Rare Earth Metals; John Wiley \& Sons, Inc.: Hoboken, NJ, USA, 2001.

32. Lundy, T.; Murdock, J. Diffusion of Al26 and Mn54 in aluminum. J. Appl. Phys. 1962, 33, 1671. [CrossRef]

33. Messer, R.; Dais, S.; Wolf, D. Detection of vacancy-induced self-diffusion by rotating spin-lattice relaxation in aluminum. In Proceedings of the 18th Ampere Congress, Nottingham, England, 9-14 September 1974; Allen, P.S., Andrew, E.R., Bates, C.A., Eds.; North Holalnd Publishing: Amsterdam, The Netherlands, 1975; pp. 327-328.

34. Volin, T.; Balluffi, R. Annealing kinetics of voids and the Self-diffusion coefficient in aluminum. Phys. Status Solidi 1968, 25, 163. [CrossRef]

35. Fujikawa, S.; Hirano, K.; Fukushima, Y. Diffusion of silicon in aluminum. Metall. Trans. A 1978, 9, $1811-1815$. [CrossRef]

36. Mantina, M.; Shang, S.; Wang, Y.; Chen, L.; Liu, Z. 3d transition metal impurities in aluminum: A first-principles study. Phys. Rev. B 2009, 80, 184111. [CrossRef]

37. Neumann, G.; Tuijn, C. Self-Diffusion and Impurity Diffusion in Pure Metals: Handbook of Experimental Data; Pergamon Materials Series 14; Pergamon: Amsterdam, The Netherlands, 2009.

38. Hood, G. The diffusion of iron in aluminium. Philos. Mag. J. Theor. Exp. Appl. Phys. 1970, 21, 305-328. [CrossRef]

39. Murarka, S.; Agarwala, R. Diffusion of Rare Elements in Aluminum; Tech. Rep. 368; Bhabha Atomic Research Center (Indian Atomic Energy Commision): Bombay, India, 1968.

40. Schwind, M.; Agren, J. A random walk approach to Ostwald's ripening. Acta Mater. 2001, 49, 3821-3828. [CrossRef]

41. Watanabe, C.; Kondo, T.; Monzen, R. Coarsening of Al3Sc precipitates in an Al-0.28 Wt Pct Sc alloy. Metall. Mater. Trans. A 2004, 35, 3003-3008. [CrossRef]

42. Lifshitz, I.; Slyouzov, V. The kinetics of precipitation from supersaturated solid solutions. J. Phys. Chem. Solids 1961, 19, 35. [CrossRef]

43. Wagner, C. Theorie der Alterung von Niederschlagen durch Umlusen (Ostwald-Reifung). Zeitung der Electrochemie 1961, 65, 581.

44. Marder, M. Correlations and Ostwald ripening. Phys. Rev. A 1987, 36, 858-874. [CrossRef]

45. Tran, K.; Salamanca-Riba, L.; Chiou, W. In situ elevated temperature transmission electron microscopy of sensitized aluminum-magnesium alloy treated by ultrasonic impact treatment. J. Mater. Res. 2014, 29, 1456-1462. [CrossRef]

46. Feist, M. Thermal analysis: Basics, applications, and benefit. Chem. Texts 2015, 1, 1-12. [CrossRef]

47. Akinrinlola, B.; Gauvin, R.; Blais, C.; Brochu, M. Thermal stability of cryomilled Al-Mg-Er powders. J. Nanomater. 2017, 2017, 6348569. [CrossRef]

48. Deng, C.; Liu, Z.; Zhou, J.; Hou, Y. Study on thermal stability of 2524 aluminum alloy. Trans. Mater. Heat Treat. 2009, 30, 87-89.

49. Shaha, S.; Czerwinski, F.; Kasprzak, W.; Friedman, J.; Chen, D. Thermal stability of (AlSi) $)_{x}(\mathrm{ZrVTi})$ intermetallic phases in the Al-Si-Cu-Mg cast alloy with additions of Ti, V, and Zr. Thermochim. Acta 2014, 595, 11-16. [CrossRef] 
50. Sediako, D.; Kasprzak, W.; Czerwinski, F.; Nabawy, A.; Farkoosh, A. High temperature creep evolution in Al-Si alloys developed for automotive powertrain applications: A neutron in-situ study on hkl-plane creep response. In Light Metals 2016; Williams, E., Ed.; Springer: Cham, Switzerland, 2016.

51. Kasprzak, W.; Czerwinski, F.; Niewczas, M.; Chen, D.L. Correlating hardness retention and phase transformations of $\mathrm{Al}$ and $\mathrm{Mg}$ cast alloys for aerospace applications. J. Mater. Eng. Perform. 2015, 24, 1365. [CrossRef]

52. Vlach, M.; Stulikova, I.; Smolna, B.; Zaludova, N.; Cerna, J. Phase transformation of isochronally annealed mould-cast and cold-rolled Al-Sc-Zr based alloy. J. Alloys Compd. 2010, 492, 143-148. [CrossRef]

53. Garb, C.; Leitner, M.; Grun, F. Effect of elevated temperature on the fatigue strength of cast AlSi8Cu3 aluminum alloy. Proceedia Struct. Integr. 2017, 7, 497-504. [CrossRef]

54. Fadhel, E. Effect of the elevated temperature on fatigue behavior of aluminum alloy AA7075. Journal of Univ. Babylon Eng. Sci. 2018, 26, 256-263.

55. Suresh, S. Fatigue of Materials; Cambridge University Press: Cambridge, UK, 1998.

56. Maeguchi, T.; Kawahara, Y.; Yamamoto, R.; Sakma, K.; Tamaki, H. Effects of long-term aging and annealing on mechanical properties of A3004-H112 aaluminum alloy. J. Jpn. Inst. Light Met. 2018, 68, 653-659. [CrossRef]

57. Robinson, J.; Cudd, R.; Evans, J. Creep resistant aluminium alloys and their applications. Mater. Sci. Technol. 2003, 19, 143-155. [CrossRef]

58. Dumitraschkiewitz, D.; Uggowitzer, P.; Gerstl, S.; Loffler, J.; Pogatscher, S. Size-dependent diffusion controls natural aging in aluminium alloys. Nat. Commun. 2019, 10, 4746. [CrossRef] [PubMed]

59. Zakharov, V. Aluminum alloys: Some problems of the use of aluminum-lithium alloys. Met. Sci. Heat Treat. 2003, 20, 49-54. [CrossRef]

60. Shneider, G. Stability of supersaturated solid solution of aluminum-lithium alloy 1470. Met. Sci. Heat Treat. 1998, 40, 294-298. [CrossRef]

61. Zakharov, V. Thermal stability of Al-Li alloys. Met. Sci. Heat Treat. 1999, 41, 39-43. [CrossRef]

62. Rioja, R.; Liu, J. The evolution of Al-Li base products for aeropace and space applications. Metall. Mater. Trans. A 2012, 43, 3325-3337. [CrossRef]

63. Noble, B.; Harris, S.; Katsikis, S.; Dinsdale, K. Low temperature thrmal stability of quarternary Al-Li-Cu-Mg alloys. Mater. Sci. Forum 2006, 519-521, 209-214. [CrossRef]

64. Wanhill, R. Chapter 15-Aerospace applications of aluminum-lithium alloys. In Aluminum-Lithium Alloys_Processing, Properties, and Applications; Butterworth-Heinemann: Amsterdam, The Netherlands, 2014; pp. 503-535.

65. Balducci, E.; Ceschini, L.; Wenner, S.; Holmestad, R. Thermal stability of the lightweight 2099 Al-Cu-Li alloy: Tensile tests and microstructural investigations after overaging. Mater. Des. 2017, 119, 54-64. [CrossRef]

66. Yu, X.; Zhao, Z.; Shi, D.; Dai, H.; Sun, J.; Dong, X. Enhanced high-temperature mechanical properties of $\mathrm{Al}-\mathrm{Cu}-\mathrm{Li}$ alloy through $\mathrm{T} 1$ coarsening inhibition and Ce-containing intermetallic refinement. Materials 2019, 12, 1251. [CrossRef]

67. Ortiz, D.; Brown, J.; Abdelshehid, M.; Clark, R. The effects of prolonged thermal exposure on the mechanical properties and fracture toughness of C458 aluminum-lithium alloy. Eng. Failure Anal. 2006, 13, 170-180. [CrossRef]

68. Inoue, A. Amorphous, nanoquasicrystalline and nanocrystalline alloys in Al-based systems. Prog. Mater. Sci. 1998, 43, 365-520. [CrossRef]

69. Wilson, T.; Bai, J.; Choo, H. Enhanced thermal stability of amorphous aluminum alloys through microalloying. Mater. Lett. 2008, 62, 3790-3792. [CrossRef]

70. Kim, S.; Lee, G.; Park, G.; Kim, H.; Lee, A.; Lee, M. High strength nanostructured Al-based alloys through optimized processing of rapidly quenched amorphous precursors. Sci. Rep. 2018, 8, 1090. [CrossRef] [PubMed]

71. Asgharzadeh, H.; McQueen, H. Grain growth and stabilisation of nanostructured aluminium at high temperatures: Review. Mater. Scie Technol. 2015, 31, 1016-1034. [CrossRef]

72. Peng, H.; Gong, M.; Chen, Y.; Liu, F. Thermal stability of nanocrystalline materials: Thermodynamics and kinetics. Inter. Mater. Rev. 2017, 62, 303-333. [CrossRef]

73. Tan, G.; Kalay, Y.; Gur, C. Long-term thermal stability of Equal Channel Angular Pressed 2024 aluminum alloy. Mater. Sci. Eng. A 2016, 677, 307-315. [CrossRef] 
74. Zhang, F.; Levine, L.; Allen, A.; Campbell, C.; Creuzinger, A.; Kazanteva, N.; Ilavsky, J. In situ structural characterization of ageing kinetics in aluminum alloy 2024 across angstrom-to-micrometer length scales. Acta Mater. 2016, 111, 385-398. [CrossRef]

75. Kumar, N.; Mishra, R. Thermal stability of friction stir processed ultrafine grained Al-Mg-Sc alloy. Mater. Charact. 2012, 74, 1-10. [CrossRef]

76. Loginova, I.; Solonin, A.; Prosviryakov, A.; Pozdnyakov, A.; Ryazantseva, M.; Churyumov, A. Development of heat resistant aluminum alloys for electrical engineering purposes based on the A-Fe-Si system. Met. Sci. Heat Treat. 2018, 60, 360. [CrossRef]

77. Baig, M.; Ammar, H.; Seikh, A.; Mohammed, J.; Al-Mufadi, F.; Alaboodi, A. Thermal stability of nanocrystalline Al-10Fe-5Cr bulk alloy. Trans. Nonferrous Met. Soc. China 2019, 29, 242-252. [CrossRef]

78. Nikitina, M.; Islamgaliev, R.K.; Kamalov, A.F. Thermal stability of the ultrafine grained Al-Cu-Mg-Si aluminum alloy. Rev. Adv. Mater. Sci. 2010, 25, 74-81.

79. Han, J.; Zhu, Z.; Li, H.; Gao, C. Microstructural evolution, mechanical property and thermal stability of Al-Li 2198-T8 alloy processed by high pressure torsion. Mater. Sci. Eng. A 2016, 651, 435-441. [CrossRef]

80. Raj, J.; Shanmugavel, B. Thermal stability of ultrafine grained AA8090 Al-Li alloy processed by repetitive corrugation and straightening. J. Mater. Res. Technol. 2019, 8, 3251-3260.

81. Cg-Adapco.Com. Available online: www.cd-adapco.com (accessed on 20 October 2015).

82. Lu, Y.; Zhang, X.; Xiang, P.; Dong, D. Analysis of thermal temperature fields and thermal stress under steady temperature field of diesel engine piston. Appl. Therm. Eng. 2017, 113, 796-812. [CrossRef]

83. Knipling, K.; Dunand, D.; Seidman, D. Criteria for developing castable, creep-resistant aluminum-based alloys - A review. Int. J. Mater. Res. 2006, 97, 246-265. [CrossRef]

84. Pouget, G.; Sigli, C. Thermal stability of Al-Cu-Mg alloys. Mater. Sci. Forum 2014, 794-796, 691-696.

85. Pouget, G.; Sigli, C. Understanding of the thermal stability of Al-Cu-Mg aluminum alloys. MATEC Web Conf. 2013, 7, 01015. [CrossRef]

86. Gable, B.; Shiflet, G.; Starke, E. Alloy development for the enhanced stability of $\Omega$ precipitates in Al-Cu-Mg-Ag alloys. Metall. Mat. Trans. A 2006, 37, 1091-1105. [CrossRef]

87. Liu, X.; Pan, Q.; Lu, Z.; Li, W. Thermal stability of Al-Cu-Mg-Ag heat-resistant alloy. Chin. J. Nonferrous Met. 2011, 21, 1244-1251.

88. Nikulin, I.; Kipelova, A.; Gazizov, M.; Teleshov, V.; Zakharov, V.; Kaibyshev, R. Novel Al-Cu-Mg-Ag alloy for high temperature applications. In Proceedings of the 12th International Conference on Aluminum Alloys, Yokohama, Japan, 5-9 September 2010.

89. Nogita, K.; McDonalds, S.D.; Dahle, A.K. Eutectic modification of Al-Si alloys with rare earth metals. Mater. Trans. 2004, 45, 323-326. [CrossRef]

90. Li, Y.; Liu, Z.; Zhou, J.; Xia, Q. Microstructure and mechanical properties of Al-Cu-Mg-Ag alloyed with Ce. Trans. Nonferrous Met. Soc. China 2007, 17, s266-s270.

91. Alkahtani, S.; Elgallad, E.; Tash, M.; Samuel, A.; Samuel, F. Effect of rare earth metals on the microstructure of Al-Si based alloys. Materials 2016, 9, 45. [CrossRef] [PubMed]

92. Matveeva, I.; Dovzhenko, N.; Sidelnikov, S. Development and research of new aluminium alloys with transition and rare-earth metals and equipment for production of wire for electrotechnical applications by methods of combined processing. In Proceedings of the Symposia Light Metals 2013; John Wiley \& Sons Inc.: Hoboken, NJ, USA, 2013; pp. 443-447.

93. Hu, Z.; Yan, H.; Rao, Y. Effects of samarium addition on microstructure and mechanical properties of as-cast Al-Si-Cu alloy. Trans. Nonferrous Met. Soc. China 2013, 23, 3228-3234. [CrossRef]

94. Røyset, J.; Ryum, N. Scandium in aluminium alloys. Inter. Mater. Rev. 2005, 50, 19-44. [CrossRef]

95. Czerwinski, F. Assessing differences between the use of cerium and scandium in aluminum alloying. Mater. Sci Technol 2020, 36, 255-263. [CrossRef]

96. Czerwinski, F. Cerium in aluminum alloys. J. Mater. Sci. 2020, 55, 24-72. [CrossRef]

97. Xu, P.; Jiang, F.; Tang, Z.; Yan, N.; Jiang, J.; Xu, X.; Peng, Y. Coarsening of $\mathrm{Al}_{3} \mathrm{Sc}$ precipitates in $\mathrm{Al}-\mathrm{Mg}-\mathrm{Sc}$ alloys. J. Alloys Compd. 2019, 781, 209-215. [CrossRef]

98. Marquis, E.; Seidman, D. Coarsening kinetics of nanoscale Al3Sc precipitates in an Al-Mg-Sc alloy. Acta Mater. 2005, 53, 4259-4268. [CrossRef]

99. Marquis, E.; Seidman, D. Nanoscale structural evolution of $\mathrm{Al}_{3} \mathrm{Sc}$ precipitates in $\mathrm{Al}(\mathrm{Sc})$ alloys. Acta Mater. 2001, 49, 1909-1919. [CrossRef] 
100. Van Dalen, M.; Karnesky, R.; Cabotaje, J.; Dunand, D.; Seidman, D. Erbium and ytterbium solubilities and diffusivities in aluminum as determined by nanoscale characterization of precipitates. Acta Mater. 2009, 57, 4081-4089. [CrossRef]

101. Melotti, F.; Dustan, A.; Hirst, T.; Griffiths, W. Effects of Ce on the thermal stability of the $\Omega$ phase in a cast aluminum metal matrix composite. In Advances in the Science and Engineering of Casting Solidification; Nastac, L., Liu, B., Fredriksson, H., Lacaze, J., Hong, P., Catalina, A., Buhring-Polachek, A., Monroe, C., Sabu, A., Ruxanda, R., et al., Eds.; Springer: Cham, Switzerland, 2015.

102. Ramirez, A.; Beltran, F.; Yanez-Limon, J.; Vorobiev, Y. Effects of porosity on the thermal properties of a 380-aluminum alloy. J. Mater. Res. 1999, 14, 3901-3906. [CrossRef]

103. Zakharov, V. About alloying of aluminum alloys with transition metals. Met. Sci. Heat Treat. 2017, 59, 67-91. [CrossRef]

104. Toropova, L.; Eskin, D.; Kharakterova, M.; Dobatkina, T. Advanced Aluminum Alloys Containing Scandium: Structure and Properties; Taylor \& Francis: London, UK; New York, NY, USA, 1998.

105. Shaha, S.K.; Czerwinski, F.; Kasprzak, W.; Chen, D.L. Tensile and compressive deformation behavior of the Al-Si-Cu-Mg cast alloy with additions of Zr, V and Ti. Mater. Des. 2014, 59, 352-358. [CrossRef]

106. Shaha, S.K.; Czerwinski, F.; Kasprzak, W.; Friedman, J.; Chen, D.L. Effect of solidification rate and loading mode on deformation behavior of cast Al-Si-Cu-Mg alloy with additions of transition metals, 2015. Mater. Sci. Eng. A 2015, 636, 361-372. [CrossRef]

107. Shaha, S.K.; Czerwinski, F.; Kasprzak, W.; Friedman, J.; Chen, D.L. Improving high-temperature tensile and low-cycle fatigue behavior of $\mathrm{Al}-\mathrm{Si}-\mathrm{Cu}-\mathrm{Mg}$ alloys through micro-additions of Ti, $\mathrm{V}$ and $\mathrm{Zr}$. Metall. Mater. Trans. A 2015, 46A, 363-378. [CrossRef]

108. Yang, Y.; Zhong, S.-Y.; Chen, Z.; Wang, M.; Ma, N.; Wang, H. Effect of Cr content and heat-treatment on the high temperature strength of eutectic Al-Si alloys. J. Alloys Compd. 2015, 63-69, 647. [CrossRef]

109. Shaha, S.K.; Czerwinski, F.; Kasprzak, W.; Friedman, J.; Chen, D.L. Ageing characteristics and high-temperature tensile properties of $\mathrm{Al}-\mathrm{Si}-\mathrm{Cu}-\mathrm{Mg}$ alloys with micro-additions of $\mathrm{Cr}, \mathrm{Ti}, \mathrm{V}$ and $\mathrm{Zr}$. Mater. Sci. Eng. A 2016, 652, 353-364. [CrossRef]

110. Farkoosh, A.; Chen, X.; Pekguleryulez, M. Dispersoid strengthening of a high temperature AlSiCuMg alloy via Mo addition. Mater. Sci. Eng. A 2015, 620,181-189. [CrossRef]

111. Shaha, S.K.; Czerwinski, F.; Kasprzak, W.; Friedman, J.; Chen, D.L. Ageing characteristics and high-temperature tensile properties of $\mathrm{Al}-\mathrm{Si}-\mathrm{Cu}-\mathrm{Mg}$ alloys with micro-additions of Mo and Mn. Mater. Sci. Eng. A 2017, 684, 726-736. [CrossRef]

112. Fan, Y.; Makhlouf, M. The $\mathrm{Al}-\mathrm{Al}_{3} \mathrm{Ni}$ eutectic reaction: Crystallography and mechanism of formation. Metall. Mater. Trans. A 2015, 46, 3808-3812. [CrossRef]

113. Suwanpreecha, C.; Pandee, P.; Patakham, U.; Limmaneevichitr, C. New generation of eutectic Al-Ni casting alloys for elevated temperature services. Mater. Sci. Eng. A 2018, 709, 46-54. [CrossRef]

114. Budurov, S.; Yaneva, S.; Stoichev, N.; Van Ba, P. Eutectic crystallization of aluminum nickel alloys. Cryst. Res. Technol. 1975, 10, 505-510.

115. Suwanpreecha, C.; Toinin, J.; Pandee, P.; Dunand, D.; Limmaneevichitr, C. Isothermal aging of Al-Ni-Sc alloy containing $\mathrm{Al}_{3} \mathrm{Ni}$ microfibers and $\mathrm{Al}_{3} \mathrm{Sc}$ nanoprecipitates. J. Met., Mater. Miner. 2019, 29, 37-41.

116. Suwanpreecha, C.; Toinin, P.; Michi, R.; Pandee, P.; Dunand, D.; Limmaneevichitra, C. Strengthening mechanisms in AlNiSc alloys containing $\mathrm{Al}_{3} \mathrm{Ni}$ microfibers and $\mathrm{Al}_{3} \mathrm{Sc}$ nanoprecipitates. Acta Mater. 2019, 164, 334-346. [CrossRef]

117. Amenova, A.; Belov, N.; Smagulov, D.; Toleuva, A. Perspective high strength aluminium alloys of new generation based on Al-Ni-Mn-Fe-Si-Zr system. Mater. Res. Innov. 2014, 18 (Suppl. 1), S1-S50. [CrossRef]

118. Barth, O. Die Erhohung der chemischen Widerstandsfahigkeit mechanisch noch gut bearbeitbarer, fur Konstructionszwecke verwendbarer Legierungen; Teil II: Uber den Einfluss des Cers auf die mechanischen und chemischen Eigenschaften des Aluminiums (in German). Metallurgie Zeitschrift fur die Gesamte Huttenkunde 1912, 8, 261-276.

119. Gillett, H.; Schnee, V. Cerium in aluminum alloys. Ind. Eng. Chem. 1923, 15, 709-711. [CrossRef]

120. Schulte, J. Uber den Einfluss des Cers auf die Eigenschafter des Aluminiums. Metall und Erz 1921, 18, $236-240$.

121. Meissner, K.L. Metall und Erz 1924, 21, 42. 
122. Glauner, R.; Lehl, H.; May, B.; Woitinek, H.; Kadniner, H.J. Gmelins Handbuch der Anorganischen Chemie, 8 Auflage, Aluminium: Teil A-Lieferung 5. Legierungen von Aluminium mit Zink bis Uran; Legierungen mit Cer page 818-821; Springer: Berlin/Heidelberg, Germany, 1937.

123. Weiss, D. Improved high temperature aluminum alloys containing cerium. J. Mater. Eng. Perform. 2019, 28, 1903-1908. [CrossRef]

124. Czerwinski, F; Shalchi Amirkhiz, B. On the Al-Al11Ce3 eutectic transformation in aluminum-cerium binary alloys. Metall. Mater. Trans. A 2020, in press.

125. Waterloo, G.; Jones, H. Microstructure and thermal stability of melt-spun Al-Nd and Al-Ce alloy ribbons. J. Mater. Sci. 1996, 31, 2301-2310. [CrossRef]

126. Zhang, Z.; Bian, X.; Wang, Y. Microstructural characterization and microhardness of rapidly solidified Al-Ce alloys. Z. Metallkunde 2002, 93, 578-584. [CrossRef]

127. Czerwinski, F. Modern aspects of liquid metal engineering. Metall. Mater. Trans. B 2017, 48, 367-393. [CrossRef]

128. Czerwinski, F.; Birsan, G. Gas-Enhanced Ultra-High Shear Mixing: A concept and applications. Metall. Mater. Trans. B 2017, 48, 983-992. [CrossRef]

129. Czerwinski, F.; Benkel, F.; Birsan, G. Gas-Enhanced Ultrahigh-Shear Mixing:An application to molten aluminum alloys. Metall. Mater. Trans. B 2020, 51, 1079-1087. [CrossRef]

130. Wang, L.; Qi, R.; Ye, B.; Bai, Y.; Huang, R.; Jiang, H.; Ding, W. Improved tensile strength of Al-5Ce alloy by permanent magnet stirring. Metall. Mater. Trans. A 2020, 51, 1972-1977. [CrossRef]

131. Fine, M.; Starke, E. Rapidly Solidified Powder Aluminum Alloya; ASTM: Philadelphia, PA, USA, 1986.

132. Krainikov, A.; Neikov, O. Rapidly solidified high-temperature aluminum alloys. II. Mechanical properties. Powder Metall. Met. Ceram. 2013, 51, 554-565. [CrossRef]

133. Ayer, A.; Angers, L.; Mueller, R.; Scanlon, J.; Klein, C. Microstructural characterization of the dispersed phases in Al-Ce-Fe system. Metall. Trans. A 1988, 19, 1645-1656. [CrossRef]

134. Yuan, Y.; Wang, Z.; Zheng, R.; Hao, X.; Ameyama, K.; Ma, C. Effect of mechanical alloying and sintering process on microstructure and mechanical properties of Al-Ni-Y-Co-La alloy. Trans. Nonferrous Met. Soc. China 2014, 24, 2251-2257. [CrossRef]

135. Kumar, S.; Singh, S.; Kumar, J.; Murtaza, K. Synthesis and characterization of Al-alloy by mechanical alloying. Mater. Today: Proc. 2018, 5, 3237-3242. [CrossRef]

136. Kieper, M.; Blaz, L.; Sugamata, M. Effect of magnesium addition on properties of Al based composite reinforced with fine $\mathrm{NiO}$ particles. Archiv. Metall. Mater. 2014, 59, 431-435. [CrossRef]

137. Koo, J.; Ortiz, R.; Ong, B.; Wu, H. Laser additive manufacturing. In Materials, Design, Technologies, and Applications; Woodhead Publishing: Cambridge, UK, 2017; pp. 205-235.

138. Kurnsteiner, P.; Bajaj, P.; Gupta, A.; Benjamin, W.; Weisheit, A.; Li, X.; Leinebach, C.; Gault, B.; Jagle, E.; Raabe, D. Control of thermally stable core-shell nano-precipitates in additively manufactured Al-Sc-Zr alloys. Addit. Manuf. 2020, 32, 100910. [CrossRef]

139. Chen, B.; Xi, X.; Tan, C.; Song, X. Recent progress in laser additive manufacturing of aluminum matrix composites. Curr. Opin. Chem. Eng. 2020, 28, 28-35. [CrossRef]

140. Lin, T.; Cao, C.; Sokoluk, M.; Jiang, L.; Wang, X.; Schoenung, J. Aluminum with dispersed nanoparticles by laser additive manufacturing. Nat. Commun. 2019, 10, 4124. [CrossRef]

141. Li, Y.; Gu, D.; Zhang, H.; Xi, L. Effect of Trace Addition of Ceramic on Microstructure development and mechanical properties of selective laser melted AlSi10Mg alloy. Chin. J. Mech. Eng. (Engl. Ed.) 2020, 33, 33. [CrossRef]

142. Jia, Q.; Rometsch, P.; Cao, S.; Zhang, K.; Wu, X. Towards a high strength aluminium alloy development methodology for selective laser melting. Mater. Des. 2019, 174, 107775. [CrossRef]

143. Uzan, N.; Ramati, S.; Shneck, R.; Frage, N.; Yeheskel, O. On the effect of shot peening onfatique resistance of AlSi10Mg specimens manufactured by additive manufacturring. Addit. Manuf. 2018, 21, 458-464.

144. Yamasaki, S.; Mitsuhara, O.T.M.; Nakashima, H.; Kusui, J.; Adachi, M. Effect of Fe addition on heat-resistant aluminum alloys produced by selective laser melting. Metals 2019, 9, 468. [CrossRef]

145. Sun, S.; Zheng, L.; Liu, Y.; Liu, J. Characterization of Al-Fe-V-Si heat-resistant aluminum alloy components fabricated by selective laser melting. J. Mater. Res. 2015, 30, 1661-1669. [CrossRef]

146. As Ductile as Titanium, as Light as Aluminium. Available online: https://apworks.de/en/scalmalloy/ (accessed on 24 June 2020). 
147. Kaufman, J. Fire Resistance of Aluminum and Aluminum Alloys and Measuring the Effects of Fire Exposure on the Properties of Aluminum Alloys; ASM International: Materials Park, OH, USA, 2016.

148. Faggiano, B.; De Matteis, G.; Landolfo, R.; Mazzolani, F. Behaviour of aluminum alloy structures under fire. J. Civil Eng. Manag. 2004, 10, 183-190. [CrossRef]

149. Maljaars, J.; Soetens, E.; Katgerman, L. Constitutive model for aluminum alloys exposed to fire conditions. Metall. Mater. Trans. A 2008, 39, 778-789. [CrossRef]

150. Summers, P. Microstructure-based Constitutive Models for Residual Mechanical Behavior of Aluminum. Ph.D. Thesis, Virginia Polytechnic Institute and State University, Blacksburg, VA, USA, 2014.

151. Free, J.; Summers, P.; Lattimer, B.; Case, S. Mechanical properties of 5000 series aluminum alloys following fire exposure. In TMS 2016 145th Annual Meeting E Exhibition; Springer: Cham, Switzerland, 2016; pp. 657-664.

152. Chen, Z.; Lu, J.; Liu, H.; Liao, X. Experimental investigation on the post-fire mechanical properties of structural aluminum alloys 6061-T6 and 7075-T73. Thin Walled Struct. 2016, 106, 187-200. [CrossRef]

153. Dais, S.; Messer, R.; Seeger, A. Nuclear-magnetic-resonance study of self-diffusion in aluminium. Mater. Sci. Forum 1987, 15-18, 419-424. [CrossRef]

154. Mantina, M.; Wang, Y.; Arroyave, R. First-principles calculation of self-diffusion coefficients. Phys. Rev. Lett. 2008, 100, 5901-5904. [CrossRef]

155. Moreau, C.; Allouche, A.; Knystautas, E. Measurements of the diffusion rate of lithium in aluminum at low temperature by elastic recoil detection analysis. J. Appl. Phys. 1985, 58, 4582. [CrossRef]

156. Costas, L. The Diffusion of Lithium in Aluminum; AEC Research and DEvelopment Report DP-813; AEC: Aiken, SC, USA, 1963.

157. Paccagnella, A.; Ottaviani, G.; Fabbri, G.; Ferla, G.; Queirolo, G. Silicon diffusion in aluminium. Thin Solid Films 1985, 128, 217-223. [CrossRef]

158. Mantina, M.; Wang, Y.; Chen, L. First principles impurity diffusion coefficients. Acta Mater. 2009, 57, 4102-4108. [CrossRef]

159. Fujikawa, S.; Hirano, K. Diffusion of $28 \mathrm{Mg}$ in aluminum. Mater. Sci. Eng. 1977, 27, 25-33. [CrossRef]

160. Moreau, G.; Cornet, J.; Calais, D. Acceleration de la diffusion chimique sous irradiation dans le systeme aluminium-magnesium. J. Nucl. Mater. 1971, 38, 197-202. [CrossRef]

161. Du, Y.; Chang, Y.; Huang, B.; Gong, W.; Jin, Z.; Xu, H.; Youa, Z.; Liu, Y.; He, Y.; Xie, F. Diffusion coefficients of some solutes in fcc and liquid Al: Critical evaluation and correlation. Mater. Sci. Eng. A 2003, 363, 140-151. [CrossRef]

162. Verlinden, J.; Gijbbels, R. Impurity diffusion in aluminum as determined from ion-probe mass analysis. Adv. Mass Spectrom 1980, 8A, 485-495.

163. Bergner, D. Diffusion von Fremdelementen in Aluminium. Neue Hutte 1984, 29, 207-217.

164. Marumo, T.; Fujikawa, S.; Hirono, K.J. Diffusion of zirconium in aluminum. J. Jpn. Inst. Met. 1973, 23, 17-25. [CrossRef]

165. Murarka, S.; Anand, M.; Agarwala, R. Diffusion of vanadium in aluminium and nickel. Acta Metall. 1968, 16, 69-72. [CrossRef]

166. Tiwari, G.; Sharma, B. Diffusion of $\mathrm{Nb}$ in Al. Trans. Indian Inst. Met. 1967, 20, 83.

167. Agarwala, R.; Murarka, S.; Anand, M. Diffusion of chromium in aluminium. Acta Metall. 1964, 12, 871-874. [CrossRef]

168. Rummel, G.; Zumkley, T.; Eggersmann, F.K.; Mehrer, H. Diffusion of implanted 3d-transition elements in Aluminium. Part II: Pressure dependence. Z. Metallkd 1995, 86, 131-140.

169. Van Chi, N.; Bergner, D. Diffusion in Metals and Alloys DIMETA-82; Trans Tech Publications: Zuruch, Switzerland, 1983; p. 334.

170. Hood, G.; Schultz, R. The diffusion of manganeese in aluminum. Philos. Mag. J. Theor. Exp. Appl. Phys. 1971, 23, 1479-1489.

171. Hirano, K.; Agarwqala, R.; Cohen, M. Diffusion of iron, nickel and cobalt in aluminum. Acta Metall. 1962, 10, 857-863. [CrossRef]

172. Alexander, W.; Slifkin, L. Diffusion of solutes in aluminum and dilute aluminum alloys. Phys. Rev. B 1970, 1, 3274. [CrossRef]

173. Erdelyi, G.; Beke, D.; Kedves, F.; Godeny, I. Determination of diffusion coefficients of Zn, Co and Ni in aluminium by a resistometric method. Phil. Mag. B 1978, 38, 445-462. [CrossRef]

174. Peterson, N.; Rothman, S. Impurity diffusion in aluminum. Phys. Rev. B 1970, 1, 3264-3273. [CrossRef] 
175. Murphy, J. Interdiffusion in dilute aluminium-copper solid solutions. Acta Metall. 1961, 9, 563-569. [CrossRef]

176. Simonovic, D.; Sluiter, M. Impurity diffusion activation energies in Al from first principles. Phys. Rev. B 2009, 79, 054304. [CrossRef]

177. Hillard, J.; Averbach, B.; Cohen, M. Self and interdiffusion in aluminum-zinc alloys. Acta Metall. 1959, 7 , 86-92. [CrossRef]

178. Fujikawa, S. Diffusion of scandium in aluminum. Kakuriken Kenkyu Hokoku (Japan) 1997, 30, $62-68$.

179. Fujikawa, S. Impurity diffusion of scandium in aluminum. Defect Diffus. Forum 1997, 143-147, 115-120. [CrossRef]

180. Kerkove, M.; Wood, T.; Sanders, P.; Kampe, S.; Swenson, D. The diffusion coefficient of scandium in dilute aluminum-scandium alloys. Metall. Mater. Trans. A 2014, 45, 3800-3805. [CrossRef]

181. Cai, W. Diffusion of cerium in the aluminium lattice. J. Mater. Sci. Lett. 1997, 16, 1824.

182. Ji, C.; Ning, C.; Wang, A.; Yang, J. Yttrium ion implantation in pure aluminum. Surf. Coat. Technol. 1994, 66, 240-244.

183. McAlister, A. The Al-Li (Aluminum-Lithium) system. Bull. Alloy. Phase Diagr. 1982, 3, 177-183. [CrossRef]

184. Landolt-Börstein. New Series IV/5. In Phase Equilibria, Crystallographic and Thermodynamic Data of Binary Alloys; Springer: New York, NY, USA, 1998.

185. Itkin, V.; Alcock, C.; van Ekeren, P.; Oonk, H. The Al-Ca (Aluminum-Calcium) system. Bull. Alloy. Phase Diagrams 1988, 9, 652-657. [CrossRef]

186. Alcock, C.; Itkin, V. The Al-Sr (Aluminum-Strontium) system. Bull. Alloy. Phase Diagr. 1989, 10, 624-630. [CrossRef]

187. Ikhmayies, S. Phase Diagrams of Al-Si System. In Energy Technology; The Minerals, Metals \& Materials Series; Wang, T., Chen, X., Guille, D., Zhang, L., Sun, Z., Wang, C., Haque, N., Howarter, J., Neelamaggham, N., Ikhmayies, S., et al., Eds.; Springer: Cham, Switzerland, 2019.

188. Murray, J. Binary Alloy. Phase Diagrams; Massalski, T.G., Ed.; ASM: Metals Park, OH, USA, 1986; p. 173.

189. Okamoto, H. Al-Zr (Aluminum-Zirconium). J. Phase Equilib. 2002, 23, 455. [CrossRef]

190. Rokhlin, L.; Bochvar, N.; Dobatkina, T. Al-rich portion of the Al-Hf phase diagram. Russ. Metall. (Metally) 2009, 2009, 258-262. [CrossRef]

191. Kenney, D.; Wilhelm, H.; Carlson, O. Aluminum Vanadium System; Ames Laboratory Technical Reports 5.1; Iowa State University: Ames, IA, USA, 1953.

192. Hu, B.; Yao, B.; Wang, J.; Zhao, J.; Min, F.; Du, Y. Thermodynamic assessment of the Al-Mo-V system. J. Min. Metall. Sect. B-Metall. 2017, 53, 95-106. [CrossRef]

193. Fedorov, V.; Elagin, V. Structure and properties of Al-W, Al-Mo, and Al-Nb alloys obtained from granules. Met. Sci. Heat Treat. 1979, 21, 210-212. [CrossRef]

194. Okamoto, H. Al-Ta (Aluminum-Tantalum). J. Phase Equilib. Diffus. 2010, 31, 578-579. [CrossRef]

195. Murray, J. The Al-Cr (aluminum-chromium) system. J. Phase Equilib. 1998, 19, 367. [CrossRef]

196. Saunders, N. The Al-Mo system (aluminum-molybdenum). J. Phase Equilib. 1997, 18, 370. [CrossRef]

197. Godecke, T.K.W. Constitution of the aluminum-manganese system. Z. Metallkd. 1971, 62, 727-732.

198. Asgar-Khan, M.; Medraj, M. Critical evaluation and thermodynamic modeling of the Mg-Mn, Al-Mn and Mg-Al-Mn systems. In Proceedings of the Materials Science and Technology (MS\&T) Conference, Pittsburgh, PA, USA, 5-9 October 2008.

199. Li, X.; Scharf, A.; Hallmeier, M.; Stein, F. The Al-rich part of the Fe-Al phase diagram. J. Phase Equilib. Diffus. 2016, 37, 162-173. [CrossRef]

200. Mondolfo, L. Aluminum Alloys: Structure and Properties; Butterworth: London, UK, 1976; p. 24.

201. McAlister, A. The Al-Co (Aluminum-Cobalt) system. Bull. Alloy. Phase Diagr. 1989, 10, 646-650. [CrossRef]

202. Froes, F.; Kim, Y.; Murthy, S. Rapid solidification of lightweight metal alloys. Mater. Sci. Eng. A 1989, 117, 19-32. [CrossRef]

203. Okamoto, H. Al-Ni (Aluminum-Nickel). J. Phase Equilib. Diffus. 2004, 25, 394. [CrossRef]

204. Massalski, T. The Al-Cu (Aluminum-Copper) system. Bull. Alloy. Phase Diagr. 1980, 1, 27-33. [CrossRef]

205. McAlister, A. The Ag-Al (Silver-Aluminum) system. Bull. Alloy. Phase Diagr. 1987, 8, 526-533. [CrossRef]

206. Murray, J. The Al-Zn (Aluminum-Zinc) system. Bull. Alloy. Phase Diagr. 1983, 4, 55-73. [CrossRef]

207. Gale, W.F.; Totemeier, T.C. (Eds.) Smithells Metals Reference Book, 8th ed.; Elsevier, Butterworth-Heinemann Ltd.: Oxford, UK, 2004; p. 11.

208. Murray, J. The Al-Sc (aluminum-scandium) system. J. Phase Equilib. 1998, 19, 380-384. [CrossRef] 
209. Okamoto, H. Al-Y (Aluminum-Yttrium). J. Phase Equilib. Diffus. 2008, 29, 114. [CrossRef]

210. Foley, J.; Perepezko, J.; Skinner, D. Formation of metastable $\mathrm{L}_{2}-\mathrm{Al}_{3} \mathrm{Y}$ through rapid solidification processing. Mater. Sci. Eng. A 1994, 179-180, 205-209. [CrossRef]

211. Cao, Z.; Kong, G.; Che, C.; Wang, Y.; Peng, H. Experimental investigation of eutectic point in Al-rich Al-La, Al-Ce, Al-Pr and Al-Nd systems. J. Rare Earths 2017, 35, 1022-1028. [CrossRef]

212. Drits, M.; Kadaner, E.; Shoa, N. Solid solubility of rare earth metals in aluminum. Izv. Akad. Nauk SSSR 1969, 1, 219-223.

213. Okamoto, H. Supplemental literature review of binary phase diagrams: Al-Nd, Al-Sm, Al-V, Bi-Yb, Ca-In, $\mathrm{Ca}-\mathrm{Sb}, \mathrm{Cr}-\mathrm{Nb}, \mathrm{Cu}-\mathrm{Ga}, \mathrm{Ge}-\mathrm{O}, \mathrm{Pt}-\mathrm{Sn}, \mathrm{Re}-\mathrm{Y}$, and Te-Yb. J. Phase Equilib. Diffus. 2016, 37, 350-362. [CrossRef]

214. Savitskii, E.M.; Stepanov, E.S.; Terekhova, V.F. Neodymium and its alloys with aluminum. Izv. Akad. Nauk SSSR 1960, 3, OSTI 4140972.

215. Li, Z.; Liu, X.; Wen, M.; Wang, C.; Tang, A.; Pan, F. Thermodynamic assessments of the Al-Th and Th-Zn systems. J. Nuclear Mater. 2010, 396, 170-175. [CrossRef]

(C) 2020 by the author. Licensee MDPI, Basel, Switzerland. This article is an open access article distributed under the terms and conditions of the Creative Commons Attribution (CC BY) license (http://creativecommons.org/licenses/by/4.0/). 